\title{
INTRODUCCIÓN AL ESTUDIO TIPOLÓGICO DE LAS ESPADAS ESPAÑOLAS: SIGLOS XVI-XVII
}

POR

GERMÁN DUEÑAS BERAIZ

\section{RESUMEN - ABSTRACT}

Este artículo pretende reflexionar sobre las espadas españolas de los siglos XVI y XVII. La historia de esta producción ha sido eclipsada por la fama de Toledo. La identificación de los tipos españoles se ha basado en sus marcas, firmas y algunas tipologías, pero se sabe muy poco sobre otros centros productores. Por ello este artículo aborda la variedad y riqueza de las producciones españolas contemporáneas, no sólo de Toledo.

This article pretends to reflect on the spanish swords from $16^{\text {th }}$ and $17^{\text {th }}$ centuries. The history of this production has been eclipsed by Toledo fame. The identification of spanish types have been mainly made according its marks, signatures and some typologies, but little is know about another centers. Therefore this article studies the variety and richness of the spanish contemporary productions, not only from Toledo.

\section{PALABRAS CLAVE - KEY WORDS}

Espada, Ropera. Armas blancas. Tipología. Renacimiento.

Sword. Rapier. White Arms. Typology. Renaissance. España.

Unos traducen obras celebradas, y en asadores vuelven las espadas: otros hay que traducen las peores, $y$ venden por espadas asadores.

(Fábula de la espada y el asador de Tomás de Iriarte)

La común arma de que se usa y los hombres la traen de ordinario ceñida para defensa y para ornato y demostración de que lo son Covarrubias $373 r$

\section{INTRODUCCIÓN}

La espada, además de ser un arma, encarnó toda una serie de valores que hicieron de ella y de su posesión todo un símbolo. Los siglos XVI y XVII fueron uno de los momentos más importantes en el desarrollo de este arma, aunque paradójicamente, coincidiera con el co- 
mienzo de su ocaso en los campos de batalla en favor de otro tipo de armas. En cambio su presencia en la sociedad y en el mundo civil se vio reforzada. Muchos hombres la portaban a diario con independencia de su estrato social, aunque a mayor nivel mayor calidad en su espada. Esta situación provocó que se alcanzara un alto grado de perfección tanto en las técnicas de manufactura, como en la riqueza de los materiales utilizados para su elaboración. Además su posesión representaba el conjunto de valores más importantes del momento, como eran el honor, el valor, la clase social, etc..

La fama de las espadas realizadas durante la Edad Moderna en diferentes ciudades de la corona española es conocida, tanto para los historiadores, como para gran parte de la opinión pública. Su reputación traspasó las fronteras del entonces imperio español, llegando hasta prácticamente nuestros días, aumentada y a veces desvirtuada por el paso del tiempo, especialmente durante el transcurso del siglo XIX, por la influencia de alguna corriente de pensamiento como el romanticismo. Este será el tema central del presente artículo, las espadas producidas y utilizadas en la corona española, fundamentalmente en el ámbito civil, durante los siglos XVI y XVII.

A pesar del renombre que alcanzaron las espadas españolas, son pocos los datos y estudios existentes en la actualidad dedicados a estos artesanos y a su producción. Esto provoca grandes lagunas y confusiones entorno a muchos de los temas más importantes que rodean a la fabricación de espadas. Esta situación se agrava si lo comparamos con el panorama internacional donde, con más o menos fortuna, se han hecho distintas aproximaciones a sus propios núcleos productores. Algunos de los cuales gozaron en el pasado de una menor consideración, en comparación a los hispanos ${ }^{1}$.

Son muchos y variados los campos en los que hay que profundizar para empezar a conocer algo de esta rica e interesante producción. Su estudio está lleno de dificultades, muchas derivadas de la falta de historiografía, y a la existencia de abundantes mitos y aproximaciones faltas de metodología al tema. Por ello sólo trataremos de realizar un primer acercamiento al estado de la cuestión y trataremos de establecer unos campos básicos y unas líneas de investigación sólidas. Sobre las cuales poder trabajar en el futuro para avanzar en el conocimiento de este campo.

En primer lugar deberíamos de preguntarnos si se puede abordar un estudio de espadas españolas, es decir si realmente existió una tipología claramente hispana dentro del ámbito internacional. Y de ser así, si se podrían conocer algunos de los rasgos que permitieran identificar las espadas españolas del resto de la producción europea. Aquí trataremos de dar unos primeros pasos en esa dirección, para poder seguidamente avanzar en el conocimiento de las espadas españolas, y ser capaces algún día de marcar aquellos elementos que señalen un posible origen en talleres de la corona española.

Relacionado con este punto también trataremos de poner unas bases mínimas sobre la terminología y tipología relacionada con el tema, para poder identificar más fácilmente referencias concretas al mundo de la espadería en las fuentes documentales contemporáneas.

\section{INTRODUCCIÓN HISTÓRICA}

Las espadas son un producto más dentro de un entorno sociopolítico concreto, y desconocerlo o tratar de obviarlo lastraría negativamente desde su inicio cualquier intento de estudio serio sobre el tema. En primer lugar hay que tener en cuenta que la realidad sociopolítica de la corona española del momento era más compleja que la actual. Bajo una misma corona convivían varias realidades que poseían sus propias formas de gobierno, leyes, economías, etc. Ade-

\footnotetext{
1 Véase por ejemplo para Alemania (Cronau, 1885).
} 
más existían territorios no peninsulares que integraban ese imperio, tan alejados entre si como eran los territorios italianos, América, Flandes, Alemania, etc., que influenciaban y recibían influencia de la Península Ibérica.

Ser conscientes de esta realidad es importante para entender mejor el tema que intentamos abordar, ya que en algunos aspectos, existía una homogenización de criterios estéticos y tipológicos, que también podían afectar al mundo de la espadería. Los gustos de la corte española eran conocidos y podían ser satisfechos también por otros talleres, fundamentalmente italianos.

La producción de espadas al igual que las del resto de objetos de la época estuvo enmarcada dentro de un tipo de organización económica y productiva muy concreta, como fue el mundo artesanal. Estos artesanos funcionaban dentro de un entorno urbano, con una organización también muy específica. A su vez estaban incluidos dentro de un sistema gremial, sobre el cual giraba toda la producción y venta de sus productos, y que, como veremos más adelante, mediatiza y condiciona dicha producción. Aun así, el objeto del presente trabajo serán exclusivamente las piezas y tipologías que salieron de talleres espaderos ubicados en la Península Ibérica, ya que el estudio de la espadería española desde el punto de vista de su organización gremial ya ha sido objeto de estudio por nuestra parte².

\section{LA ESPADA COMO OBJETO DE ESTUDIO}

La falta de trabajos sobre la espada española a la que antes nos hemos referido, se ve agravada por el hecho de que los estudios existentes no abordan la investigación sobre el tema desde un punto de vista científico. Existen estudios de tipo arqueológico que se centran en establecer tipologías basándose exclusivamente en aspectos externos de las piezas, y que además tratan de abarcar periodos y espacios geográficos muy extensos. Esto provoca que los resultados sean muy generales, y de difícil aplicación al caso hispano. En algunas ocasiones se utilizan teorías evolucionistas lineales, poco realistas y eficaces de cara a explicar la existencia de diferentes tipos de hojas y de empuñaduras ${ }^{3}$. El estudio de las fuentes para conocer la producción de espadas ha sido prácticamente inexistente, siendo anecdótica su utilización en algunos casos concretos ${ }^{4}$.

Para la primera cuestión hemos dividido la espada en sus dos partes más importantes y conocidas: la hoja y la empuñadura. La hoja a su vez quedará dividida en varios elementos que creemos pueden ser objeto de estudio como son: las secciones de la propia hoja, el recazo o las puntas. Existen otros motivos en las hojas hispanas que permiten identificarlas, con más o menos claridad, como tales. Nos referimos a las inscripciones, marcas, dibujos, etc. Estos elementos no serán objeto de estudio en este artículo, al menos de forma directa. Es mucho el trabajo que todavía queda por realizar respecto al conocimiento y estudio de estos elementos, y lograr así cierta seguridad a la hora de hablar de dicho tema. Si que utilizaremos algunos de ellos con el objeto de sentar determinadas bases tipológicas, siempre atendiendo a casos fuera de toda duda y contrastados con las fuentes documentales existentes.

Esto también limitará el presente trabajo en el ámbito geográfico, ya que conocemos mejor los elementos, inscripciones, marcas, etc., utilizados en Toledo, que los usados en el resto de las ciudades españolas. A pesar de ello, trataremos de introducir noticias de otros centros hispanos de producción de espadas, para tratar de paliar la inmediata identificación de la producción española de estas armas exclusivamente con el núcleo toledano. Dicho problema

2 Dueñas (1999): Aproximación al estudio de los gremios espaderos en la Península Ibérica. Grado de Salamanca ( inédito).

3 Pelaez del Valle (1983); Laking, (1920-1922); Charles (1993).

4 Ocete, (1988). 
se verá limitado por el hecho de que conocemos la gran movilidad geográfica de los artesanos espaderos españoles por toda la península. Por ello, no consideramos que se dieran grandes diferencias entre unas zonas y otras, y si en cambio respecto a la producción de ámbito internacional.

La empuñadura será también objeto de división para que podamos obtener más información de cara a identificar rasgos hispanos en ellas. Hablaremos por tanto de la empuñadura en general, y de posibles tipologías peninsulares. Al mismo tiempo, nos centraremos en diferentes partes como el pomo, el puño, las guardas y elementos decorativos que aparecen en todas o alguna de las partes enumeradas anteriormente.

Así mismo consideramos muy necesario tratar brevemente sobre toda una serie de conceptos referidos a las denominaciones de las diferentes partes que componen las espadas y a la espada misma. Son muchos los errores y confusiones que sobre este tema se cometen, debido principalmente al desconocimiento o mal uso de determinadas expresiones referentes a las espadas, y a sus diferentes partes, como por ejemplo las empuñaduras.

Existen términos en castellano que se refieren a partes concretas de las armas blancas que no se utilizan en la actualidad, usándose en cambio términos de otros idiomas que no se corresponden con el significado original. Incluso se producen situaciones extrañas, como cuando una palabra de origen español, y tras ser asimilada por otros idiomas, retorna al nuestro con un significado diferente al original. El mejor ejemplo es el del término «ropera», que servía para definir a cualquier espada que se llevaba con la vestimenta civil, de cara a diferenciarla de las militares, y sobre cuya interpretación volveremos más tarde.

La importancia de la producción de espadas en la corona española fue tal, que nuestro idioma, tanto el castellano como otros presentes en la Península Ibérica, generaron e incluso exportaron expresiones que sirven para definir ciertas partes de las espadas, caso del recazo, o incluso tipos concretos de espadas como la «Bilbo» 5 .

Uno de los motivos de esta falta de consenso y de conocimiento de estas expresiones ha sido el tradicional divorcio entre el estudio de las espadas y la investigación de las fuentes. Por ello nosotros a la hora de utilizar cualquier expresión referida al tema del mundo de las armas blancas, siempre lo justificaremos a través de las fuentes. Existe, como es natural, el inconveniente de que desconocemos exactamente el significado de algunas expresiones de la época, pero trataremos de lanzar hipótesis lógicas sobre las mismas.

Esto es más grave aún, si tenemos en cuenta que existen meritorios trabajos al respecto, (Leguina, 1912). Este es un instrumento muy valioso a la hora de entender y estudiar este tema, ya que basa parte de su estudio en las fuentes de la época.

A la hora de hablar de armas blancas largas, ya que sobre este tipo de piezas nos centraremos, consideramos que el término más apropiado es el de espada. Al margen de una serie de piezas, que por sus características reciben una denominación concreta, esclabonas, pappenheimer, ginetas, montantes, etc. A la hora de identificar una pieza se puede descender más en base a una serie de criterios como son: la finalidad (de guerra, de caza, civil, de gala, de ejecución, de esgrima, etc.); el tipo de guarnición (de cruz, lazo, conchas, taza, etc.); y el tipo de hoja (estoque, verdugo, calada, flamígera, etc.).

Volviendo al término ropera anteriormente citado, decir que el origen de esta palabra no está claro, aunque son muchos los autores que lo consideran hispano ${ }^{6}$. El otro posible origen se ubica en Francia procedente del término, rapiere, ya que aparece por primera vez el término en documentos franceses de $1474^{7}$. Lo cierto es que en trabajos ingleses del primer

5 Este concepto ha tenido diferentes significados a lo largo del tiempo, pero siempre identificando tipologías de espadas que tenían relación con los talleres espaderos bilbainos. Más información en (Dueñas, 2001).

6 Varios autores citan como el origen de esta teoría que dicho término aparece citado por primera vez en 1468 en el Inventario de los bienes del Duque don Alvaro de Zúñiga, (Leguina, 1912).

7 Gay (Glosssaire Archeologique, II 1928: 287). habla incluso de la utilización de este término ya en el siglo XIII. 
tercio del siglo XVI el término francés rapiere se traducía como espada española, lo que parece sugerir el origen hispano del término ${ }^{8}$. Otros autores consideran la teoría del origen español al mismo nivel que la de su origen italiano (Seitz, 1981: 304). Al margen de la procedencia de la expresión, es un concepto del que se abusa en exceso a la hora de identificar a determinadas espadas, especialmente en el mundo anglosajón, provocando así frecuentes confusiones. Este vocablo es sólo uno más, y no precisamente el más usado, de los que se utilizaron para definir una espada cuyo fin no era el uso militar, por contraposición a la espada de armas, sino el ser llevada con la ropa civil. Su utilización como sinónimo de espada civil realizada en los siglos XVI y XVII la consideramos empobrecedora y simplista (Pelaez del Valle, 1983).

Su uso en la época que estamos tratando, está fuera de toda duda apareciendo en ordenanzas de espaderos como los de Granada: guarnezca una espada ropera; o Toledo: Una guarnición negra para una espada ropera (Dueñas: 1999). También se recoge en inventarios, como el ya mencionado de Don Alvaro de Zúñiga: Otra espada rropera dorada y avirada (Leguina: op. Cit.); el de Beltrán de la Cueva9; y el de Gaspar de Bricio: una espada rropera de la onça partida (Leguina: op. Cit.). También en la literatura del siglo XV se recoge este término en un contexto que indica que se trata de una espada que formaba parte de la indumentaria del momento ${ }^{10}$. Por lo tanto podríamos concluir que este término sirvió en la baja edad media para definir a todas aquellas espadas occidentales que no eran para la caza 0 la guerra, y que podían llevarse como parte de la indumentaria común en la época, al margen de la riqueza y forma de empuñaduras y hojas.

El mal uso de este término ha venido procedente de otros idiomas, como el francés y el inglés fundamentalmente, que pretenden englobar con la palabra ropera a cualquier espada del siglo XVI o XVII, especialmente si poseen una empuñadura decorada y una hoja estrecha. Extendiéndose este término a cualquier espada, independientemente de la hoja o su naturaleza, del siglo XVI y XVII.

Existen otros términos de época, como son los de espada de galán, de cinta, de ceñir, que son sinónimas de la anterior, refiriéndose a un tipo de arma muy general. Por ello consideramos más acertado utilizar la palabra espada seguida de cualquiera de los elementos anteriormente citados, permitiéndose así una más correcta identificación. Lógicamente, las más mencionadas son las espadas como tales, sin especificar el subtipo o modelo concreto. Hacen mención a ellas, utilizando variadas nomenclaturas como: — espada de una mano- (Nueva España 1556); - espada ropera - (Granada 1531); — de una espada de una mano para un galan- (Sevilla 1478); —espada nueba- (Segovia 1536); —espada nueba de Toledo(Toledo 1622) etc. (Dueñas, op.cit.)

La documentación española de la época distingue fundamentalmente cuatro tipos de armas blancas largas: la espada, el estoque, el montante y el verdugo. Existe la idea, especialmente a nivel internacional, que la producción de espadas en España se limitaba a unos modelos muy concretos, las que normalmente se denominan roperas. Especialmente en los casos que montaban empuñaduras de taza, y que poseían marcas o inscripciones de las tradicionalmente consideradas españolas. Pero este marco de trabajo tan estrecho para un grupo

8 Ibid. DUWES Introductorie for to lerne to rede, to pronounce an to speake Frenche trewly, 1532-1533?,

9 Inventario de Don Beltrán de la Cueva. Tercer duque de Alburquerque 1560, (Rodríguez; 1883). Aquí se utiliza el término ropera no para referirse a una pieza en concreta sino para englobar una serie de espadas, y diferenciarlas de otro grupo compuesto por espadas extranjeras, alfanjes; espadas de caza; espadas militares como estoques; y de menor tamaño, terciados.

10 Un miércoles que partiera

el príncipe don Enrique

a buscar algún buen pique

para su espada ropera,

Juan de Mena (1411-1456). Coplas de la panadera. 
de artesanos de tanta fama y calidad técnica parece un poco ilógico. Veamos pues la posible participación de espaderos españoles en la realización de armas blancas que poseen una personalidad propia por su forma, tamaño o función. Diferentes autores ya enumeran toda una serie bastante amplia de armas blancas producidas en los talleres españoles:

\footnotetext{
Hallanse muchas diferencias de armas, como montantes, alfanges, cuchillos de monte, estoques de ristre, espadas de mano y media, dos espadas en una, puñales, dagas y otras ${ }^{11}$.
}

El primer grupo es el de los montantes. El término mandoble para referirse a este tipo de armas tiene como origen la necesidad de colocar ambas manos en el puño, además de en el recazo o falsaguarda, para su manejo. Aunque este término no se utilizaba en la época para referirse a este tipo de armas. Posiblemente su origen sea decimonónico, dentro del interés que estas armas suscitaron en los entornos románticos por su aspecto, y por tanto inexacto. El término mandoble, si que fue utilizado en la época, pero servía para referirse a algunos golpes de esgrima en concreto, tal y como nos lo señala Cristóbal de Cala ${ }^{12}$ :

Si habiendo sujetado la espada al contrario no se determinare á obrar ninguna cosa de las ya referidas y tratare de salir por más secreto con un revés transversal, que los antiguos llamaron mandoble, obrando con solo el movimiento de la muñeca, de manera que habiendo sujetado la espada al contrario vuelven la mano uñas abajo y pasan la espada por entre los dos cuerpos, y ángulo agudo, ejecutan el golpe en la cabeza

Estas poderosas espadas de gran tamaño y características morfológicas muy concretas han venido siendo normalmente identificadas, como realizadas en Italia, y especialmente en Alemania ${ }^{13}$. A pesar de que algunos poseen marcas e inscripciones españolas. La atribución de la mayoría de estas armas a talleres alemanes quizá venga motivada por la utilización de este arma por los mercenarios alemanes conocidos como Lansquenetes. Lo cierto es que existen varios ejemplos de montantes que salieron de fraguas españolas. El primero al que haremos referencia fue realizado por el espadero conquense ${ }^{14}$ Adrián de Zafra (MS 2404). Esta pieza posee una larga y estrecha hoja, sólo tiene $38 \mathrm{~mm}$ de anchura la hoja, con falsaguarda. Monta una empuñadura tripartita rematada en un pomo bulboso gallonado y una arriaz recto y largo con dos puentes, en guarda y contraguarda (Fig. 3). No es el único ejemplo de hojas fuertes para montantes de este espadero existiendo otro ejemplar en la Real Academia de la Historia ${ }^{15}$ y otra en Madrid (MNM No Inv. 6342), este último ejemplar montado con una guarnición de lazo.

Otro ejemplo de montantes que normalmente no se atribuyen a espaderos hispanos lo hallamos en el existente en Londres (WC A 473). Esta hoja pese a estar firmada, IOANES DE AGIRE, se sigue considerando como realizada en un taller alemán ${ }^{16}$. La presencia de un espadero de origen vasco del mismo nombre y que marcaba de igual forma, una S tumbada sobre una cruz, está documentada en la ciudad de Zaragoza a mediados del siglo XVI ${ }^{17}$. Palomares también incluye a este espadero en el anexo que hace a su nómina años más tarde (Dueñas, 2003).

\footnotetext{
11 Suarez de Figueroa, (1617).

12 Cala, Cristóbal de (1642) Desengaño de la espada y Norte de diestros. Cadiz.

13 Uno de los pocos autores que elogia la manufactura de mandobles en España es Laking (IV, pp. 271-272).

14 Este forjador de espadas trabajó en la población de San Clemente, actual provincia de Cuenca.

15 Soler del Campo, A. (2001): «Montante». Tesoros de la Real Academia de la Historia (Cat. expo.). Madrid, 255.

16 Mann hace referencia a un armero de Marquina del mismo nombre existente en las cuentas reales de Simancas, pero sigue considerando el arma como alemana.

17 Ximenez Embun. Descripcion historica de Zaragoza: Juan Aguirre. Por marca una ese con cruz encima. Actas de 1556.
} 


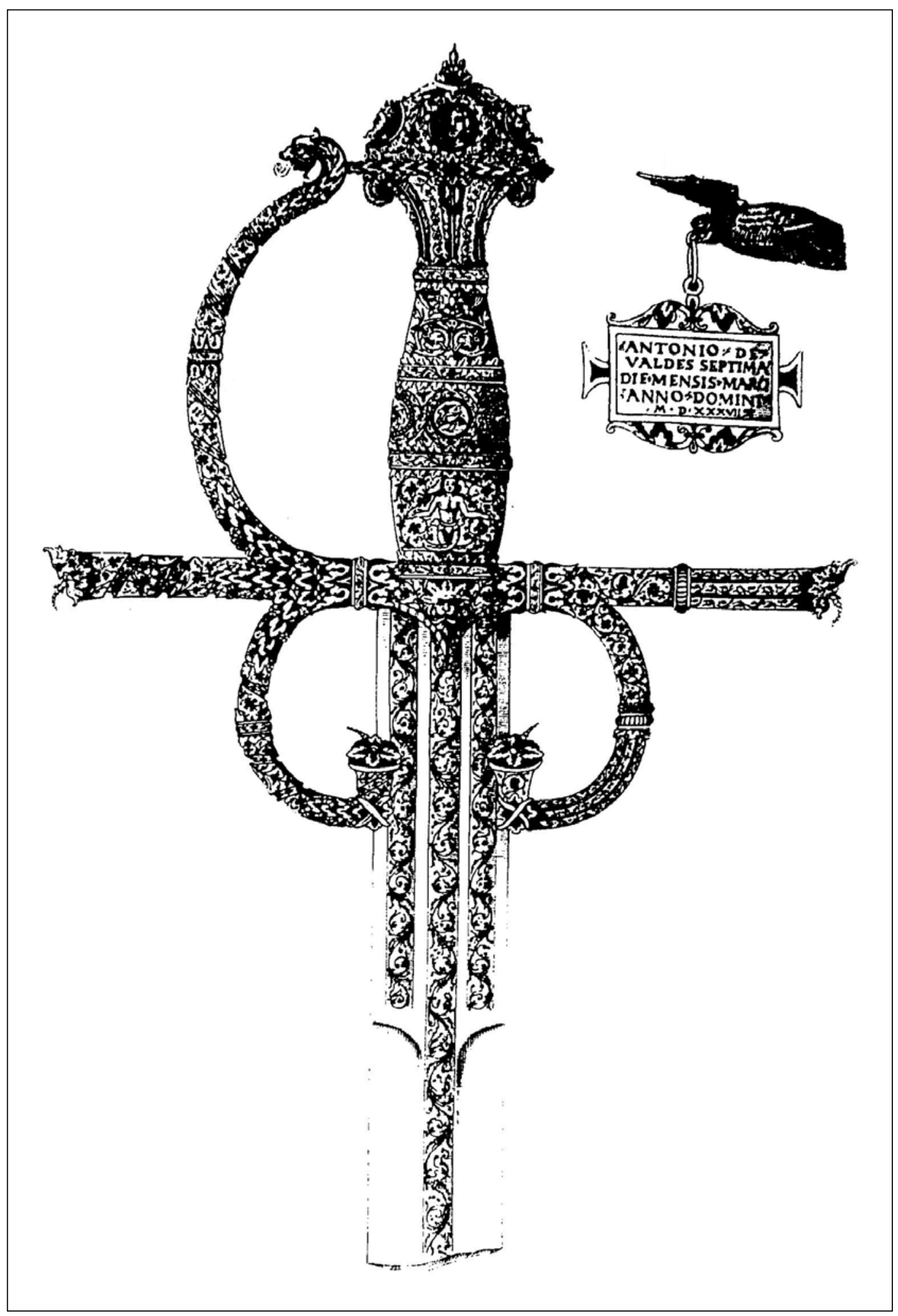

Obra maestra realizada por el platero barcelonés Antonio de Valdes en 1537. 
El término verdugo o verduguillo aparece frecuentemente citado en la documentación, sobre todo en la literatura y en la legislación sobre espadas. Su significado no está claro del todo aunque si tomamos la definición que de dicho término da Covarrubias (Covarrubias, 1611: 206v): estoque angosto y alomado, podemos pensar que se trataba de espadas con hojas estrechas de sección romboidal y con una punta muy aguda.

$\mathrm{Al}$ igual que en otras ocasiones, es posible que el término no sólo se refiriera a un tipo de pieza concreta ${ }^{18}$. La definición que más nos interesa se refiere a hojas muy estrechas, del grosor del dedo meñique, de sección cuadrangular, muy largas y con una punta muy aguda. Pese a su estrechez y longitud eran muy resistentes de modo que podían atravesar una gruesa tabla de nogal ${ }^{19}$.

El uso de este término está documentado desde el siglo XVI, ya que este término aparece recogido en diferentes ordenanzas de ese siglo. En la legislación sobre el tamaño de las hojas de 1564 se hace uso de ese término prohibición de espadas, verdugos y estoques de más de 5 cuartos de vara (Martínez del Peral: 1992). Probablemente no sea la misma pieza que posteriormente en el XVII reciba esta denominación, pero suponemos que compartirían las principales características. Es decir una hoja estrecha, posiblemente de sección romboidal, larga y con una punta muy aguzada.

El término estoque es muy ambiguo, ya que bajo él se esconden varios tipos de armas blancas diferentes, dependiendo de su función y momento histórico. Originalmente fueron una espadas militares de gran tamaño usadas fundamentalmente para combatir a caballo. Su uso era independiente de que se portara además una espada. Estos estoques tienen normalmente una hoja estrecha ${ }^{20}$ y larga de sección romboidal o triangular vaciada ${ }^{21}$. La empuñadura estaba formada por un arriaz recto, o ligeramente curvados los extremos hacia la hoja, con un fuerte pomo para equilibrar el peso de la hoja. Su uso militar no evitaba que pudieran poseer empuñaduras ricamente ornamentadas.

Similares son los estoques de caza que se usaban para cazar jabalíes o ciervos, aunque las puntas y las secciones de las hojas eran diferentes más apropiados para los fines venatorios. Otro tipo concreto son los llamados estoques ceremoniales, entre los cuales se hallan los Pontificios. Sus hojas no son precisamente estrechas, aunque si tenemos en cuenta su tamaño longitud de hoja y tamaño de empuñadura, si que son menores que la de un arma equivalente en tamaño como era el montante. Los pontificios son herederos de estos estoques de guerra que tuvieron su momento de esplendor en los siglos XV y comienzos del XVI.

A mediados del siglo XVI, ya se consideraba el estoque como una espada de hoja estrecha y no excesivamente larga ${ }^{22}$. Sus empuñaduras eran las mismas que cualquier otro tipo de espada de uso civil. Por extensión se consideraba como estoque a toda aquella espada que tenía como finalidad principal la de herir de punta, frente al tajo, ya que la estocada era el golpe que se da de punta con la espada. Algunos de ellos empezaron a fabricarse de una

\footnotetext{
18 Madame d'Aulnoy en 1679 (García Mercadal, op. Cit) nos da otra referencia del término verduguillo cuando dice que es un pequeño estilete de sección cuadrangular cuya hoja era menos gruesa que una aguja gorda de acero fino.

19 Ibidem.

20 Un estoque es bien delgado. el amigo que hoy se usa, de acero tan mal templado, que aun en la vaina se excusa de hallarse con vos al lado. 75 Doctor Carlino Luis de Góngora y Argote 1561-1627.

${ }^{21}$ Las mesas no son planas sino curvadas hacia interior, es decir cóncavas.

22 Covarrubias $374 \mathrm{v}$. Al hablar de una hierba denominada espadaña dice que la llaman también yerva estoque por ser en respeto de las hojas de la espadaña como un estoque, espada angosta y no larga, porque produze sus hojas unas cortas y otras estrechas.
} 
longitud mayor al común de las espadas. A estos se les decía que eran mas asadores que espadas, por la estrechez y longitud de sus hojas ${ }^{23}$.

Son varias las ordenanzas de espaderos que poseen referencias a dichas armas: Segovia 1536; Salamanca 1538; Toledo 1566 y 1622; Granada 1531. En dos de ellas, las dos toledanas los nombran como estoques de armas de tres esquinas, refiriéndose seguramente a los tres ángulos que se forman en cada cara de la hoja, al tener una sección triangular. Mientras que en el resto son estoques de armas (Segovia 1536), o estoques a secas (Salamanca 1538) ${ }^{24}$.

Los estoques fueron también objeto de legislación en cuanto a la forma y el tamaño de sus hojas. En primer lugar estaban incluidos en la limitación del tamaño de sus hojas a cinco cuartas de vara ${ }^{25}$. Pero además se prohibían los estoques buidos, es decir acanalados, ya que se pensaba que eran más mortíferos. También se regulaba la anchura de su hoja debiendo de tener una anchura mínima. Este dato de la anchura no aparece recogido en ninguna de las leyes existentes sobre el tema, aunque un viajero de la época nos dice que las hojas de los estoques no podían ser como el meñique de anchas ${ }^{26}$.

Un tipo de hoja muy característico y pocas veces relacionado con una producción española es el de las hojas denominadas flamígeras, también se las conoce como llameantes. Quizás lo poco conocido de su producción, se deba a que eran armas poco apreciadas, e incluso censuradas por la jerarquía eclesiástica, debido al parecido de la forma de la hoja con la serpiente, símbolo del mal. Aunque por otra parte también se la identificaba con la espada de fuego que solía portar el arcángel San Miguel en su lucha contra el diablo.

Ejemplos de este tipo de espadas forjadas en España no faltan. El primero lo hallamos en Suecia en una espada con la hoja firmada por Sahagún (LS 10853). Los motivos ondulantes de la hoja se repiten en los gavilanes y en el pomo. Citar así mismo dos espadas de este tipo presuntamente españolas. La primera la hallamos en Berlín (DGM Nº. AK 204149). Además del interés de la pieza nos permite conocer a un espadero de probable origen judío debido a su nombre, Abraham de Vilina ${ }^{27}$. La otra pertenece al Museo Lázaro Galdiano (FLG No Inv. 7262), tiene guarnición de platillo y en el canal parece leerse Juan Martínez.

Otro tipo de hoja existente en la península ibérica a comienzos del siglo XVII es la denominada «frantolpino» o «colichemarde». No sabemos si su presencia se debía a la importación de esas hojas de la zona italiana o si existía una producción propia. Lo cierto es que las leyes que prohibían su uso y fabricación se referían también a sus posibles fabricantes hispanos $^{28}$.

prohiben las espadas de hoja cuadrada en sus dos primeros tercios aunque luego terminen en sólo dos filos,

Otra tipología especial de espadas de las cuales poseemos ejemplos de manufactura española son aquellas armas combinadas, blancas y de fuego a la vez. Esto se consigue montando una llave y un cañón de arma de fuego en una de las caras de la hoja. En París se conserva una espada firmada RUIZ EN TOLEDO que tiene montada en la hoja una pistola de rueda (MAP J 364), y otra valenciana (MAP J 362) con una llave a la francesa que al parecer perteneció a Enrique II. En esta misma ciudad se conserva una pieza similar procedente del

23 Ibid. $385 \mathrm{v}$.

24 Estas referencias, ciudad y año de realización, han sido sacadas de las diferentes ordenanzas de espaderos estudiadas, en Dueñas (1999): op. Cit.

${ }^{25}$ La vara castellana equivale aproximadamente a o,83 metros.

26 Jouvin, en Garcia Mercadal op. cit.: 609.

27 No hemos podido constatar el origen español de dicho espadero. El apellido no parece español, aunque la trascripción podría no ser correcta y tratarse de Villena en lugar de Vilina.

28 Real Crida y Edicte sobre les coses concernents al be comu de la present ciutat y Regne de Valencia... por don Luys Faxardo de Requesens y Zúñiga, el 14 de febrero de 1628. 
gabinete de armas de Luis XIV, y que aparece identificada en sus inventarios como une petit espée a léspagnole sur laquelle il y a une petit canon monté sur un tambour damasquiné $d^{\prime}$ or et une batterie de pistolet ${ }^{29}$.

Otro tipo de arma, relacionada con las anteriores, que se fabricaba y conocía en la península ibérica eran las llamadas espadas secretas. Recibían este nombre porque se hacían pasar por otro objeto, estando montadas en cayados o bordones de peregrino, Estos eran simplemente bastones de madera vaciados en los que se introducía una hoja larga y estrecha de estoque, y que servía para defenderse a la población que normalmente no iba armada, caso de los religiosos y sobre todo de los peregrinos que atravesaban la península, permitiéndoles de este modo hacer frente a cualquier agresión.

Eso no -respondió el otro peregrino_, y si desta verdad no puedo darte testigos, remitiré su falta a los filos de mi estoque, que en este bordón traigo oculto, (...) viendo que luego, desenvainando del bordón que tenía un estoque, o a lo menos una arma que lo parecía, acometió a mi señor, el cual le salió a recebir con otro estoque, que yo sé que en el bordón traía ${ }^{30}$.

La espada secreta que es muy hordinario en los pelegrinos (sic) llevar por bordón y asi mismo muchos clerigos quando se les ofrece de noche salir de sus casas y yo me acuerdo averla visto a muchos de esta suerte metida en un bordon una espada como e dicho secreta ${ }^{31}$.

Estas piezas están documentadas por ejemplo en la Real Armería de Madrid, tal y como lo indica el siguiente inventario: Mas quatro hojas de estoques que estan metidas en los cayados $^{32}$. En la Relación de Valladolid se las llama estoque largo metido en un palo, y en la armería del Duque del Infantado estoques de ristre uno que sirve de báculo ${ }^{33}$.

En la legislación gremial sólo son mencionados una vez en las ordenanzas de espaderos hispanos, concretamente en las de Toledo de 1622 en los siguientes términos: Item un berdón de clérigo con su espada dentro (Dueñas, op. cit.).

También dependiendo de la forma de la hoja que contuviera el báculo recibían diferentes nombres a saber báculo con espada o báculo con estoque. Siendo ambas armas usadas por personas que en principio no iban armadas, pero que necesitaban alguna defensa como clérigos, maestros y médicos (Rojo, op. cit.). De la existencia de piezas de este tipo quedan constancia en los inventarios de la colección Wrangler en la que aparecen este tipo de piezas con el adjetivo de españolas, existiendo hoy todavía un ejemplar que por la decoración del puño, pavonada y damasquinada, pudiera tratarse de manufactura hispana. Además en Nueva York (MMA Nr. 04.3.42) existe una pieza de estas características con una hoja posiblemente toledana, y empuñadura de bordón alemana.

Un tipo de arma blanca menos conocido, y que se fabricaba en la España del siglo XVI, era el terciado. Según Covarrubias (Covarrubias, op. cit.: 85 v) su nombre se debía a que a la longitud de su hoja le faltaba la tercia parte de la marca. Si tenemos en cuenta que la marca eran cinco cuartos de vara, que equivale a unos $83 \mathrm{~cm}$, el terciado tendría una hoja de unos $50 \mathrm{~cm}$. aproximadamente. Además nos dice que era una espada corta y ancha, aunque no dice nada sobre si era curva o recta, o si poseía uno o dos filos. La anchura de su hoja nos la confirman varios textos de la época, como este:

El gigante alçó el bastón para darle y ladeó Marcelino el cuerpo y dio con el bastón en tierra, que le saltó de la mano. Luego echó mano a un terciado, que muy ancho y rezio era, y tiróle un golpe a Marcelino que le derribó la falda toda del escudo y Marcelino le dio otro que le acertó en el${ }^{34}$.

\footnotetext{
29 Reversau (1993).

30 Cervantes (1617): Los trabajos de Persiles y Segismunda.

31 Alonso Venegas. Tratado y discurso Militar. Ms de la Biblioteca Colombina, en Leguina (1912: 439).

32 AGS. Cuentas particulares. Leg. 5231.

33 Armería del Duque del Infantado.

34 Gernert, F. (2001). Baldo (Sevilla, Dominico de Robertis, 1542). Alcalá de Henares.
} 
Otro posible sinónimo para referirse a este tipo de armas es el de machete. Que se definía en la época como el terciado que no era tan largo como la espada, ni tan corto como el puñal y la daga (Covarrubias, op. Cit. 531r). Es posible que la única diferencia fuera en que el machete más que un arma fuera un instrumento, un cuchillo de grandes dimensiones que sirviera para diferentes funciones agrícolas y ganaderas. De otras referencias se deduce que el término terciado también fuera sinónimo de la expresión alfanje. Siendo quizás el término castellano para referirse a este tipo de arma de origen árabe.

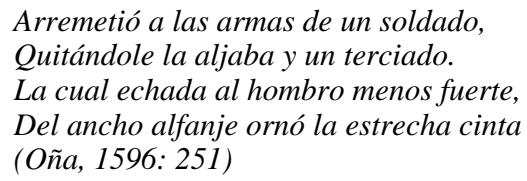

Mencionar el hecho de que el terciado, del mismo modo que algunos alfanjes, se considere un arma de ejecución, más concretamente de decapitación. Son muchos los cuadros de finales del siglo XV y comienzos del XVI en los que aparece un arma de este tipo, especialmente en escenas religiosas relacionadas con algún martirio, San Juan Bautista, San Pablo, etc. Por lo tanto existe una relación entre estas piezas, eminentemente de tajo, y su uso como arma de ajusticiamiento.

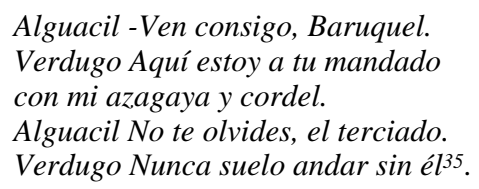

Volviendo al término alfanje tenemos que decir que pese a su origen musulmán, tuvo una fuerte presencia en la península ibérica, más allá de la presencia musulmana en el territorio hispano. Estas armas tenían las hojas más cortas y anchas que las cristianas, y servían sólo para jugar de tajo tal y como Lope de vega nos dice: cortos los alfanjes son y no hieren de estocada (Lope de Vega, El Hamete de Toledo: 350). Tipológicamente se corresponden a espadas de hoja corta, ancha y curva, con empuñadura sencilla, normalmente de arriaz recto. Es decir se corresponden a los denominados falchion, ingleses, badelaire, franceses, o el cotellaccio o sttorta italiano ${ }^{36}$.

Respecto a la curvatura de la hoja, elemento que podría diferenciarlo del terciado hispano, tenemos constancia de ella desde fechas tan tempranas como el siglo XIII.

Et cada uno quanto mas a desto; tanto mas semeia a dios. \& tanto mas se llega a la natura del. \& por Mercurio nos dan los sabios a entender el triuio que son los tres saberes cuyo alhange es el apuesto razonamiento \& ell entendimiento de las cosas. de entender las bien. \& esto alcanca omne por aquellos saberes. \& por aquel recoruamiento dell alfange que es espada fecha como corua. \& ques torna en si; Diz maestre Johan que se /2/ entiende que el omne lleno de uertudes. \& que estos tres saberes a; por el entendimiento que alcança con ellos retorna en si los mouimientos de la soueruia quando la quiere fazer. como es aquella espada recoruada; \& castiga los que los non dexa salir fuera de los mienbros nin de uenir al fecho nin aun a la su uoluntat ${ }^{37}$.

\footnotetext{
35 Aucto de la degollación de Sant Juan Baptista 1570-1578. Miguel Ángel Pérez Priego, Castalia (Madrid), 1988.

36 el cuchillo, o como dezimos en Castilla, el alfange (...). La forma es de los antiguos alfanges que los Romanos dexaron en España, aunque no el nombre que es Arabigo, heredado de los Moros, con otros muchos de que vsamos. La cuchilla con la empuñadura, es de vara en largo, de ancho quatro dedos, de vn corte Sigüenza, Fray José, 1600. Segunda parte de la Historia de la Orden de San Gerónimo. Sigüenza.

37 Alfonso X General Estoria. Segunda parte. 1275.
} 
Son frecuentemente mencionados en los inventarios de bienes de personajes de alto nivel, especialmente nobles y reyes ${ }^{38}$. Aunque también los poseían el resto de la población (Rojo, 1996: 37). Muchos procedían de su captura en diferentes conflictos sostenidos con los musulmanes hispanos primero, y los turcos después. Otro origen era su posesión por parte de los moriscos hasta su expulsión. Aunque creemos que al igual que sucedió con otras armas de origen musulmán fueron adoptadas por la población cristiana, al igual que sucedió con las dagas de oreja o las adargas. Por ello también fueron fabricadas en la península ibérica. En las ordenanzas de espaderos de Barcelona de 1567 se mencionan entre las labores que habían de realizar para ingresar como maestro en el gremio un alfange morisco (Bofarull, 1910). Además un centro productor de armas blancas como fue Durango también produjo este tipo de piezas. Una variante más corta de este tipo de armas se conocían como alfanjillos. Los alfanjes serían también las armas conocidas como espadillas del moro que aparecen en algunos documentos de la época.

Relacionada con esta tenemos otra arma de origen árabe, como es la cimitarra. A pesar de que Covarrubias diga que es igual que el alfange, eso si remarcando la curva de su hoja, al decir que es una espada vuelta a manera de hoz (Covarrubias, op. Cit. 283 r). Esta tipología se corresponde a los shamsires turcos, que resultaban algo más largos que los alfanjes, con hojas más estrechas y curvadas.

Otros tipos de armas blancas fabricadas en la península ibérica a lo largo de los siglos XVI y XVII se ven enriquecidos con variedades regionales como los machetes vizcainos o los puñales de Chelva, machinets, medias espadas, espadillas del moro, cuchillos y puñales triangulares ${ }^{39}$.

Otro tipo de espada existente en la época es la denominada espada negra, y que equivalía al florete francés ${ }^{40}$. Las espadas negras son por tanto las que se usaban para aprender la esgrima. Su nombre venía de que eran de hierro, y su aspecto externo era de color negro debido a que no se amolaban, ni acicalaban, ya que no se les sacaban ni los filos ni la punta, conservando por tanto la pátina oscura que conseguían tras la forja:

Bien notorio es ke las espadas de korte, desnudas, se llaman espadas «blankas» porke están azikaladas i luzias, a diferenzia de las de esgrima ke se llaman «negras» porke lo están ${ }^{41}$

Además en su extremo se colocaba un botón, que se denominaba también zapatilla, que embotaba la punta, haciéndola inofensiva en la esgrima de punta ${ }^{42}$. El aspecto oscuro era un efecto buscado para diferenciarlas de las blancas, espadas auténticas, y evitar daños en la esgrima de enseñanza y en los juegos de armas. El efecto negro también podía acentuarse barnizando la hoja, aunque esto parece que se realizaba especialmente en la empuñaduras: espadas negras barnizadas las guarniciones ${ }^{43}$. Además en algunos textos se hace referencia

38 En los inventarios de la colección del Duque del Infantado se mencionan un Alfanje turquesco y tres alfanjes damasquinos.

39 Real Crida y Edicte sobre les coses concernents al be comu de la present ciutat y Regne de Valencia... por don Luys Faxardo de Requesens y Zúñiga, el 14 de febrero de 1628.

40 García Mercadal (1999) T. III: 406. ... le dijo que no haría lo mismo si se tratase de espadas y no de floretes lo que llaman en España a la espada negra.

41 Correas (1627).

42 Nariz grande, entrelarga y puntiaguda, vale lo mismo que una alquitara; y a las que las tuvieren con arzones $y$ caballetes, mandamos que las envainen para besar a sus galanes, porque no los ahoguen; $y$ si son demasiado puntiagudas, las pongan zapatillas como a espada de esgrima. Quevedo y Villegas, 1619-1626; el otro no traía otra cosa que dos espadas negras de esgrima, nuevas y con sus zapatillas. Cervantes 1615: 782.

43 AGS. Relación de Valladolid. Descargos del Emperador Carlos V. Leg No 13. 
a espadas mulatas. Creemos que este término se puede referir a espadas para esgrima, que podían ocasionar heridas no estando exentas de los elementos de seguridad de las negras ${ }^{44}$.

También los montantes eran utilizados por los maestros de esgrima. Se usaban por ellos para regular los enfrentamientos en las clases y en los juegos de esgrima que se hacían en las plazas con ocasión de las fiestas ${ }^{45}$, e incluso para delimitar los espacios en los cuales debían de discurrir dichos encuentros ${ }^{46}$. Los juegos de esgrima era una práctica común en la Castilla del siglo XVI formando parte de los actos festivos, junto con los toros o los juegos de cañas ${ }^{47}$. Además se realizaban demostraciones de esgrima por parte de los maestros en ocasiones especiales, realizando diferentes movimientos con los montantes. Así en 1560 con ocasión de la entrada en la ciudad de Toledo de la reina, y entre otros festejos, entre ellos la danza de las espadas, hubo una demostración de maestros de esgrima con sus montantes en extremo bizarros (Cabrera de Córdoba, 1619: 210). Estas demostraciones se llamaban florear $^{48}$ y las armas que se usaban recibían esta denominación. Esto nos lleva a pensar que pudieran tener unas características especiales, ya que se las identificaba del resto, como en el caso de un montante de florear que poseyó el Duque de Alburquerque ${ }^{49}$.

Por último señalar la existencia de un tipo de espada que nació con el fin de evitar las leyes sobre medidas máximas, y como una muestra más de la picaresca de la época. Se desarrollaron para ello una serie de espadas que mediante un dispositivo mecánico alargaban la extensión de la hoja.

Otro estereotipo aplicado a las espadas españolas es el de identificar como tales a las espadas con guarnición de taza, y denominarlas como española o a la española. La variedad de hojas y empuñaduras realizadas en España es mucho mayor. Muchas de las tazas no eran producidas en la península, aunque si bajo los dominios de la corona hispana, ya que Milán, Nápoles y otros territorios italianos famosos por realizar ese tipo de piezas, estaban bajo su control.

Aunque la tipología de espadas españolas se ha visto ampliada, se sigue descartando una posible producción hispana, sino pertenecen a los modelos anteriormente citados. El concepto de espada a la española que aparece en numerosos inventarios y referencias literarias de los siglos XVI y XVII es diverso, según el tipo de espada que en cada momento estuviera de moda en España. A mediados del siglo XVI, y para el caso italiano que es el mejor estudiado (Boccia y Godoy, 1986: 446) spada alla spagnola significaba en un primer momento, espada de hoja ancha con guarnición más evolucionada, es decir con aro guardamano, patillas, pitones y uno o varios puentes. Poco después vino a significar espada con hoja larga y estrecha, la stricia italiana, para diferenciarse de espadas militares, como estoques y espadas de caballería. Durante el siglo XVII armas con hojas más estrechas aun, y guarnecidas con empuñaduras de conchas primero y de taza después, serían las que recibirían la denominación de españolas.

En el siglo XVII existía un tipo claro de espada española que la diferenciaba por ejemplo de la francesa tal, y como lo deja de manifiesto Jouvin (García Mercadal, op. cit. t. III: 609), al decir de una espada que estaba montada a la francesa no teniendo nada de la manera de

${ }^{44}$ El diablo cojuelo En esto, el Maestro, con el montante, barriendo los pies a los mirones, abrió la rueda, dando aplauso a la pendencia vellorí, pues se hacía con espadas mulatas.

45 Llegó el pelir[r]aposo al puesto, y desviando con toda la mano zurda dos dedos de la cabeza el sombrero, tocó la espada en el montante, que es como jurar obediencia. Hiciéronse la acostumbrada cortesía los combatientes y empezaron su batalla. Zabaleta, 1660.

46 Velez de Guevara (1641: 155). En esto, el Maestro, con el montante, barriendo los pies a los mirones abrió la rueda.

${ }^{47}$ Llegó la ora, y en lo baxo del patio uvo diversas danças, bayles, juegos de manos, esgrima y bolteadores; y después, prosiguiendo, se començó la entrada de las cañas, con sus adargas, lanças, cifras y banderillas y cavallos de palo, en Céspedes y Meneses, 1626: I, 109.

48 Covarrubias (op. Cit.: 490 v.) define el término florear como el preludio que hazen con las espadas los esgrimidores antes de acometer a herir el uno al otro, o quando dexan las espadas, que llaman asentar.

49 op. Cit. (1883): 
España. Por el momento histórico en el que se realizó dicha afirmación, mediados del siglo XVII, es posible que se refiriera a una empuñadura de taza, en contraposición de la moda francesa que tendía ya hacía los espadines del XVIII.

Por tanto parece claro que los espaderos hispanos realizaron, tal y como hemos visto, hojas de todos los tamaños, anchuras y formas. Incluyendo tipologías que se venían considerando exclusivas de otras zonas del continente, como es el caso de los montantes.

\section{LAS EMPUÑADURAS}

Existen una serie de circunstancias que condicionan negativamente el estudio de las guarniciones. En primer lugar muchas empuñaduras tenían una vida limitada respecto a las hojas. Resultaba frecuente que, al ser la espada un elemento más de la indumentaria masculina de la época, las hojas fueran teniendo diferentes empuñaduras, elemento visible de la espada, conforme avanzaban los gustos y las modas. En otras ocasiones era la calidad, antigüedad y tradición familiar de la hoja lo que provocaba que se mantuviese la misma mientras cambiaban las empuñaduras. También hay que tener en cuenta que muchas guarniciones estaban realizadas con materiales lujosos como oro, plata, piedras preciosas, etc; y en muchas ocasiones se hacía necesario recurrir a la venta de las mismas para el pago de deudas, especialmente en el momento de la muerte del propietario de la espada.

Por todo ello, la posible identificación de una empuñadura con una época o zona geográfica concreta a partir del estudio de la hoja que porta, es en principio complicado. Las hojas suelen aportar información complementaria sobre su origen, como son las marcas y las inscripciones, pero que no es posible extrapolar a la empuñadura por los motivos que antes hemos visto. Si a esto sumamos el hecho de que las empuñaduras, al igual que las hojas, eran objeto de comercio hacia otros países, podemos pensar que en muchos casos la zona de fabricación de la empuñadura y la de la hoja son diferentes.

La demostración de la existencia de características especiales en empuñaduras producidas en una zona geográfica concreta, resulta muy complicada. En primer lugar los intercambios de ideas y mentalidades, así como de tendencias artísticas, fueron muy importantes. Las empuñaduras no escaparon a esta dinámica y libros con modelos y técnicas decorativas circularon por toda Europa, repitiéndose tipologías similares en diferentes partes del continente.

Algunas de las técnicas y motivos decorativos que se identifican como hispanos, de origen musulmán, como la incrustación de oro y el uso de lacerías, fueron utilizadas en zonas tan lejanas como Inglaterra ${ }^{50}$ o Escandinavia ${ }^{51}$. Aunque el origen parece encontrarse precisamente en la utilización de las mismas por parte de artesanos españoles que recorrieron Europa al servicio de las más importantes casas reales, como fue el caso de Diego de Zayas (Blair, 1970).

Aun así, se han establecido algunas pautas que permiten identificar empuñaduras de las denominadas de lazo de origen italiano, alemán, francés e incluso inglés (North: op.cit: 60), mientras que las de origen español quedan minimizadas debido a la escasez de estudios al respecto.

Si bien la empuñadura ha sido el elemento clásico de asignación de cronología de las espadas, y una de las partes que han atraído más atención, es prácticamente nulo el conocimiento que poseemos sobre su fabricación en España ${ }^{52}$. Toda la fama que poseen hojas españolas se vuelve en desconocimiento al tratar el tema de las empuñaduras.

\footnotetext{
${ }^{50}$ Los espaderos ingleses de la factoría de Hounslow utilizaron estas técnicas en muchas de las empuñaduras (RAL IX 1329).

51 Un buen ejemplo es el estoque con hoja de Andres Munsten de Federico II de Dinamarca conservado en Copenhage.

52 Quizás el estudio más extenso y riguroso sobre las empuñaduras haya sido el realizado por Norman (1980).
} 
La consecuencia más evidente de esta situación es la dificultad que existe para identificar guarniciones de fabricación hispana del siglo XVI. Cuando se catalogan espadas con hojas españolas de ese periodo, normalmente se atribuyen las empuñaduras que portan a artesanos extranjeros, italianos y alemanes fundamentalmente ${ }^{53}$.

Se han lanzado varias teorías para tratar de justificar esta presunta falta de producción de empuñaduras en la corona española. Una de ellas la relaciona con la costumbre de las clases dominantes de importar los artículos de lujo, incluyendo las guarniciones (Pelaez del Valle, 1983). Aunque este razonamiento, que no compartimos del todo, fuera correcto, sólo explicaría parcialmente la no presencia de una producción determinada de guarniciones en la Península Ibérica, la de lujo. Pero cabría preguntarse entonces que sucedía con la mayoría de las espadas que portaban los pobladores de la corona española.

La presunta austeridad en el vestir de la corte y por extensión de la sociedad española, motivada por causas económicas y religiosas, también se usa como argumento para explicar la ausencia de una producción de empuñaduras de calidad (Pelaez del Valle, op.cit.). Según estas teorías no gustaba a la nobleza española portar empuñaduras muy trabajadas y ornadas, que pudieran desentonar con el gusto por una indumentaria más formal y discreta, normalmente relacionada con el color negro ${ }^{54}$. Estas afirmaciones carecen de todo fundamento, ya que en la corte española se usaron guarniciones doradas y profusamente decoradas con todo tipo de elementos durante todo el siglo XVI, tal y como lo demuestra la iconografía de la época. Son numerosas las referencias que existen sobre espadas con empuñaduras doradas, ya desde la Edad Media, en los inventarios y en las descripciones que se realizaron en la época de la corte y los soberanos españoles ${ }^{55}$. Sirva como ejemplo el siguiente texto: diez espadas guarnidas de plata de las castellanas, y la mi espada castellana que fis faser aquí en Sevilla con piedras e aljófar (Grassotti, 1988: 151).

Fueron muchas las pragmáticas que buscaban reducir el lujo y los metales preciosos en la indumentaria de la época, en la que se incluían las empuñaduras y los elementos metálicos de los accesorios necesarios para portar una espada ${ }^{56}$. Pero eso no supuso un freno para la decoración de las empuñaduras y los aderezos de las espadas. El uso del oro para embellecer las empuñaduras es mencionado en las ordenanzas de espaderos sevillanos. En estas se indicaba a los espaderos que no podían dar a dorar a sisa, ya que se trataba de una obra, engañosa y falsa (...) por perderse el oro que en ello se mete, (Sevilla 1478). En Nueva España, solucionaban el tema a través de un escueto, que ningun oficial pueda dar a dorar de sisa, (Nueva España 1556), sin mencionar el tema siquiera en las de 1600. Mientras, en la capital del virreinato de Perú (Lima 1605) repiten exactamente los términos sevillanos, con lo que se comprueba una vez más, lo que los veedores del gremio indicaban al comienzo de sus ordenanzas, al decir que se inspiraron en las de la capital hispalense, para rehacer las suyas. Al decir que no debían de dar a realizar, pensamos que se refieren a que no las dieran a los doradores, que eran quienes en teoría debían de realizar este trabajo. Con ello no se prohibía el dorado de las empuñaduras, sino el uso de una técnica concreta que hacía que se perdiera el oro usado.

La existencia de una producción de empuñaduras de calidad queda demostrada finalmente por la existencia de un gremio dedicado a tales menesteres, tal y como más adelante vere-

53 Incluso cuando aparecen nombres de origen hispano en las empuñaduras como es el caso de una pieza conservada en Nueva York (MMA 04.3.12) con el nombre Madrigal no se habla de una posible manufactura española, en Norman op. cit.: 333.

${ }^{54}$ El negro de los vestidos no se portaba por austeridad, sino que se consideraba un color elegante y digno de los personajes más elevados de la corte.

55 espada plateada cincelada, talabarte y pretina bordados, cuello con vainilla de seda carmesí y el collar grande del Toisón...; Relación del juramento del príncipe don Felipe 1608,en Díaz Simón, 1982.

56 Sempere y Guarinos (1788). 
mos. Por lo tanto parecen poco certeras aquellas teorías que hablan de una dependencia exterior de empuñaduras y de técnicas decorativas de calidad (Pelaez del Valle, op.cit:149).

Los encargados de realizar las empuñaduras de las espadas se denominaban maestros de hacer guarniciones o espaderos, aunque no realizaban hojas de espadas. Además existían otros artesanos involucrados en la fabricación de esta parte de las espadas como eran los doradores y los plateros. Los primeros se encargaban de embellecer las empuñaduras, entrando en conflicto a veces con los espaderos que en muchas ocasiones eran los encargados de hacerlas, en detrimento de su función de forjadores de hojas. Los plateros sólo intervendrían por tanto en las empuñaduras más lujosas.

Resulta curioso constatar que, mientras lo que prima para realizar clasificaciones de espadas del XVI y XVII son las guarniciones, en la época son muy escasas las referencias que se hacen hacia ellas, salvo para indicar si se encontraban decoradas y con que materiales.

Para el estudio de las guarniciones hispanas las hemos dividido en varias partes para tratar de dar algunos datos parciales sobre las mismas, y posteriormente comentar algunas de las tipologías presentes en espadas españolas.

La primera pieza a la que nos referiremos es el pomo. Respecto a esta pieza básica para la estructura y manejo de la espada, ya que sirve para fijar la empuñadura a la hoja y, especialmente en el caso de las espadas de comienzos del XVI, como contrapeso, no existe mucha controversia. El único asunto que nos gustaría comentar es el de la utilización del término mançana como sinónimo suyo, ya desde la Edad Media, debido al parecido de algunos pomos a la referida fruta ${ }^{57}$.

Otro tipo de pomo fabricado en los talleres españoles son los denominados como almendrillas buidas. Estos son en forma de almendras y se encuentran gallonadas o estriadas verticalmente, aunque también lo pueden estar horizontalmente, buida al través. Normalmente esta forma del pomo se repiten en el resto de la guarnición rematando los gavilanes o formando parte de los lazos. Siendo un rasgo que consideramos característico de las empuñaduras hispanas. El término buido ha sido causa de controversia en cuanto a su significado ${ }^{58}$. Aunque a nuestro parecer el significado de vaciado o acanalado es el más acertado para el caso de las espadas. Así los cuchilleros pamploneses obligaban a que las hojas tenían que ir laceradas y buida en rueda por atras y adelante (Nuñez Cepeda, 1948:123). Es decir estaban obligados a poseer una rueda de amolar con la que realizar los vaceos o canales correspondientes en ambos lados de la hoja.

El puño era una parte importante de la guarnición, ya que era el elemento que permitía asir y controlar los movimientos de la espada. De hecho existían espaderos especializados en su elaboración, identificándose incluso algunos, caso del artesano Juan Suárez, como oficial de hacer puños de espadas (Gestoso, 1899-1908). Los puños se realizaban normalmente de madera, forrada con un torzal de metal, que podía ser incluso de oro y plata, y a los que en la documentación se suelen referir como puño plateado de ylo o puno de ylo texido (Segovia 1536). Para definir este tipo de trabajos cuando formaban determinadas labores se utilizaba el término entorchado: Puño entorchado (Nueva España 1556). Otro tipo de puños eran los de alquimya, que tenían sus propios oficiales expertos en su elaboración. Hubo ocasiones en

57 AGS Relación de Valladolid, op. Cit.

58 Leguina (1912: 177). Para algunos autores significa triangular, mientras que otros consideran que significa afilar. La RAE seguramente siguiendo a Covarrubias (op. Cit): 158 r, da también la acepción de bruñir o acicalar. Nosotros proponemos siguiendo las referencias que da Leguina otra interpretación como sinónimo de vaciado ya que se refieran tanto a hojas como a partes de la guarnición, pomos y remates de los gavilanes, partes que en muchas ocasiones están «vaciadas», siendo varios de esos tipos identificados como de origen español. Tampoco descartamos la posibilidad de que posea una segunda acepción como sinónimo de aguzado o puntiagudo tal y como se desprende del siguiente párrafo de mediados del XVII: Dijo Nise que sí y él, pidiendo un ferreruelo, se tendió en el suelo y luego sobre los buidos extremos de dos estoques que sobre él puso en cruz. 
las que fue tan importante su presencia que estuvo a punto de crearse un gremio propio al margen del de los espaderos ${ }^{59}$. Esta técnica consistía en dar un aspecto dorado o plateado ${ }^{60}$ de las piezas, normalmente los puños ${ }^{61}$, mediante procedimientos químicos. El producto resultaba muy vistoso al gusto de la época, y mucho más barato para el fabricante. Los espaderos compraban estos puños por docenas en dos formatos, entorchados o llanos, resultando más caros los primeros ${ }^{62}$.

Los puños cortos también han sido señalados por algunos autores como característicos de espadas españolas (Laking, 1920-1922: 299). La causa de esta afirmación quizás lo hallemos en la forma de esgrima española del momento que dejaba el espacio del puño para algunos dedos, ya que el resto se colocaban en el recazo, para tener así más precisión y mejor agarre en el combate de estocada.

Muchas veces los puños se podían encontrar forrados de seda o terciopelo e incluso de lino, punos de seda e lino para la dicha espada (Dueñas, 1999), aunque por la fragilidad de dichos materiales pocas espadas lo han conservado. Las características y la composición de dichos tejidos también estaban reguladas en los exámenes y ordenanzas de espaderos: 1536)

guarnecer una espada y una daga de baina e punos de seda e lino para la dicha espada (Segovia

La calidad de la seda a utilizar también era objeto de regulación, exigiéndose que se utilizara seda -entorchada que fuera de seis obras siendo tomada por falsa aquella de quatro obras-(Toledo 1566), bajo pena de su incineración.

Otra técnica que se utilizada en las espadas españolas, concretamente en los puños, es la denominada de gusanillo. Esta al parecer consistía en la aplicación de diferentes colores en dicha zona ${ }^{63}$. Los puños de redecilla que se mencionan en varias ordenanzas de espaderos dentro de las piezas que debían hacer los oficiales que se examinaban de espaderos son fácilmente identificables en las labores de algunas empuñaduras, caso de la espada del Museo Luigi Marzoli con hoja punzonada de Pedro de Belmonte. Otros tipos de puños que se fabricaron en la corona española durante el siglo XVI fueron de hierro de Toledo, de hilo tejido; de oro; de red, etc. (Rojo, 1996: 342).

Bajo el término de guarnición se engloban todos aquellos elementos que buscan proteger la mano que maneja la espada de la hoja contraria. La más sencilla y antigua es el arriaz recto o cruz, que corta transversalmente a la hoja y que buscaba proteger el dorso de la mano que empuñaba la espada, del filo de una hoja contraria que pudiera resbalar por la propia.

Este elemento evoluciona ante los cambio en las formas de esgrima teniendo que defender mejor a la mano. Surgen las patillas que protegen a modo de anillo al dedo índice que se coloca por encima del arriaz para apoyarse en el recazo, parte de la hoja sin filos, y que permite una

59 AMS Papeles importantes del XVI. T. IV num. 33 en (Morell, 1986: 87) El ayuntamiento sevillano dictaminó que el realizar puños de alquimia no era parte del oficio de espadero, y que por tanto el maestro de hacer puños de alquimia Gregorio González no podía tener el título de espadero. A pesar de ello dictaminan la necesidad de crear dicho gremio ya que hay muchas personas que pretenden hacer puños de alquimia sin los saberlos hacer, de lo cual resulta daño y perjuicio a las personas que las compran y de haber examen en el dicho oficio se seguiria utildad y provecho, pido y suplico a V.S. sea servido de mandar que los executores hagan ordenanzas en lo tocante al dicho oficio de hacer alquimia y que haga examen como losd emas oficios.

60 Puños de alquimia blanca,.... Tassa general, en leguina.

61 Como no es oro todo lo que reluce, las cadenas, cintillos, joyas y brincos con solo ser de alquimya se contentaron. Cervantes el casamiento engañoso, en Leguina, 1912: 65.

62 El espadero sevillano Juan de Sotomayor compró al espadero de hacer puños de alquimia Gregorio González siete docenas de puños de alquimia. Los entorchados a 36 reales la docena, y los llanos a 30 reales, 28 de mayo de 1576. APS Of. 4, lib. I. Gestoso, op. cit: 186.

63 Así lo indica Covarrubias (op. Cit: 458 v.) al decir que existían gusanos tan pintados y esmaltados, que de ellos tomó el nombre la labor estimada que llamamos de gusanillo. 
mejor sujección del arma. En un primer momento es una, pero después son dos las patillas que salen del arriaz y con una forma curva terminan apoyándose al final del canto del recazo.

Posteriormente surgen los pitones que salen perpendicularmente desde el final de las patillas, y que pueden estar rematados en formas aplanadas o esféricas. Este último elemento tiene también una función de proteger la mano y los dedos que se apoyaban en el recazo de un tajo de la espada contraria. Posteriormente se formaron los puentes que unían los extremos de ambos pitones, y otro que surgía de los brazos del arriaz, formando las empuñaduras de puentes. A lo largo del siglo XVI se fueron multiplicando las defensas en las empuñaduras de las espadas dando lugar a lo que hoy conocemos como espadas de lazo. Para algunos expertos este proceso de complicación de la guarnición tiene un origen español (Boccia y Godoy, 1986: 446). Una palabra que actualmente se usa para referirse a estas piezas es la de gavilán. Este término tiene su origen en el siglo XVII, tal y como se deduce del siguiente texto.

\footnotetext{
Preguntóme cúya era la espada que llevaba al lado. Respondíle que mía, y, mirándola, dijo: Esos gavilanes habían de ser más largos, para reparar los tajos que se forman sobre el centro de las estocadas (Quevedo, 1626).
}

El contexto en el que se usa el término gavilán derivado del texto precedente, nos lleva a pensar que el significado de esta palabra se refería sólamente a los primitivos brazos del arriaz, que en empuñaduras del siglo XVII, especialmente en las de conchas y de taza, se desarrollaron tanto en su longitud como las alas desplegadas de un gavilán: con daga y espada de crecidos gavilanes (Suárez de Figueroa, Cristóbal, 1617: 498). Aunque también podía referirse al resto de las barras que rodean al puño como se desprende de la siguiente expresión de Lope de Vega en el Buscón: la espada con más gavilanes que la caza del Rey (Quevedo, 1626: 137).

Son escasas las referencias precisas a este tipo de guarniciones. Además, cuando aparecen expresiones concretas son susceptibles de interpretación, ya que hacen referencia a formas con cuyo significado no estamos familiarizados en muchas ocasiones. Son normales los términos que aluden a formas de frutas o vegetales, para que el lector de la época entendiera a que tipo de motivo se estaba aludiendo. Este tipo de expresiones se usan sobre todo para definir diferentes formas de pomos y remates de los arriaces y gavilanes, a los que nos hemos referido antes. Así a los pomos lenticulares se les denomina, como no podía ser de otra manera, como pomo liso de hechura de lantexa (Sánchez Cantón Vol. II: 156).

Uno de los elementos que remataban los gavilanes son los denominados alcaparrones. Estos como su ilustrativo nombre indica, no eran mas que botones aplastados en muchas ocasiones agallonados. Están presentes en muchas empuñaduras de lazo, rematando los gavilanes de parada, aunque también pueden aparecer en el aro guardamano, o en el centro de otros puentes y de las guardas. Las referencias a esos elementos son escasas y se suelen resolver utilizando expresiones tales como guarnición dorada lisa con unos botones en medio (Rodríguez, 1883: 85); o botones de encestado (Sánchez Cantón, op. Cit: 438).

Las guarniciones que poseen el pomo y los remates de los gavilanes en forma de huevo reciben el nombre de guarnición aobada (Leguina, 1912: 76). Esto no quiere decir que todas las guarniciones que presenten esta forma sean españolas, pero si que no se debe descartarse a priori su origen hispano, ya que en la Península Ibérica se trabajaba con ese tipo de elementos. Ejemplo de este tipo de motivos lo hallamos en París (MAP J 84).

Otra expresión utilizada en la época es la de empuñaduras melonadas. Esta referencia aparece por ejemplo en la almoneda de los bienes del capitán conquense Diego Jimenez del Barrio espada y daga con guarnicion melonada, espada acanalada con baina de zapa tasada en $2992 M_{r v d s}^{64}$. Ejemplos de este tipo de formas las podemos encontrar en muchas co-

${ }^{64}$ APC Jud. 56-9. Inventario de bienes del Capitán Diego Jiménez del Barrio. 
lecciones, como en una montada con una hoja de Francisco Ruiz, y que presenta incrustaciones de plata con motivos vegetales en la empuñadura (VAM M 73-1953) ${ }^{65}$.

También son frecuentes en los talleres españoles las guarniciones a base de gallones o vaciadas verticalmente guarnición dorada y canalada. Mientras que si estos canales eran hechos diagonalmente del estilo de las empuñaduras sogueadas recibían la denominación de labrado de canalado torcido.

Así mismo las guarniciones españolas podían portar empuñaduras escamadas, encestadas de ovalos y canales picadas; guarniciones de unos circulos de medio relieve, escaqueada, labrada de toda de entorchado, etc.Otro término utilizado a la hora de hablar de tipos de labores en las guarniciones es el de costilla de vaca. Parece lógico pensar que se refiere a aquellas empuñaduras en forma de gallones, que se asemeja al aspecto de esa parte del animal mencionado, aunque también podría referirse a un tipo de empuñadura formada por varios puentes paralelos, y que a veces se denomina de esqueleto.

Cuando se hace referencia a las guarniciones, término también ambiguo, sin decoración ni por cincelado ni por incrustación o pavonado, se suele utilizar la expresión lisa o blanca. Esta última se debe al color del acero que se dejaba, aunque también se usa para referirse a la hoja.

Al hablar de la decoración, tanto de ataujía como por pavonado en negro o azul, nos podemos encontrar con la expresión doradas y negras. Esta última expresión también es ambigua, ya que del mismo modo se llaman a las espadas usadas para entrenamiento o de esgrima, como ya vimos anteriormente.

Una labor muy utilizada en las empuñaduras españolas era la que se conocía bajo la denominación de embarnizar o barnizar. Según Covarrubias (Covarrubias, fol. 122) el barniz era una especie de goma que manaba del enebro, y que mezclado con grasa, aceite de linaza o de olivo se obtenía este elemento, que se usaba para dar lustre a toda pintura. Aunque consideramos que en este caso se usa en su acepción de barnizar el hierro al fuego que creemos que se refiere al proceso de dar el barniz mencionado en caliente, tras sacarlo de la fragua para que así las guarniciones tuvieran una pátina protectora y de aspecto brillante.

Tradicionalmente se han venido asignando a los talleres hispanos unos tipos muy concretos de guarniciones de espadas, considerando el resto de formas como extranjeras, incluso cuando están montadas con hojas españolas.

Así autores como Laking, Norman u Oaekshott mencionan dos o tres tipos muy concretos a la hora de hablar de empuñaduras españolas, como las de conchas, o bilbo para el mundo anglosajón; y las de taza o cazoleta. Este pequeño grupo se ve aumentado a veces con tipos concretos de empuñaduras, que por estar muy presentes en diferentes colecciones hispanas, o por estar documentado de alguna manera su origen español se las trata como tales ${ }^{66}$. Cuando se habla de empuñaduras españolas se aplican, en algunos casos, estereotipos carentes de cualquier análisis científico, como es el de considerar hispanas a aquellas empuñaduras que poseen, bien en el pomo o en el remate de los gavilanes, cabezas de figuras con rasgos norteafricanos o turquescos (Charles, 1993: 258). Esta asociación se trata de justificar, en gran medida, por los continuos enfrentamientos con los árabes, durante la reconquista en una primera fase, y contra la piratería y los ataques otomanos en una segunda.

Si bien es cierto, que no se conoce ninguna obra española con diseños de empuñaduras, si que existen algunas referencias sobre fabricación de empuñaduras de lujo en exámenes de maestría. Así encontramos bellísimos diseños de empuñaduras de diferentes tipos de armas

\footnotetext{
65 Espada cuya guarnición está formada por un pomo amelonado, arriaz recto, aro guardamanos, patillas al recazo y dos puentes.

66 Caso de las empuñaduras tipo 47 de Norman presentes en la Real Armería de Madrid (G-55 y 58). Curiosamente una tipología tan clara no la recoge en el apartado de guarniciones, y sólo se hace eco de ella en el apartado de pomos y en el capítulo dedicado a Special Dating Faeatures: 55.
} 
blancas en los dibujos de las piezas que los plateros de Barcelona debían de hacer para conseguir la categoría de maestros ${ }^{67}$. Además la existencia de tratados prácticos de platería demuestran el nivel de conocimiento de técnicas orfebres y su posible aplicación a la fabricación de empuñaduras de lujo ${ }^{68}$.

La falta de marcas o inscripciones alusivas al fabricante, al contrario de lo que sucede en las hojas, dificulta la identificación de las piezas españolas, en contraposición a algunas empuñaduras alemanas, y sobre todo italianas que si poseen este tipo de datos ${ }^{69}$.

Los datos sobre los grupos de artesanos que fabricaban guarniciones de espadas en España son muy escasos. Esto se debe en gran parte a la indefinición del concepto de espadero. Este muchas veces sólo monta la hoja y realiza la vaina. Su función depende de las ciudades donde trabaje y del momento cronológico, siendo más acusado este papel desde el tercer tercio del siglo XVI. Dentro del gremio de espaderos también están englobados los espaderos que se conocen como maestros de hacer guarniciones, así como toda una serie de artesanos que adornan y decoran dichas empuñaduras.

Otro motivo más que ha llevado a obviar la posible fabricación de empuñaduras en la corona española se debe a que se conocen muchos casos en los que hojas, normalmente toledanas, se exportaban para ser montadas con guarniciones de lujo fabricadas en los lugares de destino. Como por ejemplo varias hojas adquiridas por los Electores de Sajonia y montadas con guarniciones realizadas por plateros alemanes. Caso de la espada del Principe-Elector de Sajonia Christian II (MMA 1970.77) con hoja de Juan Martínez y montada con una empuñadura del platero alemán Israel Schuech. En Francia también queda constancia de la importación de hojas como en el del inventario de l'hotel de Montmorençy de 1568 cuando en una de las partidas aparece el siguiente texto Item deux lames d"epees de espaigne (Reversau,1993).

La venta directa de hojas al extranjero tiene una explicación en la legislación real y gremial, que no permitía a un espadero de la fama de Tomás de Ayala vender una pieza finalizada. Sólo podía vender la hoja a un espadero guarnecedor quien tras ponerle la empuñadura y la vaina la comercializaba. Por lo tanto todas las ventas de espadas de calidad acabadas no las podía realizar el forjador de las hojas, sino era a través de un espadero guarnecedor. Esto provocaba la compra directa al forjador sólo de las hojas por parte de la alta sociedad europea, o la compra de una espada acabada a un espadero comerciante montada al gusto español. Lo que podía provocar, la venta sólo de la hoja, quedando la decoración y la colocación de una empuñadura a artesanos compatriotas del comprador extranjero.

Aun así, también se realizaban frecuentes ventas y regalos no solo de hojas sino también de espadas terminadas ${ }^{70}$ :

Viólo el Príncipe todo y él le presentó dos pinturas del Ticiano y una del Mudo, un montante y dos espadas, ofreciéndole con gran galantería todo cuanto tenía en su casa. Lo que llevó el Príncipe se apreciaría en ocho mil ducados, porque también dió cuatro alajas y dos pinturas, arcabuces y espadas a dos caballeros ingleses que fueron con el Príncipe,

67 Davillier recoge del Libro de Pasantías de los plateros barceloneses (Archivo Histórico de la Ciudad. Cat. 51),el dibujo de una empuñadura de espada del platero castellano Antonio de Valdés (1537), y una daga, que parece de orejas, con su vaina todo decorado a base de motivos manieristas con una riqueza y complejidad de primer orden.

68 Obras como las de Pérez de Vargas (De re metallica, 1569), o Arfe y Villafañe (Quilatador de la plata, oro y piedras, 1572), demuestran que los conocimientos y capacidad de los artesanos orfebres españoles no tenían nada que envidiar a los de el resto de Europa.

69 Así Othmar Wetters firma una empuñadura de la colección de Copenhague, y el florentino Donatelli hace lo propio con una pieza de Turín. Donde más nombres de espaderos aparecen es en empuñaduras de taza como Palumbo, Cilenta, etc. (Norman, op. Cit: 178).

70 Anónimo (1621-1627): Noticias de Madrid, en González de Amezúa, 1942: 74. Esto da una idea de la fama e importancia que las espadas, y más concretamente las españolas tenían en el siglo XVI, ya que son objeto de regalo al mismo nivel que joyas, o cuadros de Navarrete el Mudo o Tiziano. 
La presencia de espaderos fabricantes de guarniciones está fuera de toda duda. Poseen ordenanzas gremiales propias, entrando incluso en conflicto, con otros gremios relacionados con la fabricación de espadas, como el de los propios forjadores o el de los doradores ${ }^{71}$.

El tema de las empuñaduras se puede subdividir en dos: la realización en sí de las empuñaduras, y la decoración, a través de diferentes técnicas, de la misma. El primer paso, tal y como antes hemos indicado, lo realizaban los espaderos llamados maestros de hacer guarniciones de dagas y espadas, o simplemente espaderos. Estos las fabricaban utilizando fundamentalmente la forja y la lima, y eran capaces de realizar todo tipo de guarniciones. Posteriormente estos mismos u otros grupos, dependiendo de las zonas y circunstancias económico sociales, terminaban los trabajos para dejar la pieza acabada. Normalmente se trataba de decorar y proteger la empuñadura. Es decir se barnizaban, pavonaban, doraban y decoraban, e incluso colocándoles piedras preciosas en ellas.

En algunas regiones los espaderos eran los encargados de proteger y decorar las empuñaduras:

Ordenanzas de espaderos: usen el dorar, y el pavonar sin otro examen

En el Ayuntamiento, q la muy Noble, y muy leal ciudad de Murcia tuvo 15 dias del mes de junio de mil y seiscientos y diez y nueve años, se acordó que se guarde la costumbre que ha havido en el dorar y pabonar los espaderos: $y$ todos los espaderos exerçan el oficio de pabonadores, $y$ doradores sin que sea necessario otro examen mas que el de espadero, como hasta aquí se ha hecho ${ }^{72}$

Aunque en otras ocasiones, eran varios los grupos que podían realizar estos trabajos, surgiendo tensiones entre varios gremios, normalmente los espaderos y doradores. Una de las formas de acabar con dichos problemas era la de unir ambas agrupaciones en un mismo gremio. Los espaderos de Barcelona, se vieron obligados por las autoridades municipales, a adoptar este sistema, integrando a los empabonadores sueltos, al gremio y cofradía de spasers i llancers ${ }^{73}$. Eso si se marcaban claramente cuales eran las funciones que se permitía desarrollar a los oficiales de cada grupo.

Cuando existía un gremio consolidado de doradores se entablaba una fuerte lucha por el trabajo. A veces los espaderos conseguían hacerse, al menos parcialmente, con la decoración de guarniciones de armas blancas, como fue el caso de Zaragoza.

El trabajo de los doradores no sólo consistía en aderezar, decorar, las empuñaduras, sino que también las perfeccionaban:

El dorado, plateado y bruñido, tiene también sus oficiales, con nombre de doradores, a quien pertenece perfeccionar todo genero de herramientas y guarniciones como lisas, labradas, de diamantes, jaspeadas, entorchadas, de botones, de grano de trigo, de botones de cordoncillo, sogueado, de ovalillos y otras muchas de varias labores.

Suceden los que hacen varios puños de plata tirada por extremo curiosos. (Suárez de Figueroa,1615)

Los doradores zaragozanos tenían entre sus funciones dorar, platear, pabonar, bruñir, estañar y dar de azul todas y qualesquiere cosas de hierro, metal y arambre. En el examen que debían de pasar para poder usar el oficio de dorador tenían que saber realizar una guarnición labrada de botoncillos de cortado y después de cortada la haya de enseñar y mostrar a los dichos mayordomo y examinador. También debían de saber hacer una guarnición de espada labrada de linias quadradas y cortada y la haya de platear; y assi mesmo ha de aplanar una guarnicion de espada a esquina viva jaspeada y pavonada a dos caldas...

${ }^{71}$ Estos eran los encargados de colocar los metales preciosos, oro y plata, en las empuñaduras de las espadas.

72 Los muy ilustres señores de Murcia mandaron imprimir las ordenanzas que tienen para el gobierno de ella y de su campo, y huerta aprovadas, por la Magestad catolica de N. Rey y señor D. Carlos II. Impreso por Vicente Llopiu. 1695.

73 Libro Consular del Gremio 1606, en Capmany Montpalau. Op. Cit: 77. 
La otra técnica decorativa que tiene una fuerte presencia en las empuñaduras de las espadas es el cincelado, o como se denomina en los documentos de la época el labrado. Son variados los motivos que aparecen representados en las empuñaduras, todos relacionados con el momento artístico en el que fueron producidos, renacimiento y barroco fundamentalmente. Así mascarones, volutas, escenas religiosas o mitológicas, motivos geométricos, zoomorfos y vegetales aparecen representados en muchas guarniciones.

Al hablar de guarniciones de calidad con motivos cincelados siempre se habla de los magníficos artesanos de Brescia y de Nápoles, citándose incluso al escultor Benvenuto Cellini como creador de empuñaduras ${ }^{74}$. En el caso alemán se cita a la escuela de Munich con los hermanos Daniel y Emanuel Sadeler y sus trabajos de motivos grutescos cincelados sobre fondos de azul y oro (Norman, 1980: 374).

Otra vez son raras las guarniciones de este tipo que son atribuidas a talleres españoles. Si bien la existencia de artesanos capaces de realizar ese tipo de trabajos está de sobra documentada, especialmente entre plateros y orfebres. Esta contradicción se pone más de manifiesto si pensamos en los meritorios trabajos que aparecen en las empuñaduras denominadas de taza o cazoleta. Allí se crean magníficos motivos calando incluso las superficies, tanto de la guarda como del pomo y del guardapolvo. Este hecho ha pasado desapercibido para los grandes especialistas provocando un gran vacío de información sobre el tema (Norman, 1980: 377).

\section{a) Tipologías de empuñaduras}

Un primer grupo de empuñaduras que se han venido considerando españolas (Oakeshott, 1980: 133) son aquellas formadas por brazos del arriaz curvados hacia la hoja y aplanados, que a veces se calan con formas circulares ${ }^{75}$. Se completan este tipo de arriaces con pomos, normalmente lenticulares, y con patillas, a veces rematadas en pitones, que partiendo de la mitad del brazo del arriaz se curva hasta llegar más o menos a la zona final del canto del recazo (Fig. 1).

Representantes de esta tipología de empuñaduras las encontramos en la espada del Gran Capitán (RAM G 29); o la atribuida a Fernando el Católico (RAM G 31).

El origen de las patillas, en francés pas $d^{\prime} a n e^{76}$, y de los pitones no está claro, aunque algunos autores lo consideran español (Charles, 1993: 20). Con ellas se busca proteger el dedo índice en el momento que se apoya en el canto del recazo para así dirigir mejor la trayectoria de la espada ${ }^{77}$. Un magnífico ejemplo de este uso lo hallamos en el combate de ángeles contra demonios en el «Apocalipsis» del Maestro de Cueza, principios del siglo XVI, en el que los ángeles batallan con rodela y espada de arriaz recto con patillas, mostrando incluso algunos el dedo índice por debajo de la cruz. Otro ejemplo de espada de patillas en la iconografía española lo hallamos en el San Miguel Pesando las almas del mismo pintor, en el que empuña la espada pasando el dedo índice por dentro de la patilla casi tocando el pulgar. Existen ejemplos de patillas en pinturas españolas de mediados del siglo XV como la que lleva en la mano San Martín ${ }^{78}$, y algún ejemplo español de patillas tempranas, que consistía en la exis-

74 En el Catálogo de la Real Armería de 1898 se decía que podía ser obra de este escultor la empuñadura G 47 también denominada de los mascarones, sin aportar ningún dato más respecto a su atribución. Valencia de don Juan (1898: 222).

75 Este autor la denomina de estilo español, citando dos ejemplos existentes en la colección Oldescalchi (C.O. 1099 y 149) y en la colección Vogel de Zürich. Relacionando este tipo de guarniciones con la de los montantes y con los tipos bávaros D y D1 de su clasificación.

${ }^{76}$ Este nombre procede de la forma que tiene, parecida a la huella que deja la pezuña de un burro al andar, (Laking, op. Cit: Vol.. II 294).

77 Sobra decir que este tipo de empuñaduras van asociadas a hojas con recazo, es decir con una porción de la hoja con los lomos sin filos, ya que era la zona donde se apoyaba el dedo índice.

78 San Martín partiendo la capa tabla hispanoflamenca de Martin Bernat, (activo entre 1469-1497). 
tencia de una sola en el lado que se colocaba el dedo índice (WC No 28) ${ }^{79}$. Este tipo de empuñaduras con una sola patilla «finger ring» se corresponde al tipo 4 de Norman (Norman, 1980). Este autor cita varias pinturas italianas con representación de este tipo de empuñaduras, pero reconoce que existían dos espadas de este tipo en el Inventario Iluminado de la Real Armería. También en Venecia se conservan algunas espadas variantes de este tipo, tipo 6 de Norman, (APD A 953), ya que tiene sólo una patilla, pero el brazo del arriaz del que surge la patilla sube hacia arriba en ángulo recto formando una especie de aro guardamano recto. Más piezas con un sólo anillo de patilla aparecen en el Arsenal de Alejandría.

Un elemento que aparece como evolución lógica de la aparición de las patillas, son los pitones. Estas piezas salen perpendicularmente del final de las patillas, y suelen estar rematadas en bolas o en formas espatuladas curvadas. Su origen radica en la necesidad de proteger el dorso de la mano de la hoja del contrario, que al resbalar sobre el plano de la misma podía llegar a dañar la mano que asía la espada. Ejemplos de este tipo de elementos los encontramos en Venecia (APD A 600), y en Madrid (RAM G 37, G 38 y G 39) montadas con hojas valencianas, según el Inventario Iluminado, y sobre todo en la espada atribuida a Pizarro (RAM G 36). Norman (tipo 20) la relaciona con la obra maestra ${ }^{80}$ realizada por el platero barcelonés Antonio Valdés ${ }^{81}$, aunque esta posee los arriaces rectos y sin estar rematadas en formas aplanadas vueltas en direcciones opuestas (Fig. 8).

Relacionado con estas guarniciones aparece también un tipo de pomo que se ha venido considerando español, y que aparecerá también asociado a una tipología de guarnición española del siglo XVI. Este tiene forma troncopiramidal y suele estar calada con unas formas que se suelen repetir en los calados de los remates en los brazos del arriaz.

Dentro de las guarniciones denominadas de lazo existe otra tipología que se cree originaria, o por lo menos común, en la Península Ibérica ya entrado el siglo XVI, y que tiene una vinculación directa con la empuñadura anterior.

En principio esta guarnición se presenta con arriaces rectos (Collección de la familia Vogel $^{82}$ y MPP 57783); o incluso con los gavilanes de parada curvados en direcciones opuestas (RAL IX 939); o en la misma hacia la hoja (MSF 2182). Poco a poco se complicaron con un aro guardamanos y gavilanes de parada, como la espada existente en Londres (VAM M 701947). Los mejores ejemplos de este tipo de empuñaduras las encontramos en varias montadas con hojas de Sebastián Hernández (RAM G. 55, G. 56, G. 56 y G. 58 $8^{84}$ ).

Son varios los elementos característicos de este tipo de empuñaduras (Fig. 2). El primero es un gran pomo troncopiramidal formado por dos o cuatro cuerpos en ángulo recto perforados con formas circulares o trapezoidales. El segundo elemento común a estas empuñaduras son los gavilanes, tanto del arriaz como los de la guarda, que normalmente forman dos anillos, y los de la contraguarda, aplanados. Estos también se encuentran calados con las mismas formas existentes en el pomo, normalmente rematando los brazos del arriaz, que se curvan en direcciones opuestas, y al final del aro guardamano. En las fuentes de la época a la hora de

79 Laking Op. Cit: II, 294. Esta espada porta al parecer las armas de Lopez de Zúñiga (S. XIII), así como una inscripción que hace referencia al Cid.

80 Ese nombre recibían las piezas que debían de realizar los aspirantes a maestros en cualquier gremio para demostrar sus conocimientos y maestría.

81 Este dato lo toma de Davillier, 1879: pl. VII.

82 Bosson et alii, 1972: 25. En esta misma colección existe otra pieza ( $\left.\mathrm{N}^{\circ} 85\right)$ en este caso un montante con el mismo tipo de empuñadura, con las únicas diferencias de no tener patillas ni un segundo anillo en la guarda al final del recazo, y el hecho de que los remates de los brazos del arriaz están ligeramente curvados hacia la hoja.

83 Boccia y Godoy, op. cit: 428). En el catálogo de la colección citan respecto al origen de este tipo de empuñaduras tres posibilidades: Alemania (Sajonia), Italia y también España. Atribuyendo a su pieza una procedencia italiana hecha al gusto español.

84 Varias de ellas están montadas en hojas de Sebastián Hernández, pero otras ocasiones han sido colocadas en hojas posteriores, caso de la G. 57 (Silvestre Nieto). 


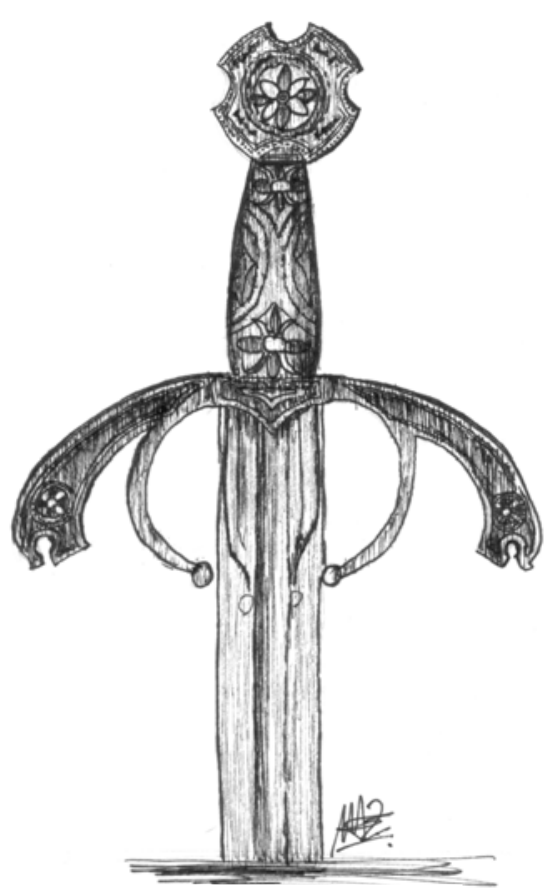

Figura 1

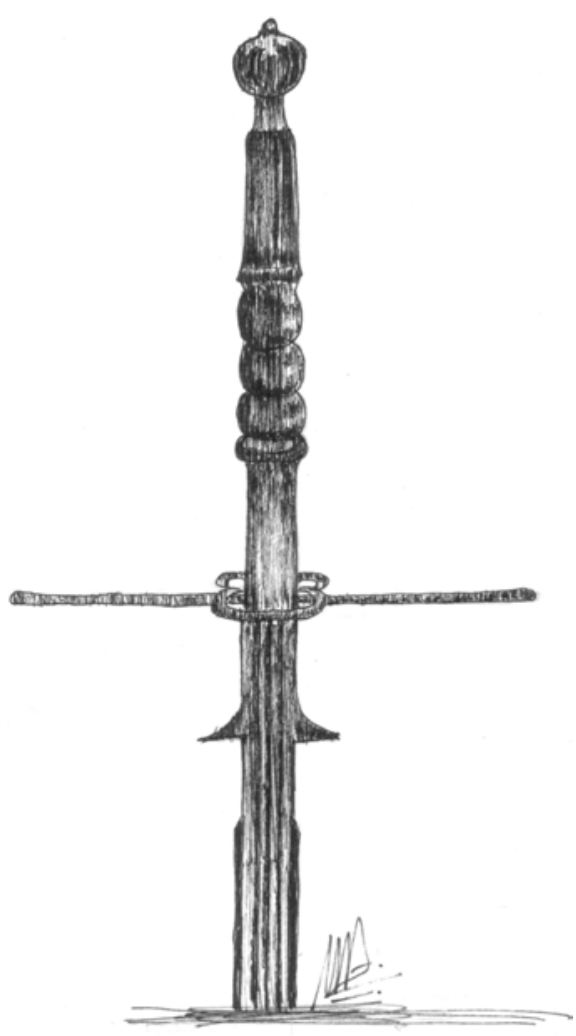

Figura 3

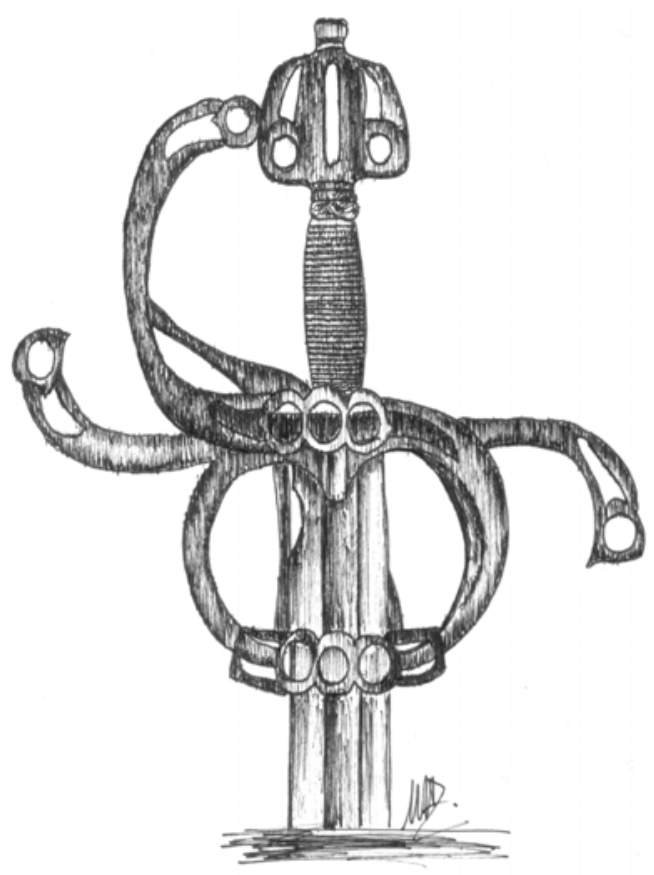

Figura 2

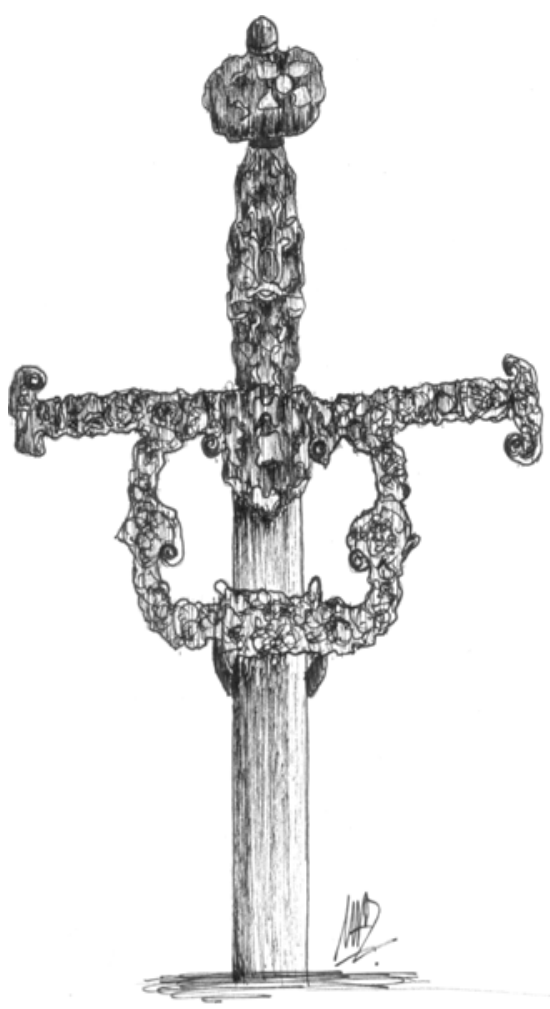

Figura 4 
referirse a este tipo de guarniciones se utiliza la palabra aventanada, debido evidentemente a los huecos que aparecen en las mismas (Norman, op. 1980: 55) ${ }^{85}$.

A pesar de que todavía no se ha podido documentar el origen hispano de este tipo de empuñaduras, son muchos los autores que así lo piensan ${ }^{86}$. También se cita su uso en Venecia, e incluso se ha relacionado con la marca de la ciudad de Augsburgo que alguna pieza similar presenta (Norman, 1980: 55). Lo que sí parece claro es la cronología que se atribuye a este tipo de empuñaduras, que abarca desde finales del XV, las primitivas, hasta mediados del siglo XVI.

Otro tipo de guarnición que aparece con frecuencia en hojas españolas es la encadenada o de eslabones. Esta, que se podría incluir dentro de las denominadas de lazo, aparece en varias espadas con hojas españolas: (Stuyvesant F 3987; KMV 1106, etc.) ${ }^{88}$. Algunos autores consideran que fue en la década de los 70 del siglo XVI cuando hicieron aparición este tipo de empuñaduras ${ }^{89}$. Un buen ejemplo de empuñadura de este tipo la encontramos en París (MAP J 120). Esta se considera como espada española, ya que incluso la hoja está firmada ME FECIT/ IN VALENCIA, y es mencionada como tal en el inventario de los bienes del Archiduque Carlos II de Estiria (Norman, 1980: 113). Nuevamente se ha venido dando a estas empuñaduras un origen extranjero, en este caso francés, descartando que los talleres españoles las pudieran realizar ${ }^{90}$.

Además de estas guarniciones existían otras con guardas más sencillas de sección circular, exagonal, etc. En ellas se multiplicaban los gavilanes para proteger la mano en la guarda y contraguarda, además de los puentes y patillas. Normalmente se conoce genéricamente a este tipo de empuñaduras como de lazo No hemos podido documentar ninguna referencia de época a este tipo de guarniciones utilizando la expresión de lazo. Cuando se habla en las fuentes de la época de este tipo se utiliza la expresión de puentes. Este término es muy ambiguo, y hay autores que consideran que se usa en referencia a las patillas, o incluso a los anillos de la guarda que surgen como evolución de los pitones. Esta teoría se ve reforzada por la documentación cuando en 1529 el guarnicionero de espadas sevillano Alonso de Medina se obliga a realizar quince docenas de guarniciones de espadas de buen hierro blancas de dos puentes barreta por la mitad ${ }^{91}$. La fecha y la identificación de la guarnición nos está hablando de un empuñadura de puentes como resultado de una guarda derivada de la evolución de los pitones. Lo cierto es que también existen referencias posteriores que indican claramente que se refieren a las guardas que se conocen como lazos. Así se habla de una guarnición de tres puentes (Leguina, 1912: 729) o incluso de una guarnicion de seis puentes para derecha e izquierda y una guarda al pomo ${ }^{92}$. Por lo que creemos que el término decimonónico de empuñadura de lazo debería de ser sustituido por el más correcto de puentes. Algunos autores consideran que este tipo de empuñaduras no ofrecían suficiente protección frente a las estocadas de punta, y que por tanto hicieron necesaria la colocación de placas perforadas en

85 Esta referencia alude a una espada del Duque del Infantado que poseía una hoja con una inscripción que rezaba RECAREDUS REX GOTHORUM, y que pasó a formar parte de la colección Bosson.

86 Este tipo de empuñaduras y su posible origen español ya habían llamado la atención de los especialistas (Bosson et alii, op. Cit.. 25). Entre ellos conviene destacar a Valencia de Don Juán, Laking, Blair, De Carlos (Espadas del siglo XVI en la Real Armería)etc.. También existen otros que le dan un doble origen incluyendo a Italia (Norlfo di Carpegna. Colecction Oldescalchi $\left.\mathrm{N}^{\circ} 234\right)$.

87 Dean (1914) nos advierte que en el siglo XIX un artesano de Barcelona que denomina Berrouista, realizaba este tipo de empuñaduras. Parece que trabajaba mucho para el entonces conservador de la Real Armería Zuloaga.

${ }^{88}$ Esta espada perteneció a Don Juan de Austria y se conserva con sus tiros y pretinas. Algunos autores reputados la consideran, sin razón aparente, obra del norte de Italia, (Seitz, 1981: 327).

89 Véase como ejemplo: (HRKM, inv. A. 1106).

90 Laking. (op. Cit.): 296 explica esta relación en base a los trabajos de este tipo realizados por Claude de Sauvigny (1578-1595) en Tours (MAP J. 135).

91 APS Manuel Sigura 1529, en (Gestoso, 1899).

92 Referencia al aro guardamano. Inventario del Príncipe Carlos, ibidem. 
la parte inferior de las mismas, considerando a los tucks alemanes como las primeras espadas en poseer estas defensas alrededor de 1570 (North, 1982: 9).

La empuñadura que más rápidamente se identifica con una producción española es la denominada de taza o cazoleta. Aunque muchas veces su manufactura proceda de talleres italianos con destino al mercado peninsular ${ }^{93}$. En términos prácticos, algunos autores la consideran como el final lógico de la evolución de la empuñadura, con el fin de dotar a la mano que empuña la espada una protección completa. Lo cierto es que también es un magnífico espacio en el que expresar el talento artístico de esos espaderos fabricantes de guarniciones con magníficos trabajos de cincelado, calado y grabados dignos de atención por parte del mundo de la historia del arte.

Sobre cuando se empiezan a utilizar estas guarniciones no existe un consenso. Algunos autores señalan como fecha inicial de su aparición la mitad del siglo XVII (Oaekshott, 1980:167) ${ }^{94}$. Otros adelantan unos años su llegada, y así parece demostrarlo la existencia de retratos de personajes que portan ya este tipo de espadas en sus tahalíes. Existiendo incluso teorías que hablan de ejemplos de finales del siglo XVI(Leguina, op. Cit.).

Para distinguir la producción de tazas realizada en territorio italiano, bajo la corona española ${ }^{95}$, de la propiamente peninsular, se citan varias diferencias entre ambas. Algunos autores piensan que las principales diferencias serían que las tazas españolas eran menos profundas, de un menor diámetro y con un pomo más pequeño y achatado, que las italianas (Laking, op. Cit: t, V 64). Así mismo se cita como elemento diferenciador la presencia en el interior de las tazas españolas de un elemento conocido como guardapolvo, frente a su ausencia en las italianas. Un último elemento que haría posible identificar unas de otras, sería la existencia del denominado borde rompepuntas en las españolas ${ }^{96}$.

Menos conocida que la anterior, pero también vinculada a la península ibérica, es la guarnición conocida en el mundo anglosajón como bilbo, mientras que en el mundo hispano reciben varias denominaciones como: guarnición bivalva, de conchas o de veneras. El tema del origen del término, y sus posibles vinculaciones con los centros productores vascos con Gran Bretaña, ya se trató en un trabajo anterior (Dueñas, 2001). Por ello aquí nos limitaremos a describir varios ejemplos y las características de este tipo de guarniciones.

Nuevamente comparte el origen de su fabricación y uso con diferentes zonas de la zona italiana, y aunque en algunas ocasiones se identifiquen como tales no se mencionan los motivos que llevan a dicha conclusión.

Se ha tratado de explicar la forma de esta protección y su relación con la Península Ibérica a través de la forma de concha de la protección de la empuñadura, y su relación con la concha o venera de Santiago Apóstol. Existiendo muchos ejemplos de este tipo de guarniciones en cuya cara exterior se muestran los gallones propios de las conchas (Estruch G 54). Este tipo de empuñadura podría ser la misma que se denomina en algunos documentos de época como de medio caracolillo ${ }^{97}$.

Estas guardas también se realizaron en otras zonas de la península ibérica, como Portugal, tal y como se desprende del siguiente texto:

le mandaron dorar una guarnición de alcaparrones a la portuguesa con las conchas labradas, con su pomo y contera, y pabonar una guarnición a la portuguesa con las conchas labradas ${ }^{98}$

93 Nápoles y Milán son los dos centros más importantes de producción de este tipo de empuñaduras. Charles, op. Cit.: 47, considera que el trabajo a rinceaux, es decir anillas es típicamente italiano relacionado con la arcabucería de cerdeña.

94 Charles, sitúa su aparición no antes del 1620.

95 Fundamentalmente Milán, Palermo y Nápoles.

96 Charles (op.cit.): 51. Esta pieza servía al parecer para bloquear la punta del contrario y así intentar desarmarlo, y no tanto romperla como parece indicar su nombre.

97 APC. Judi. Leg. 96-21.

98 Aprobación y examen de maestro dorador de fuego [Documentos sobre la vida privada española] 1726 Agustín G. de Amezúa y Mayo, Ilustre Colegio Notarial de Madrid (Madrid), 1950. 
Son muchas las expresiones que encontramos en la documentación de la época referente a diferentes tipos de guarniciones, y que en muchos de los casos no podemos identificar con casos concretos existentes en colecciones actuales. Así nos encontramos con expresiones tales como de claraboyas y espejuelos, de diamantes y rosetas, de rosetas y cartones (Rojo, op. Cit.)

\section{b) Técnicas decorativas}

Tradicionalmente se ha venido identificando la producción española de empuñaduras del resto por la presencia de unos motivos y técnicas decorativas muy concretas ${ }^{99}$. Estos elementos que permiten en principio reconocer una producción hispana son la técnica del damasquinado y los motivos decorativos englobados bajo el término genérico de «arabescos» e inscripciones cúficas (MAP J 70). Una vez más se pone en relación la producción hispana con la presencia árabe en la península.

Esta técnica de incrustación de metales preciosos sobre el hierro, va acompañada de fondos pavonados en negro o azul. Esta forma decorativa es considerada tradicionalmente como de origen árabe, aunque no se halla muy presente en las espadas hispanoárabes que se han conservado. Los motivos decorativos representados como las lacerías si que fueron muy utilizados en la decoración de la arquitectura y objetos musulmanes.

En la literatura anglosajona se la denomina azzimina, y que quizás pueda tener un origen común en la palabra árabe alarajia, que en español derivó en ataujía. Incluso sobre este tipo de piezas también se habla de la posibilidad de otro origen, como es el de la zona veneciana (Laking, op. Cit: T. IV 260) ${ }^{100}$. El motivo es el comercio de armas blancas que existió entre la zona del véneto con el norte de Africa y Turquía ya desde el siglo XV, y que supuso un intercambio de técnicas y gustos entre ambas zonas (Laking, op. Cit: 260).

Así algunas espadas con este tipo de decoración se consideran italianas, (WC A 509), debido a la riqueza decorativa y a la marca de la hoja, una cruz patada, que además recuerda a alguna de las utilizadas en la ciudad de Bilbao a mediados del siglo XVI (Dueñas, op. cit.). Es cierto que algunos artesanos italianos conocían y utilizaban estas técnicas para decorar espadas (MMA 04.3.21; RAM G 34), ya desde mediados del siglo XVI. Otro ejemplo de espada española que posee esta técnica lo tenemos en el estoque de caballo (MPP A 591).

Son varios los artesanos hispanos a los que se atribuye, si no ya su invención, si su utilización con mejores resultados en la decoración de armas blancas. Este es es el caso de Salvador de Avila, Perez de las Cellas, Diego de Zayas, etc. De todos estos quizás sea este último el más famoso por ser el mejor estudiado (Blair: 1970). Este armero español realizó espadas, mazas, dagas de oreja para las cortes más importantes del momento, como España, Francia e Inglaterra. Pero además era un buen conocedor del damasquinado, decorando sus armas con dicha técnica (Lavin: op. cit.).

El trabajo de guarniciones de lujo por artesanos españoles no está reconocido. Sólo la existencia de alguna pieza documentada permite afirmar que los espaderos españoles sabían manejar esta técnica alcanzando las mayores cotas de perfección. Ejemplo claro de que la producción de empuñaduras de calidad estaba a la altura de cualquier otra zona, lo hallamos en las magníficas empuñaduras de espadas atribuidas a plateros españoles como la de Viena (HRKM A 588). En este último caso se había venido atribuyendo su autoría a un taller italiano (Laking, op.cit: t, V 295), y en ninguno de los casos se las había relacionado con una posible manufactura

99 Por ejemplo cuando se identifica como española una espada (WC A 671), por poseer la empuñadura damasquinada, y por ser similar a la que porta Felipe II en un cuadro pintado por Tiziano (Laking, op. cit: t. V 299).

100 Ejemplos de empuñaduras con este tipo de decoración de origen italiano las encontramos en la espada del conde de Pio Capodilisto, o la de la existente en Solingen (Klingenmuseum 72.W3), que tiene dorado sobre pavonado tanto en la empuñadura como en el recazo. 


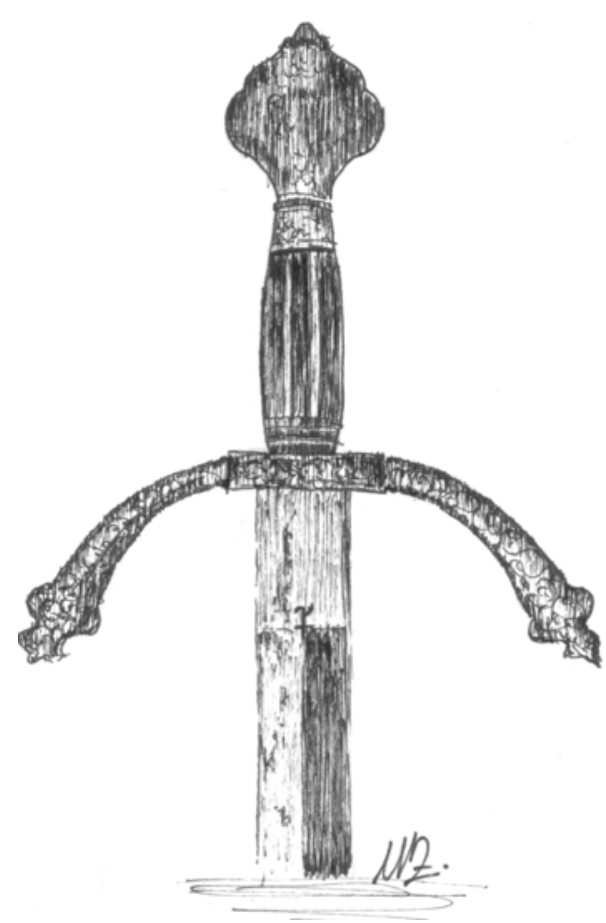

Figura 5

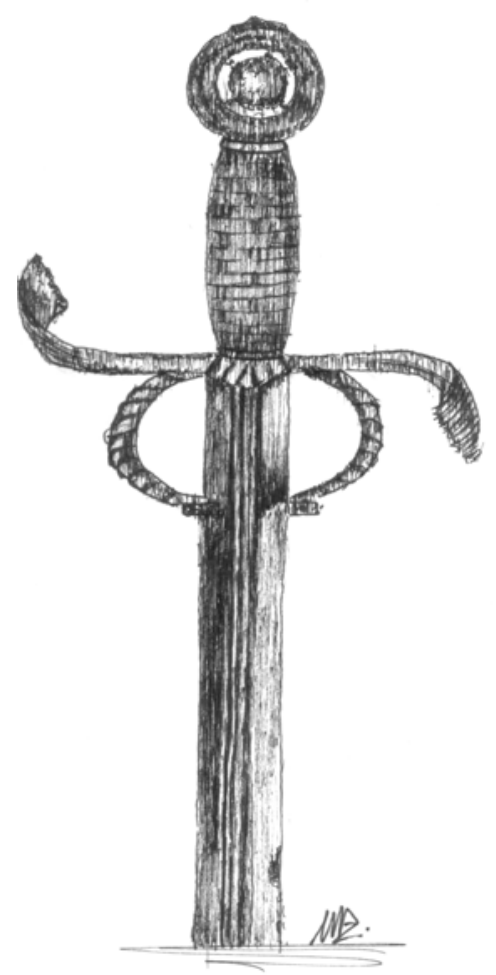

Figura 7

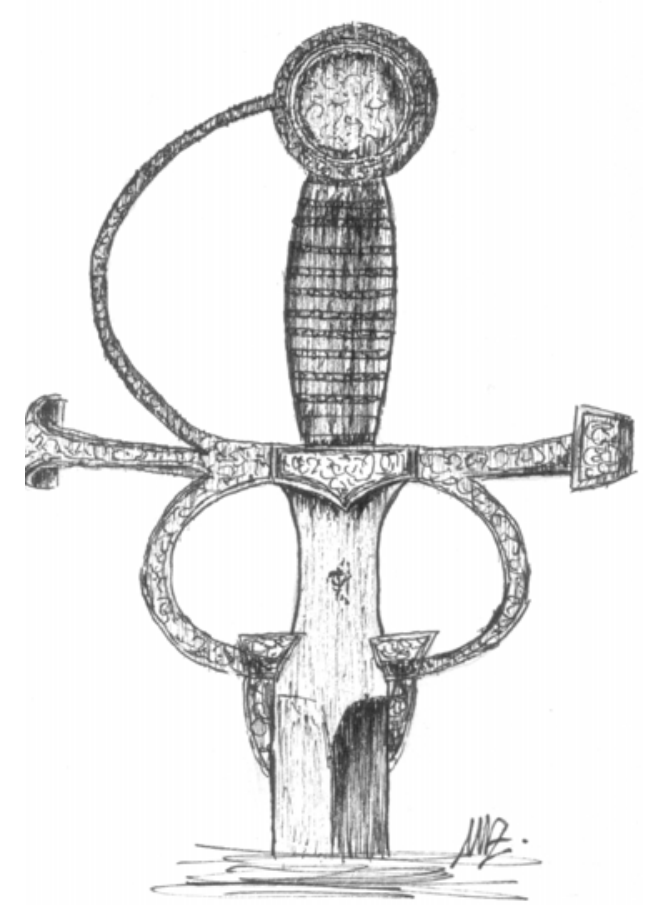

Figura 6

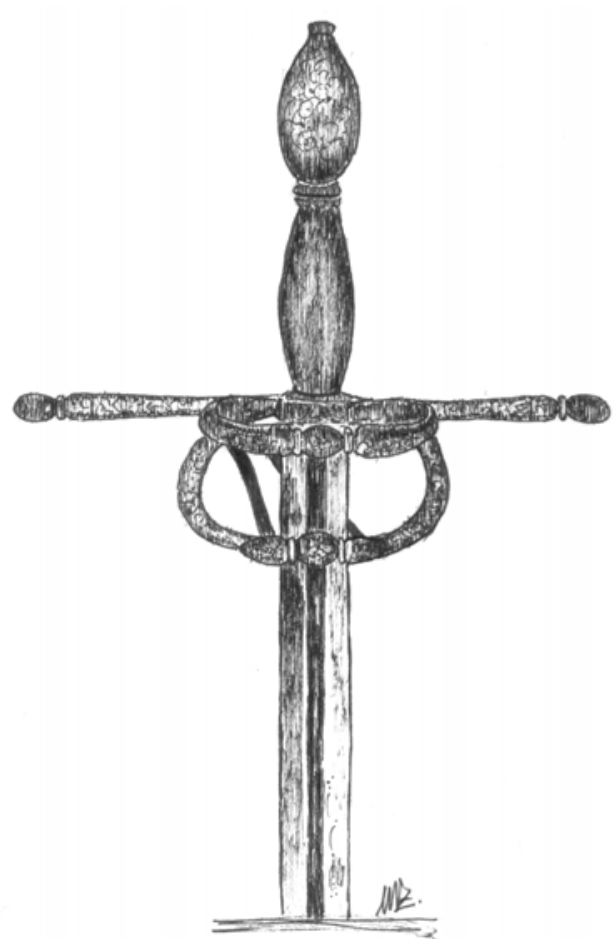

Figura 8 
hispana. A raíz de las investigaciones de Gamber ${ }^{101}$ se pudo determinar que la fabricación de ambas se debían al platero barcelonés Pery Juan Pockn ${ }^{102}$.

Por lo tanto parece demostrado que los plateros y los fabricantes de guarniciones hispanos tenían un alto nivel de calidad, y que sus guarniciones se montaban en el extranjero en hojas no españolas, ya desde el siglo XVI. Por lo tanto la existencia de motivos decorativos con materiales preciosos en las empuñaduras, incluso en espadas con hojas italianas, no tiene por que hacernos pensar en una producción no española.

De hecho los doradores españoles de empuñaduras tenían fijadas las calidades de los metales preciosos a utilizar en sus trabajos, que en ocasiones dependía de la cantidad utilizada. Así decorar una empuñadura de espada y daga si era con oro usando tres capas y dos veces bruñido costaba ciento treinta reales. Mientras que si era de plata con la misma cantidad de plata delgada costaba ciento diez reales ${ }^{103}$. También los argenters, doradores, barceloneses estaban obligados a usar en las «obras menudas», dentro de las cuales estaban las espadas, los estoques, las dagas y los cuchillos, una aleación de doce dineros y ser blanchas y bellas ${ }^{104}$.

De la existencia de diferentes técnicas decorativas relacionadas con la incrustación de oro y plata sobre las empuñaduras de las armas blancas, tenemos noticias gracias a las ordenanzas de los doradores sevillanos ${ }^{105}$. Así cuando vendían productos dorados o plateados, entre los que incluían guarniciones de espadas, debían de indicar cuantas hojas de oro o plata habían utilizado en su confección. Más interesante aun resulta constatar que debían de informar al comprador sobre la técnica que habían utilizado para su fabricación si lo plateado o dorado va sobre cortado o sobre aplanado. Es decir si se habían realizado incisiones sobre el metal y luego se habían incrustado los metales preciosos, damasquinado o ataujía, o si simplemente se habían colocado utilizando algún mordiente, dorado al fuego. En el examen de doradores de Zaragoza los aspirantes debían de hazer una guarnicion de espada labrada de linias quadradas y cortada. Después tenía que enseñarla a los maestros examinadores para posteriormente platearla (Redondo, 1982: 39).

Tan similares eran a veces las competencias de los espaderos con otros gremio afines como los doradores y los pavonadores que a veces tenía que intervenir las autoridades municipales para poner orden. Para ello se establecían claramente las competencias y labores permitidas apara ambos gremios. Así los conflictos que se vivieron entre ambos colectivos en Zaragoza a principios del siglo XVII provocaron la elaboración de varias resoluciones. Una de ellas establecía que los espaderos sólo pudieran pavonar las empuñaduras que les llevasen a sus talleres para arreglar, principal función de los espaderos en este momento. Mientras que el resto, es decir las nuevas que se fabricaran o se comprasen tanto dentro como fuera de la ciudad, eran competencia del gremio de doradores. Además cuando un espadero quisiera examinarse del oficio de pavonar debía de estar presente un representante del gremio de doradores ${ }^{106}$.

No fue el final de los conflictos entre ambos gremios, antes al contrario, ya que sólo dos años después se llegó a otro acuerdo en el que se citaban de una manera expresa las labores

${ }^{101}$ La espada vienesa que posee una hoja italiana de Antonio Picinino aparece en los inventarios de los bienes del Archiduque Fernando del Tirol (1529-1595) diciendo que la empuñadura era trabajo de un platero español. Le fue regalada en 1554 por su hermano, el que sería posteriormente el Emperador Maximiliano II, a quien a su vez se la había ofrecido Graf Bernstein cuya esposa era española. (Blair, op.cit: 86).

102 Este platero catalán, Pere Juan Poch, aparece en el libro de Pasantías de los plateros de Barcelona realizando un aguamanil de estilo manierista en 1560., Dalmases y Martin op. cit: 94.

103 Esto costaban las empuñaduras vizcainas en la Sevilla de 1627. Tasa General de precios, op. Cit.

104 AHCB Gremios reg. 1132 año 1449, en Bonassie, 1975: 143.

105 Ordenanzas del gremio de doradores de Sevilla. 20 de agosto de 1512, en Recopilación de Ordenanzas gremiales recogidas en la Recopilacion de las ordenanças de la Muy Noble y Mui leal Cibdad de Sevilla: de todas las leyes y ordenamientos antiguos y modernos (...). Por Andrés de Grande, 1632.

${ }^{106} \mathrm{El}$ concejo de Zaragoza dictamina una cuestión de competencia profesional entre los espaderos y los doradores de metales no preciosos. AMZ, Libro de Actos Comunes, año 1610, fol. 127-128, en Redondo Veintemillas, op. cit: 93. 
que podían realizar ${ }^{107}$. Es quizás la mejor definición que podemos dar del oficio de espadero en los reinos hispanos durante los siglos XVI y XVII:

Al Officio de espaderos peculiarmente toca el comprar y vender ojas d'espadas y dagas y el amolarlas y acicalarlas y el hazer las vaynas para ellas y el guarnecerlas y asi mesmo el enbernizar guarniciones y aderezos de espadas y dagas estribos y otras cosas semejantes de tal manera que a los officilaes exsaminados de dicho officio de espaderos tan solamente y no a otros algunos toca y pertenece el hacer las sobredychas cossas como consta por las ordinaciones viejas y nuevas a ellos dadas por los señores jurados de la presente Ciudad en diversos años hasta el de mil seyscientos dos inclusibe

Otro tipo de empuñaduras de lujo que normalmente se asocia con producciones italianas, alemanas, francesas o inglesas, son aquellas que utilizan piedras preciosas incrustadas en el metal. A este tipo de empuñaduras se refieren los espaderos vallisoletanos cuando se conciertan para que les fabriquen guarniciones de perlas encima de los lazos (Rojo, op. Cit.). Existen ejemplos de este tipo de guarniciones fabricadas en la península ibérica como las ya citadas de Dresde, Viena y Londres atribuidas a Pedro Juan Puch, y otras como la existente en París (Beaumont: 1885). (Fig. 4)

La fabricación de empuñaduras de taza o cazoleta para las espadas, y de vela para las dagas si que se identifica con una producción hispana. Estas, en muchas ocasiones, se encuentran caladas y cinceladas a base de motivos vegetales, antropomorfos y geométricos, de una alta calidad y belleza. No parece lógico pensar que artesanos capaces de realizar dichos trabajos no fueran capaces pocos años antes de realizar empuñaduras de lazo, en principio menos complicadas.

Parece claro que los maestros de fabricar guarniciones de espadas hispanos si sabían realizar todo tipo de guarniciones, y así se enumeran gran cantidad de modelos diferentes. Ejemplo de dicha riqueza tipológica lo encontramos a la hora de valorar dichas labores ${ }^{108}$ :

Los adereços de espada y daga, hierros de tiros y pretina que son las dychas veintiseys pieças labradas en Vizcaya de lima, de todas labores de harpon, axedreçados ${ }^{109}$, abollados ${ }^{110}$, de botones, de nudos de sarmiento, ochavas encontradas, almendrilla buida, buida al traves y otras labores que al presente se usan, pabonados, bruñidos, a quarenta reales cada adereço

\section{LAS HOJAS ESPAÑOLAS}

Si bien el estudio de las hojas, con el fin de establecer diferentes tipos de clasificaciones tipológicas de espadas, ha sido abandonado en beneficio del de las empuñaduras, creemos que el estudio de las mismas puede ofrecer mucha información. Algunos especialistas, como Oaekshott, consideraron que la hoja merecía ser objeto de atención, aunque siempre supeditada a la empuñadura. Bruhn de Hoffmeyer justificaba esta falta de atención a la hoja en el hecho de que estas últimas eran producidas en serie, mientras las empuñaduras eran obras individuales, especialmente los pomos ${ }^{111}$. Este fenómeno de no prestar tanta atención a las

107 Parece que amos grupos interpretaban las leyes según les convenía dando lugar a más disputas: aunque se dieron y promulgado (las leyes anteriores) para fin y effecto de que huviese paz y concordia entre los dichos officios empero no solamente no se ha seguido el fin deseado antes bien han causado entre ellos mayores discordias y pleytos.los compromisarios nombrados por los gremios de doradores-pavonadores y de espaderos en 1 de junio de este año dictaminan sobre las cuestiones el litigio entre dichos Oficios (AHPZ, Martín Español, año 1612, fol 203-212) en Redondo Veintemillas, op. cit.: 110.

108 Tassa General de Precios 1627, en Leguina (op.cit).

109 Un ejemplo de este tipo de puños lo encontramos en el puño de una espada toledana (CW 4399).

110 Esta término podría referirse a una labor que aparece en algunas guarniciones que tiene vaciados a modo de abolladuras en todas sus partes, como en una espada con hoja de Sebastián Hernández y empuñadura atribuida al artesano de Dresde Wolf Paller (ART G 77).

111 Cirlot, (op.cit): 17. Aunque estas consideraciones se referían fundamentalmente a espadas medievales, se han seguido aplicando a las hojas posteriores. 
hojas se produjo tanto a nivel internacional como nacional, produciéndose un vacío de información al respecto ${ }^{112}$.

Por ello tenemos que contradecir, al menos parcialmente, a toda una serie de especialistas en el tema cuando afirman que no es posible una organización cronólogica en base al estudio de las hojas ${ }^{113}$. El estudio de las hojas punzonadas, y sobre todo firmadas, sumado al conocimiento y documentación de los espaderos, permitiría no sólo su autentificación y periodización, sino también crear unas bases tipológicas, tanto cronológicas como por fabricantes.

El objetivo principal de este apartado es el de encontrar elementos comunes en la fabricación de hojas de los espaderos hispanos del XVI y comienzos del XVII. Es decir, ver si cada espadero tenía uno o varios modelos de hojas característicos y que forjaba de manera regular, repitiendo con cierta frecuencia tipologías de hojas. Utilizando esta metodología podríamos incluso conocer determinados paralelismos tipológicos y cronológicos entre ellos, como el establecimiento de lazos familiares o de taller, y entre las diferentes zonas productoras.

Resulta muy complicado conseguir distinguir a alguno de los artesanos fabricantes de hojas de espadas por la forma y características externas de un tipo de hojas por ellos fabricadas. Pero al menos queremos mostrar algunos ejemplos de tipologías que presentan rasgos comunes en algunos espaderos.

Creemos que sí existían unos parámetros comunes de fabricación dependiendo de las manos de las que saliera cada hoja, y que incluso, era una especie de sello personal que identificaban sus obras, al margen de los punzones y las inscripciones.

El ejemplo más claro de que existían estas tipologías por espaderos lo hallamos en el documento recogido por Lhermite ${ }^{114}$. Además de dar una serie de información sobre cada de los espaderos allí mencionados, nos aporta datos sobre tipologías de espadas, especialmente sobre los tipos de hojas y recazos que cada artesano fabricaba.

Analizemos ahora la información que ofrece el citado documento sobre determinados espaderos. Cuando habla del cordobés Antonio de Baena dice son sus espadas de medio talle, y a continuación explica que quiere decir la citada expresión, que quiere dezir un poquito mas anchita del ordinario. Además también nos indica que el recazo que solía realizar el citado espadero era llano y de tres mesas. Es decir los recazos eran planos, sin rehundimientos o vaceos, mientras que las hojas eran de tres mesas.

Uno de los espaderos sobre los que más información aporta es Sahagún el Viejo. De él dice sus espadas fueron de recasso llano y medio talle, y tambien algunas angostas sin canal $y$ de tres mesas, y tambien de lomo, en las quales en el recasso echava su nombre en cyfra.

Las hojas de Luis de Sahagún estudiadas por nosotros, poseen todas una anchura que oscila entre los 23 y los $33 \mathrm{~mm}$. Por tanto las podemos considerar de una anchura media para la época, de medio talle. Los recazos son en su mayoría muy acusados y llanos, aunque también posee varios ejemplos de recazos en los que el vaceo de la hoja se alarga entrando en el recazo (Colección Eric von Schultess; MPP 599; IVDJ N 63). En la mentalidad popular se identifica la obra de determinados espaderos con formas y medidas concretas. Así cuando se referían a la producción de la familia Sahagún se usaba la expresión:

Kortiancha i rrabiseka de pún, komo espada de Sahagún. «Pún» dize por «punta», por hazer konsonanzia ${ }^{115}$.

\footnotetext{
112 Norman (op.cit.) y Cirlot (op. Cit.).

113 Una autoridad en la materia llegó a afirmar que: «...a division of the swords according to their blades is impracticable..» en Bruhn de Hoffmeyer (1982): Arms and Armours in Spain II. A Short Survey. Gladius.

114 Cortesano flamenco que recoge algunos documentos castellanos en su obra Les Pashtemps, entre los que figura una relación de espaderos españoles.

115 Correas, 1627: Vocabulario de refranes y frases proverbiales, en Louis Combet 1967, Institut d'Études Ibériques et Ibéro-Américaines de l'Université de Bordeaux. Burdeos.
} 
Lo que parece indicar que en la mentalidad popular las hojas de los Sahagún, se identificaban con hojas anchas, cortas y puntiagudas.

Volviendo a la descripción de las hojas de esta familia de forjadores, podemos pensar que cuando se refiere a de lomo se refiere a hojas de sección romboidal con un fuerte nervio central. Ejemplo es la espada flamígera conservada en Suecia (LSH 10853), en la que debido a la forma de la hoja no es posible colocar firma alguna, salvo los punzones del recazo, que equivaldría a la expresión utilizada en el documento recogido por Lhermite: echava su nombre en cyfra.

No pretendemos decir que las alusiones del documento que aparece en Lhermite sean infalibles respecto a los tipos de hoja que cada espadero fabricaba, pero si que aporta una información valiosísima y frecuentemente certera sobre la forma de las hojas que cada artesano forjaba.

Otro ejemplo lo hallamos en el espadero número 13 del documento reproducido en Lhermite, Tomás de Ayala. Respecto a la forma de sus hojas dice lo siguiente son sus espadas angostas y tambien de medio talle. Esta contraposición de términos nos lleva a pensar que el término angosto en espadería viene a ser lo mismo que estrecho ${ }^{116}$. Las hojas de los Ayala, Tomás y Luis, si se caracterizan por algo es por la estrechez de sus hojas que normalmente rondan los 22 mm (FLG 7380; HMD VI 416; HRKM A 1028, etc.). Existen también ejemplos de hojas más estrechas, $18 \mathrm{~mm}$, (RAM G-99). Una de las pocas hojas anchas la encontramos en una espada atribuida al Duque de Alba (MAP J 87).

Existe otra expresión que se usa en el trabajo que aparece en Lhermite, concretamente al referirse a las hojas de Lope Aguado, que podría considerarse como sinónima de angosto y que es son sus espadas todas delgadas. Nosotros pensamos que aquí podría referirse no tanto a la anchura de la hoja, como a la altura de la sección, es decir a su grosor. Decimos esto porque añade después la expresión y de corte. El hecho de tener una hoja de menor grosor hace que los filos tengan un menor ángulo, y por tanto una mejor penetración en el corte. Expresiones parecidas son sus espadas delgadas y cortadoras aparecen en los dos espaderos vallisoletanos que menciona el documento: Machín y el Maestro Pedro, números 6 y 7. Los filos de las hojas también fueron objeto de legislación por parte de las autoridades de la época con objeto de paliar en parte el gran número de muertes que provocaba el uso de la espada en la sociedad del momento.

Una de las primeras fue pregonada por el concejo de Zaragoza en 1478 con el fin de evitar que se llevaran las espadas envainadas y con filos no excesivamente cortantes.

Item intiman manden e requieren a todas e qualesquiere personas de qualquiere ley stado o condicion sian que no puedan ni sian osados levar spadas en las manos antes aquellas sian tenidos levar cenydas con sus correas e con taulas e guaspas e no sian osados levar spadas afiladas de delgado ni al rebes certifficandolos que si nenguno sera trobado levar la spada en otra manera sino cenyda e con taulas $e$ guaspa e afilada de delgado o al rebes aquella de continent le sera tirada e crebada.

Así mismo se ordena a los espaderos que no realicen este tipo de trabajos que provocarían heridas sin duda más mortales.

Item asi mesmo intiman mandan e requieren a todos los spaderos de la dicha ciutat que ninguno no sia osado afilar spada de delgado a al rebes dius pena de xixanta sueldos o xixanta acotes o star xixanta dias en la carcel117.

En líneas generales si parece fuera de toda duda que se va produciendo un estrechamiento de las hojas desde los comienzos del siglo XVI hasta el principio del XVII. Las nuevas

\footnotetext{
116 Covarruvias (op.cit.): $70 \mathrm{v}$, lo define como lo estrecho y apretado.

117 Norma de Zaragoza sobre llevar espada y a espaderos sobre filos AMZ, Libro de pregones del año 1478, ff 12 a 13, en San Vicente (op. cit.): 1988.
} 
técnicas de esgrima y los nuevos usos de la espada hicieron que se produjeran notables avances en la protección de la mano, y también en la forma y tamaño de las hojas.

El tipo de hojas que forjaban espaderos hispanos de mediados del XVI como Sebastián Hernández o Sahagún el viejo son muy diferentes a las realizadas por espaderos del XVII como Gonzalo Simón o Pedro de Belmonte, mucho más estrechas y aguzadas. Las hojas por ejemplo del espadero real Sebastián Hernández son todas de una anchura en sus recazos y hojas muy similares. En la mayoría de los casos de hojas, fuera de toda duda, de este espadero, los recazos son anchos y largos estrechándose paulatinamente conforme se acercan a la espiga (RAT G 77 y RAM G 56 ).

\section{Longitudes de las hojas}

Tradicionalmente las hojas de las espadas se han venido dividiendo en tres partes: tercio fuerte, tercio medio y tercio débil. En la época también se consideraba a la hoja en base a tres partes, ya que por ejemplo el tercio fuerte recibía la denominación de tercio postrero de la espada, lo que cae a la guarnición (Covarrubias: 41 r).

A la hora de hablar de las longitudes de las hojas españolas la fuente más importante que debemos mencionar es la legislación que se generó sobre el tema118. A lo largo del siglo XVI se puso de manifiesto la preocupación por la excesiva longitud las espadas, debido a la fabricación de algunas piezas con una longitud por encima de lo acostumbrado, lo que daba una ventaja evidente al que la esgrimía.

Así en las Cortes de 1544 ya se propuso el limitar el tamaño de las hojas de espada para las nuevas, y la reducción de las ya fabricadas a cinco palmos de largo, con la intención de reducir el número de muertos debido al uso de espadas cada vez más largas.

Poco tiempo después se volvió al tema en los siguientes términos:119

Item en algunas cortes pasadas se ha suplicado a vtra Magestad mandasse que las espadas y estoques que se hiziessen y traxessen en estos reynos fuessen yguales y de un tamaño y ley, y las que había hechas más largas se acortasen por los muchos daños e inconvenientes y muertos que de lo contrario se han visto y vuestra Magestad respondió que se platicaria en ello y se proveería como conveniesse al bien de estos reynos.

A continuación se reitera la necesidad de homogeneizar los tamaños de las hojas fabricadas en los reinos hispanos. Solicitando al mismo tiempo que estas medidas también se extendieran a las hojas procedentes de otros países.

Suplicamos a vuestra magestad lo mande luego ver y proveer por manera que las dichas espadas $y$ estoques sean como dicho es, de un tamaño y medida, como se le ha suplicado por los muchos inconvenientes que hay de ser unas mas largas que otras, porque ligeramente se matan con ellas los hombres, $y$ lo mismo se haga y guarde en las espadas y estoques que vinieren de fuera de estos reynos,

Para un mejor control de este tema se propone el uso de una medida, es decir un objeto físico, la vara de Castilla. Esta se dejarían en los ayuntamientos para que cuando un alguacil retuviera una espada que pudiera exceder de las medidas permitidas, la comparara con la vara de medir oficial.

\footnotetext{
118 Este tema poco estudiado y que aporta numerosos datos de interés sobre las formas y usos de las armas blancas hispanas de los siglos XVI y XVII, cuenta como obra de referencia el magnífico trabajo de Martínez del Peral (1992): Las armas blancas en España y América. Mapfre.

119 Pragmaticas y capitulos que su m. el Emperador y Rey ntro señor hizo en las cortes que se tovieron con el serenisimo Principe d. Phelipe nro Señor en su nombre. petición CXIVI fol XXXVI en Valladolid año de 1548.
} 
que estuviera en los ayuntamientos. y que la medida y patrón dellas esto en la casa de los ayuntamientos por que de ella no se pueda exceder con pena a los que las truxieren mayores que el patrón.

A esto vos respondemos que por agora no conviene que se haga novedad

A pesar de que en esta ocasión no se tomó ninguna resolución sobre el tema, poco tiempo después se promulgaron toda una serie de leyes tendentes a limitar el tamaño de las hojas. Quedando establecido el límite tanto de espadas, como de verdugos y estoques, en cinco cuartos de vara ${ }^{120}$.

«Ordenamos y mandamos que ninguna persona, de cualquier calidad o condición que sea, no sea osado de trayer y traiga espadas, verdugos y ni estoques de más de 5/4 de vara de cuchilla en largo; so pena que el que la traxere por la primera vez incurra en pena de 10 ducados y 10 días de cárcel, y pérdida la tal espada, estoque o verdugo y por la segunda sea la pena doblada, y un año de destierro del lugar donde se le tomare, y fuere vecino; y la dicha pena pecuniaria, y estoque o verdugo o espada aplicamos al juez o alguacil que la tomare

Ley 9 tit. 6 lib. C.R.

Las espadas españolas por tanto tenían que ser según un término de la época cumplida y de marca. Es decir las formas de las mesas, los filos, la punta y la longitud, debían de cumplir con una serie de requisitos que las autoridades establecieron para las espadas. Con el fin de que su uso, en una sociedad en la que la mayoría de los hombres la portaban de continuo, estuviera mínimamente regulado y controlado.

No podemos olvidar, una vez más, las características políticas y administrativas de la corona española en aquel momento. La corona de Aragón poseía instituciones y características propias diferentes de las de Castilla. Temas tan simples como los pesos y medidas variaban entre unas zonas y otras de la península. Incluso dentro del propio reino de Aragón convivían diferentes sistemas de medición. Esto afectaba también a la longitud de las espadas. Las normas respecto a las medidas máximas de las espadas también se promulgaron en Aragón, pero los diferentes sistemas métricos provocaron variaciones interesantes entre diferentes zonas.

Así, si seguimos los trabajos del Marqués de Cruilles (1883) sobre los gremios valencianos, descubrimos que para acatar las leyes sobre las medidas de las espadas de 1547 se dictó un acuerdo entre Aragón, Cataluña y Valencia. En él se establecían como se debía de medir las espadas, de la cruz a la punta. Forma diferente a la castellana que establecía la medida de la cuchilla, la hoja, aunque la variación entre ambas era mínima por coincidir prácticamente el final de la hoja, salvo la espiga, con la localización del arriaz, la cruz. Al mismo tiempo se establecen las equivalencias entre los sistemas métricos usados en las tres zonas. En Aragón de cinco palmos de alna, vara aragonesa; en Cataluña de cinco palmos menos un dedo de cana catalana; y en Valencia de cuatro y cuarto palmos alna valenciana.

Si tomamos por buenas las equivalencias hechas por el Marqués de Cruilles resulta la siguiente tabla:

\begin{tabular}{|l|c|c|}
\cline { 2 - 3 } \multicolumn{1}{c|}{} & PALMOS & PULGADAS \\
\hline Aragón & 5 palmos & 417.1 \\
\hline Valencia & 4.5 palmos & 415.2 \\
\hline Cataluña & $47 / 8$ palmos & 4010 \\
\hline Castilla & & 45 \\
\hline
\end{tabular}

120 Novisima recopilacion de las leyes de España mandadas formar por el señor de don Carlos IV: Del uso de armas prohibidas. Tomo $v$ tit. XX ley III.

Don Felipe II Madrid 1564: prohibición de espadas, verdugos y estoques de más de 5 cuartos de vara. 
Si estos datos fueran correctos, podríamos tener un elemento objetivo de identificación de lugar de producción de hojas, siempre en aquellos casos acordes a la ley y realizadas después de 1547.

Por desgracia en 1564 las autoridades valencianas al ver que no se cumplía lo acordado en las otras dos zonas mencionadas, se desligaron de dicho pacto. Aunque, posteriormente, se siguieron dictando normas a los espaderos sobre la fabricación de espadas que estuvieran acordes a lo marcado (Cruilles, op. Cit.).

A estas espadas que estaban dentro de las medidas máximas establecidas por las autoridades hemos dicho que se las denominaba espadas de marca, y a las que incumplían la legislación mayores de la marca. Los alguaciles podían requisar estas espadas y medirlas de acuerdo con un patrón que se guardaba en el ayuntamiento, ya mencionado anteriormente. En caso de ser mayores de la marca emprendían las acciones que estaban previstas en la ley $^{121}$. Que se traducían normalmente en el decomiso y la rotura de dichas espadas.

$\mathrm{Al}$ hablar de las puntas de las espadas tenemos que decir que la legislación de la época es muy clara a la hora de enumerar cuales estaban prohibidas por su peligrosidad. Una de las formas que se prohiben que tengan las puntas de las armas blancas fabricadas en la Península Ibérica es la de alesna. Esta es un tipo de aguja de zapatero muy aguda y fuerte que se usaba para perforar el cuero y la suela (Covarrubias, op. Cit.: 29v). Otro tipo de puntas ilegales reciben diferentes denominaciones como grano de ordio; de cebada; de diamante o de aguja espartera, o en «fulla de olivera» (hoja de olivo). Este tipo de puntas al parecer comenzaron a fabricarse en Toledo a mediados del siglo XVI ${ }^{122}$.

Estas puntas especialmente dañinas no sólo se utilizaban en Castilla, y así se promulgaron varias leyes en Valencia y Aragón prohibiendo toda una tipología de puntas entre las que destacan las de punta cuadrada ${ }^{123}$.

«... dispone que ninguna persona puede llevar espadas largas, ni estrechas, ni cualesquiera otras que no tengan la punta plana, como las comunes ni tampoco otras espadas que llaman "hondades" o afiladas al revés o sin mesas, bajo las penas que se especifican, con la obligación de romperlas inmediatamente de ser aprehendidas, y haciendo extensiva esta prohibición a los espaderos y a toda persona que tuviera licencia sea cual sea ésta, asi como a las autoridades para poder concederlas

De este texto se desprende que la única punta autorizada era la plana, y que los espaderos que realizaran este tipo de hojas y puntas podían llegar a ser castigados ${ }^{124}$. La causa de estas prohibiciones es similar a la legislación sobre hojas, y son los propios textos legales los que nos la señalan cuando dicen ${ }^{125}$ :

«ni puñales, ni ganivetes, espadas, estoques o cualquier otra arma con punta semejante a la de las agujas esparteras que por su hechura y formato se ve con claridad que han sido fabricadas para dañar o matar a sus proximos, y no para el servicio necessario castigando al culpable con penas que pueden ir hasta servir en nuestras galeras por todo el tiempo de su vida inclusive usque ad mortem, y en las mismas

121 ARCV. Sala de Vizcaya. Pleito de Pedro de la Torre y Juan Muñoz sobre el decomiso de una espada mayor de la marca 1582.

122 En las Cortes de Valladolid de 1555 se eleva una petición al rey en los siguientes términos que nadie pueda llevar espada que tenga en la punta punçon ni alesna ni otro genero de puntas que agora nuevamente se han inventado y começado a hacer en Toledo. Peticion LXVIII.

${ }^{123}$ Real Crida y Edicte sobre les coses concernents a la pacificacio de la present ciutat... por don Francisco de Moncada, Conde de Aytona... y Capitán General del Reino de Valencia, a 21 de marzo de 1586.

${ }^{124} \mathrm{He}$ aquí uno de los motivos que llevaron a muchos espaderos a no marcar ni colocar inscripciones en sus hojas por miedo a ser reconocidos como fabricantes de espadas ilegales. Este tema será tratado más extensamente en el apartado dedicado a las marcas.

125 Pragmática Real feta per la S.C.R. Magestat del Senyor Rey Don Phelip Segon... por don Juan de Ribera, arzobispo de Valencia y capitán general del Reino de Valencia, de 21 de enero de 1584. 
penas incurren quienes fabriquen tales armas, pues ellas son reprobadas, proditorias, falsas e inutiles para la guerra

Es decir, se consideraba que esas armas estaban pensadas para matar, y no para lo que se necesitaban este tipo de armas blancas. Es decir la defensa personal; las funciones sociales que vimos anteriormente; o la guerra.

Las secciones que normalmente se asocian con hojas españolas son las formadas por cuatro y seis mesas, con canal central en el primer tercio. Otras variantes respecto a los canales son aquellas que presentan una multiplicidad de canales; canales hasta la punta; etc. Si bien este tipo se repite normalmente en piezas salidas de talleres españoles, existen otras tipologías menos reconocidas como hispanas.

Las hojas de sección romboidal suelen ir asociadas a un tipo de espada muy concreto denominadas estoques. Son normalmente armas de combate y cronológicamente se sitúan en la primera mitad del siglo XVI. Algunos ejemplos de este tipo de espadas estoques españoles los hallamos en Madrid (RAM G 35), y Milán (MPP 591), etc.

Que en España, y más concretamente en Toledo se fabricaban este tipo de espadas para el mercado civil, nos da testimonio el inventario de un habitante de Toledo de mediados del XVII, cuando entre sus bienes se menciona una espada de Toledo de lomo (Aranda, 1992: 990) ${ }^{126}$. Es posible que en algunos casos se correspondan con las hojas de las piezas que en la documentación reciben el nombre de verdugos.

\section{Tipologías de recazos}

El recazo es la parte de la hoja de la espada que está situado entre la espiga y el comienzo de los filos. Es un pequeño espacio, normalmente de forma rectangular, que no posee filos. Tiene una misión fundamental para la esgrima de punta, como es la de servir de apoyo a los dedos que empuñan la espada, permitiendo así una mejor sujección y eficacia, sobre todo de cara a los tiros de estocada. Si tenemos en cuenta que la esgrima española es sobre todo de estocada o para herir de punta, tal y como sostiene Covarrubias, (Covarrubias, op. Cit: 373 r), Hiere el español ordinariamente de punta como otras naciones de tajo o revés, podemos considerar a esta parte de la espada como un elemento importante en las espadas españolas.

Otra misión secundaria, aunque muy interesante, que cumple esta zona de la espada es la de ser el lugar más común en el que se colocan los punzones de fabricante y de la ciudad. También puede llevar pequeñas inscripciones, referidas normalmente al nombre del espadero, aunque es más común en el caso de los espaderos italianos que en los españoles, o de tipo religioso ${ }^{127}$.

La aparición de esta parte de la hoja no está perfectamente datada, aunque existen ejemplos en hojas de finales de la Edad Media. Esto es lógico, ya que como indicamos anteriormente, su función era la de mejorar las estocadas, usándose con anterioridad las espadas para un uso fundamentalmente de tajo, salvo en algunos estoques medievales.

El estudio de esta parte de la hoja resulta complicado, ya que, tal y como antes hemos señalado, las hojas se fabricaban con independencia de la empuñadura. Esto provocaba que el espadero montador de la guarnición tuviera que adaptar el recazo pudiendo llegar a su mutilación parcial, como el limado lateral. Además las hojas se mantenían mientras que las empuñaduras

126 El dueño de la citada espada fue Francisco Lopez de Soto familiar del Santo Oficio (1656).

127 Este es el caso de los espaderos Piccinino y Scaachi quienes colocan sus nombres longitudinalmente en el recazo. A veces los insertan dentro de una mandorla, como en el caso del segundo espadero mencionado. Ejemplos de nombres de espaderos españoles en los recazos los hallamos en el caso del valenciano Comes Carbonell. 
variaban conforme a las modas y los tiempos, lo que provocaba que a lo largo de la vida de una hoja pudiera llevar diferentes empuñaduras que alteraban la forma original del recazo, o incluso lo llegaban a ocultar, como en el caso de algunas tazas, o espadines del XVIII.

Las tipologías de recazos en las espadas españolas son muy ricas, y pueden considerarse un elemento más para tratar de identificar un arma de origen hispano. Respecto de los recazos aparecen dos tipos muy claros: los llanos y los buhidos. Sobre de los primeros parece clara su identificación. Mientras que los segundos es en principio más complicada su comprensión. A pesar de las discusiones acerca del significado de esta palabra (Leguina, 1912:177), pensamos que se refiere a aquellos que presenten un ligero hundimiento a modo de vaceo.

La identificación entre las formas en que se hacen los recazos y algunos espaderos, a pesar de ser complicada, la creemos posible. De hecho así se pensaba en la época, tal y como aparece en el texto recogido por Lhermite ${ }^{128}$. En este trabajo se señala que determinados espaderos usaban los dos tipos de recazos mencionados: labro muchas de recasso llano, y otras de recasso buido, caso de Sebastián Hernández. Las piezas parecen darle la razón, ya que en Londres (VAM M 1748-1947) se conserva una con recazo llano, mientras que otras (RAM G 53 y ART G 77) sus recazos aparecen ligeramente rehundidos.

$\mathrm{Al}$ referirse a otros espaderos señala que sólo usaban un tipo de recazo: el llano. Este fue el caso del Maestro Domingo, todas sus espadas de medio talle, y de recasso llano. No se cita, sin embargo, ni a un solo espadero que sólo hiciera espadas con recazos buidos.

Dentro de este grupo también encontramos variaciones entre los simples y los dobles. En el primero el hundimiento tiene forma rectangular, la misma que la del recazo. Mientras que en el segundo aparecen dos hundimientos del mismo tamaño. Miguel Cantero es uno de los forjadores que usa este tipo de recazos dobles, ligeramente rehundidos y separado del canal central de la hoja (VAM 11-1955).

En el primer caso también nos encontramos con dos variantes. En la primera el hundimiento en el recazo está aislado del resto de la hoja B1 (RAM G 49). El segundo tipo, B2, el vaceo del recazo es una continuación del existente en la hoja (LSH 10027). En este caso también podemos encontrar una variación, que consiste en que además del vaceo central que se forma en el recazo, producto de la prolongación del de la hoja, se reproduce a ambos lados en tamaño y forma, resultando un recazo con tres vaceos iguales (HMD VI/412).

Entre los llanos podemos señalar los que poseen canalillos laterales (Tipo A1). Estos son dos estrechos canales situados en ambos lados del recazo y que corren paralelos al mismo. Un espadero en el que es frecuente encontrar este tipo de canalillos es Pedro de Belmonte (HMD VI 402 y HMD VI 430). En este tipo de hojas las posibles marcas figuran en los laterales de los recazos.

Otro tipo es el que posee en el recazo calados del tipo que encontramos en algunas hojas españolas e italianas. Estos pueden estar situados en los laterales de la cara del recazo (B4a), o en el centro del mismo recazo (B4b).

Otra forma de clasificar los recazos la tenemos en la forma que adoptan. Para hablar de ello tenemos que partir del hecho de que hablamos de piezas que poseen un recazo de un tamaño importante, y cuya guarnición o es de arriaz simple o de lazo, ya que si ha sido montada con una taza o cazoleta la forma del recazo quedaba normalmente tapada o alterada.

Las dos formas más comunes de recazos son las rectangulares y las triangulares. Este último tipo se puede dividir en más dependiendo de lo acusado que sean sus ángulos.

${ }^{128} \mathrm{La}$ importancia de los datos que este documento recogido por Lhermite para el conocimiento de los recazos y los espaderos que los ejecutaban es fundamental. En primer lugar es un documento casi contemporáneo a los mejores espaderos (1587-1600); y en segundo lugar si hacemos caso a lo dicho por Lhermite en su introducción los datos los ha recogido de los más viejos maestros espaderos toledanos, es decir de una fuente directa conocedora de los términos y los tipos existentes en aquel momento. 


\begin{tabular}{|c|l|c|}
\hline 1) & Identificación & Tipo \\
\hline 2) & Recazo llano & A1 \\
\hline 3) & Recazo llano con canales & A2 \\
\hline 4) & Recazo llano calado & A3 \\
\hline 5) & Recazo buido independiente & B1 \\
\hline 6) & Recazo buido continuación del canal & B2 \\
\hline 7) & Recazo buido doble separado del resto & B3 \\
\hline 8) & Recazo buido continuo tripartito & B4 \\
\hline 9) & Recazo buido calado & B5 \\
\hline
\end{tabular}

Normalmente la estructura y motivos decorativos que aparecen en el vaceo de la hoja se repiten en el recazo. Por ejemplo si posee el canal central calado, también se perfora el recazo, o si la hoja posee dos canales, se coloca un doble vaceo en el recazo (MPP 626).

Otro tipo de recazos que además consideramos típicamente españoles, son los denominados escotados. Estos presentan en uno de los cantos o en los dos, sendos rebajes hacia el interior en forma de media luna. Su explicación al margen de la estética, es puramente funcional, ya que permite que el dedo índice se apoye mejor en él. Ejemplos de este último tipo los hallamos fundamentalmente en las espadas de Sebastián Hernández (RAM G 55) y de Miguel Cantero (VAM M 11-1955).

Este tipo de casos poseen variantes en las que los gruesos cantos de los recazos poseen un dibujo a base de aspas, tanto en el lado escotado como en el recto. Estos dibujos es posible que tengan más una finalidad práctica que estética, sirviendo para el mejor agarre del dedo o dedos que se apoyaban en esa zona ${ }^{129}$..

Un recazo que también aparece en las hojas españolas es aquel resultante de la prolongación del vaceo o canal central de la hoja. Esto da como resultado un recazo divido en dos secciones iguales separadas por un canal. En algunas ocasiones este tipo de recazos son el resultado de la adaptación de empuñaduras a hojas más antiguas ${ }^{130}$. También existen piezas en las que se busca este efecto, ya que poseen cantos, y en los dos planos resultantes del recazo se colocan simétricamente los punzones. Este es el caso de Miguel Cantero (LSH B 2066). Otros ejemplos de colocación del punzón en uno de los campos resultantes de la partición del recazo por la mitad los hallamos en París y Turín (MAP J 126 y ART G 74).

$\mathrm{Al}$ igual que con las hojas y los vaceos, el conocimiento de los recazos hispanos no es el único criterio a la hora de poder considerar a una espada como tal. El motivo principal es que hubo varios espaderos extranjeros que imitaron perfectamente las hojas españolas, aunque sin intención de engañar al comprador, ya que colocan su nombre en la hoja. Una explicación es que estos fabricantes extranjeros trabajaran en España o para el mercado español, y por eso fabricaban las hojas al estilo peninsular. El caso es que algunos de esos espaderos llegaron a realizar modelos similares a los españoles, siempre hablando de trabajos contemporáneos. Este es el caso de Pietro de Formighano quien realizó hojas muy parecidas a las producidas en la corona española. Uno de los ejemplos más ilustrativos de esto es una espada de la colección Christensens (Hoffmeyer,1968: 140).

Las formas y tamaños de los recazos dependen en gran medida del tipo de espada y su cronología. En espadas de la primera mitad del siglo XVI, especialmente en aquellas destinadas al combate son recazos grandes y anchos. Los existentes en espadas civiles de mediados del siglo XVI ya buscan una determinada estética más elegante, variando los modelos

129 Hay que tener en cuenta que normalmente las espadas se sujetaban con la mano cubierta, principalmente con un guante, teniendo gran fama en la época los realizados en Ocaña.

130 Son falsos recazos, que en muchas ocasiones provocan la pérdida u ocultamiento de posibles punzones. 
rectangulares a formas más troncopiramidales. El mejor ejemplo de este tipo de recazos nos lo proporciona un espadero toledano como Sebastián Hernández (ART G 77 y RAM G 56).

Ya entrado en el siglo XVII nos encontramos con una variedad mayor de tipos de recazos. Aunque el modelo más utilizado es el de recazo largo, rectangular y ancho que está presente en hojas como las de Silvestre Nieto (RAM G 57).

\section{LA VAINA Y SUS ACCESORIOS}

El uso de la espada hacía necesarios una serie de elementos complementarios, y que se podían hacer a medida y a juego de la espada. Una de las piezas más mencionada a la hora de referirse al transporte de espadas es el talabarte. Este era el elemento del que colgaban los tiros donde iba asida la espada. Es decir el elemento intermedio entre la espada y el cinturón o pretina: Una espada con sus tiros y pretina ${ }^{131}$

Los talabartes se mandaban hacer a guarnicioneros o a maestros específicos que recibían el nombre de maestro de hacer talabartes, como el sevillano Francisco Muñoz (Gestoso, op. Cit.). Aunque los elementos metálicos necesarios para la sujección del talabarte a la pretina o cinturón y los tiros, los solían realizar también los espaderos. Estos elementos eran ganchos de unión, hebillas, etc. Existen ejemplos de ganchos de talabartes firmados por sus fabricantes como el caso de Francisco Sánchez (MEM 202594).

En las ciudades más importantes incluso podían existir oficiales especializados en este tipo de accesorios. Así en Sevilla nos encontramos a dos artesanos, Diego García y Juan Cabrera que se identifican como guarnicioneros de hacer hierros de talabarte (Gestoso, op. Cit: 218).

Los talabartes podían ser confeccionados con diversos materiales. Así se fabricaban de terciopelo, de ante, de lobo marino, etc. ${ }^{132}$. Normalmente eran de cuero, existiendo aquí también una gran variedad dependiendo del tipo de cuero usado: de vaca, de cabritilla, de cordobán, etc. Uno de los tipos más lujosos eran los de cuero forrados por fuera o por fuera y por dentro de terciopelo, e incluso de seda ${ }^{133}$.

Los motivos decorativos que podían aparecer sobre dichos elementos también variaban. Así podían llevar pespuntes, trencillas de oro, labrados en ramos, hierros dorados y plateados, de clavazón blanca, pavonados, rayados, etc.

Otro elemento utilizado para portar la espada fue el tahalí. Este consistía en una banda de cuero que se situaba por encima de un hombro y caía en uno de los laterales de la cintura atravesando el pecho, y del cual se colgaba la espada. Este sistema resultaba más cómodo en determinadas circunstancias. Así a veces era usado por aquellas personas que tenían problemas de riñones y les resultaba así más cómodo el llevar la espada (Covarrubias 37 r).

(...) y por encima del hombro diestro un tahali tachonado y guarnecido de precioso metal... (Céspedes, 1605) $)^{134}$

Atravesabale un tahali por la espalda y pechos do colocaba una espada ancha y corta a modo de las del perrillo (Rinconete y Cortadillo: 36)

Esta prenda y sistema de suspensión de la espada se la considera de origen árabe, y desde luego existen referencias iconográficas y literarias que confirman su uso por parte de la po-

131 Inventario de los bienes de Ana Maria de Vozmediano, muger de Cristobal de Montalvo, en Maroto, (1998) Edición electrónica.Toledo.

132 El Quijote portaba uno de este material: ciñose su buena espada, que pendia de vn tahali de lobos marinos, que es opinion que muchos años fue enfermo de los riñones.

133 Costaban 1020 maravedís en el Valladolid de 1562, (Rojo: 393).

134 También en el Quijote cuando se describe como aparece delante de los Duques, colgó el taheli de sus hombros con su buena y tajadora espada. El quijote 2a parte, capit. XLVI, en Bernís (op. Cit): 69. 
blación hispanoárabe ${ }^{135}$. A veces ambos conceptos Talabarte y Tatali se entremezclan y confunden en las propias fuentes de la época.

La vaina es el elemento más cercano a la espada, permitiendo el transporte y protección de la misma. Se hacía a medida de la hoja por parte del espadero encargado de terminar los trabajos que hacían de la espada un producto acabado. Normalmente estaba confeccionado con unas costillas o estructura de madera, que iba recubierta de cuero. Dos apliques metálicos que reforzaban la estructura de la misma, uno colocado a la entrada de la vaina, que se denomina brocal, y otro al final, llamado contera. Ambos elementos daban la consistencia necesaria a la vaina para evitar la rotura de la misma por los filos o la punta de la hoja. Las conteras de lujo eran piezas que se podían adquirir en el extranjero y así aparecen en la valoración de piezas que se importaban, Conteras de espada á ciento noventa la gruesa ${ }^{136}$. En los inventarios aparecen referencias a estas partes de la vaina indicando normalmente el material con el que estaban confeccionadas, plata y oro, y el lugar de procedencia. Siendo frecuentemente mencionadas las procedentes de Alemania (Rodríguez, 1883). La contera tenía también importancia en la valoración de la espada. Estas se llevaban, debido a su longitud, en diagonal con la punta levantada apoyando la mano en la empuñadura, quedando por tanto la contera muy a la vista. Por ello a mejor espada mejor contera, existiendo dichos de la época que hacían referencia a esta cuestión: mui pobre kontera á echado a su espada fulano. para dezir ke á medrado poko ${ }^{137}$.

También las formas y tipos de vainas eran objeto de la picaresca por parte de espaderos y espadachines. Los fraudes podían provenir de la calidad del cuero con el que se forraban las costillas de madera de la vaina. Por ello en las ordenanzas de espaderos son frecuentes las normas que hacían referencia a esta cuestión. Se establecían los tipos de cuero a utilizar para que no se usaran otros de peor calidad. Este tipo de reglas se encontraban recogidas ya desde mediados del siglo XV, tal y como aparecen en las ordenanzas de 1444 de los espaderos de Barcelona (Capmany, 1779.). En otras ocasiones se obligaba a ofrecer al comprador entre varios tipos, y a que se forrase la vaina con el elegido y no con otro peor y por tanto de menor coste. Así sucede en Nueva España cuando se indica que el espadero debe informar sobre... si quiere en badana o cordovan, o venado o bezerro, y lo haya conforme se le pida pena de quemada haziendo uno por otro hazerla de nuevo y diez pessos (Nueva España 1556)

El fraude más común era colocar cuero de badana en lugar del de becerro o de vaca. Este último era más resistente lo que lo convertía en un material de mayor calidad y por tanto más caro que el de badana. La badana era y es un cuero adobado muy blando y fino que se usaba como forro de otros cueros ${ }^{138}$. Solía proceder de la parte de la barriga de las ovejas y cabras, y por tanto su uso en las vainas de las espadas, sujetas a frecuentes roces y golpes, no lo hacía muy aconsejable.

Que no den vainas de cuero de badana por de bezerro

Otrossi ordenamos y mandamos que ningun oficial sea osado de dar vayna de badana por de becerro en ningun adobo, ni bezerro quemado so pena de 1000 maravedis y la obra que asi se le tomare quemada

De este punto también podemos deducir que se usaban cueros quemados y deteriorados para forrar las vainas de las espadas. Otro tipo de cuero citado en las ordenanzas de espaderos

135 Ricolus (1500): Improbatio Alcorani, en Bernis, op. Cit.:466. Aquí en una ilustración se observa a varios personajes portando la espada de este modo, al igual que en varias pinturas de la Alambra, Sala de los Reyes, o en el libro de los Juegos, fol $20 \mathrm{v}$.

136 Valuación hecha en la villa de Bilbao del precio de las mercaderías que venían de fuera del Reino. [ ... 1563, en Imprenta Real (Madrid), 1829.

137 Correas (1627) Gonzalo Vocabulario de refranes y frases proverbiales.

138 También se usaba para hacer zapatos de aquellos que tenían los pies sensibles, (Covarrubias, 78 v.). 
es el baldrés. Este era un cuero muy delgado y que se usaba también para los pliegues de los fuelles (Covarrubias, op. Cit. 417 r).

Las vainas podían forrarse también con diferentes tipos de telas o tejidos. Uno de los que aparecen mencionados es la bayeta: Cada bayna forrada en bayeta o frissa para espada de cinta tres reales ${ }^{139}$. Para Covarrubias este material era una especie de paño floxo de poco peso del qual usamos en Castilla para aforros y para luto. También señala que este tipo de material procedía de Inglaterra (Covarrubias, op. Cit 62 v). El otro tipo de tela mencionada, la frissa, era una tela de lana delgada con pelo blanda y suave, que se retorcía. Servía como forro y entretela para las bordaduras con el fin de que no se rozaran los tejidos. También se podía usar, en unión de la badana, para hacer fundas para las vainas una funda de badana forrada en frissa con sus trançaderas seys reales.

Estas fundas o sobrevainas de camino, como también se las denomina, servían para portar las espadas cuando se viajaba sin que la espada ni la vaina sufrieran las inclemencias del tiempo y los roces y golpes propios de un viaje a lomos de un animal o en una carreta.

Las vainas una vez terminadas y aderezadas, es decir con todos los hierros que la conformaban, se le daba una capa de cera para darle más lustre y mejor presencia, estando así ya lista para su venta cada bayna encerada de seys cuartas. ${ }^{140}$. Las vainas más lujosas se podían forrar con terciopelo cuyas calidades y formas también estaban reguladas en diferentes ordenanzas de espaderos hispanos.

Las vainas se podían manipular con el fin de poder desenvainar más rápidamente, o más exactamente no tener la necesidad de hacerlo. Para ello se hacían vainas sin refuerzos interiores de madera, y las costuras que cerraban la vaina por el interior no se colocaban. Cerrándose sólo con unas agujas y permitiendo que con un simple golpe de muñeca lateral, la espada quedara fuera de la vaina, ahorrándose el tiempo necesario para desenvainar y contando así con una ventaja sobre el contrario.

Ningún alguacil de corte o villa, ni de otro juez o ministro ni oficial de la sala, dependiente de ella o de la provincia, ni otras personas exentas aunque sean soldados de las guardias o familiares, aunque tengan cédulas y privilegios para poder traer qualesquiera armas ofensivas y defensivas, puedan traer en esta nuestra corte ni fuera de ella, espadas con vaynas abiertas con agujas u otros modos o invención para desenvainarlas más ligeramente,( ...) y ningún espadero ni guarnicionero, ni oficial de manos de hacer cosas de hierro o acero, ni otra persona pueda hacer las dychas vaynas abiertas con agujas, ni otros modos o invención,

de cualquier exención de fuero o privilegio que tenga, porque no se ha de extender a poder traer dichas vainas abiertas, ni estoque buidos de marca o mayores de ella... ${ }^{141}$

Como vemos, a los espaderos y oficial de manos de hacer cosas de hierro o acero ${ }^{142}$, como fabricantes de este tipo de artilugios, también les estaban dirigidas este tipo de pragmáticas. Comentar además, la existencia de licencias especiales para portar armas, que se concedían a determinadas personas por su condición social, como ser familiar de la Inquisición; estar amenazadas, etc. A pesar de sus circunstancias especiales no podían portar este tipo de armas blancas y dispositivos para desenvainar. Muchos de ellos al quitarles estas armas aludían a su especial condición para tratar así de escapar de la justicia.

Estos dispositivos no sólo se referían a trucos en las vainas, sino que también existían métodos más legales, relacionados con la forma de llevar la vaina sujeta al cuerpo (Vargas

\footnotetext{
139 Tassa General de Precios. Sevilla 1627, en (Leguina, 1898: 44).

140 Ibid.

${ }^{141}$ Ley VII Felipe IV Madrid 28 septiembre 1654 Prohibición de espadas con vaynas abiertas con agujas y otras invenciones para desenvaynar ligeramente, $y$ de estoques y verdugos buidos.

142 Esta definición es la primera vez que nos la encontramos, para referirse a artesanos que fabricaran armas blancas.
} 
Machuca, 1600: fol. 47r) ${ }^{143}$. O incluso por la forma de la empuñadura y donde apoyar los dedos a la hora de desenvainar ${ }^{144}$.

En Valencia también estaba prohibido llevar las espadas desenvainadas, o con mecanismos que hicieran pensar que la espada estaba en la vaina, o que permitieran que se sacara más rápidamente de lo normal. «nadie tenga la osadía de salir a la calle con espada sin vaina, sin mesas, abierta o sin contera, bajo pena de multa y pérdida del arma ${ }^{145}$.

Del mismo modo estas prohibiciones iban encaminadas a tratar de evitar que nadie saliera con una espada desenvainada por la ventaja que tendría respecto a otro que tuviera que desenvainar. Mientras que abierta o sin contera se refería a espadas con la vaina sin cerrar y que permitía sacarla de la espada dando un golpe lateral, treta que vimos antes, o vainas que no tuvieran contera y por tanto pudieran dar una estocada sin desenvainar, la espada en vaina abierta, que parece verga de ballesta, según la arquean porque se vea la hoja (Santos, 1663).

Otro ejemplo de espadas prohibidas lo tenemos en una pieza existente en París (MAP J 883), que se denomina epee a sisteme Su fabricación se atribuyó en un principio a Diego de Zayas, debido a los motivos y técnicas decorativas que posee en la empuñadura. Aunque posteriormente se ha descartado la autoría de dicho artesano español (Blair: 1970). En este caso se trata de una espada dentro de una vaina metálica, que al accionar un mecanismo alarga su hoja saliendo por la parte de la contera.Los espaderos por tanto estaban sujetos a determinadas leyes que autorizaban y prohibían la fabricación de algunos tipos de armas o mecanismos. En muchos casos al serles incautadas armas prohibidas alegaban desconocer dichas leyes, pese a que habían sido pregonadas. En otras ocasiones contestaban que no sabían a que tipo de armas de espadas se referían los textos legales. Este es el caso de los espaderos madrileños cuando tras dictarse en 1654 la prohibición de fabricar determinadas piezas ${ }^{146}$ :

que ningun espadero ni guarnicionero ni oficial de manos de hacer cosas de yerrro o acero ni otra persona pueda hacerlas las dichas baynas aviertas con abujas ni otros modos ni ynvenciones ni los estoques buydos de marca ni mayores de ella

Ese mismo año los espaderos madrileños con el fin de no comerciar con productos prohibidos que podían perder a manos de los alguaciles, piden, a través de su veedor, a las autoridades municipales que sean más precisas en la descripción de las armas prohibidas ${ }^{147}$ :

Juan sanchez de moscoso en nombre de los beedores y esaminadores del gremio de los espaderos desta corte = digo que para que los dichos mi partes y demas maestros del dicho gremio puedan bender en sus tiendas dignisimamente sin contrabenir en el pregon que se promulgo ultimamente en esta corte sobre las bainas abiertas y estoques prohibidos y puedan saber las espadas que an de bender y comprar necessitan de que ---tala la sea serbida de mandar que los dichos beedores con a te tencia? De uno de los vuestros alcaldes declaren cuales espadas son las prohibidas maliciosas para que estas no las puedan comprar ni vender y que se de forma de las dichas espadas que se deban traer porque de otra manera no

143 Para esto lo he yo remediado las vezes que se me ha ofrecido en escaramuças contra el enemigo, o en regozijos y fiestas, por gallardia, batallando con algun Cauallero amigo, atandola con vna liga al muslo (como queda dicho en la carrera de capa y espada) la qual se ha de atar por entre los tiros, y por debaxo de las cuchilladas de las calças, y aunque sean valones se puede hazer, porque puesto a caballo no se echa de ver.

${ }^{144} \mathrm{Y}$ el que quisiere ser mas curioso sin esta preuencion, lo podra hazer con mucha libertad y presteza (como yo lo hago) quitando de la guarnicion de la espada por la parte de adentro la guarda mas alta (como yo siempre la traygo quitada) que aun para a pie para la presteza, y a vn tiempo poner mano a espada y daga, sin ser ayudada la espada de la mano yzquierda, es cosa marauillosa y prouechosa como cada vno la hallara si lo esperimenta con quenta, que como vaya echando mano, vaya desgonçando la mano sobre los recazos de la espada, y con reportacion, y no apressuradamente, que como assi se haga a pie y acauallo la sacara, aunque sea mas larga de la marca vn gran geme.

145 Real Crida y Edicte sobre les coses concernents al be comu de la present ciutat y Regne de Valencia... por don Luys Faxardo de Requesens y Zúñiga, el 14 de febrero de 1628.

146 Bando prohibiendo vainas abiertas y espadas. AHN Libro de consejos 1264, fol. 96.

147 AHN. Libro de consejos 1239 fol 479. Sala de alcaldes de casa y corte Fecha: 1654 Pregon de las espadas. 
pueden tener en sus tiendasmercaduria en la que pierdan sus aziendas y ansimismo con la declaracion que si tienen no compraran ni benderan mas de aquellas que la sala diere forma con la declaracion que vieren los beedores = por tanto a VA suplico mande azer como pedido tengo pido justizia

Otro si digo que echo lo que la sala mandare y declarado en lo arriba refererido se mande notificar a todos los maestros no compren las de espadas prohibidas ni que las dejen ni admitan entregar de otras ni las degen en sus cassas para obiar los enconbenientes que de esto puedan resultar pido justicia

La respuesta a su petición fue que acudiera un representante del gremio al quartel del alcalde para que allí se les mostraran las armas permitidas y cuales eran las prohibidas.

Finalmente nos gustaría mencionar la existencia en muchas vainas de espadas de un compartimento situado en la parte superior delantera que servía para alojar dos pequeñas armas blancas, un cuchillo y un punzón, a juego de la espada. Sus empuñaduras se solían hacer a juego de las de la espada y daga. La realización de este tipo de vainas es mencionada frecuentemente con ocasión de los exámenes de espaderos:

Otrossi que cualquier oficial que se oviere de examinar ha de saber...e una vaina de cuero con sus dos cuchillos (Málaga, 1611)

\section{LOS CENTROS PRODUCTORES}

Otro problema que dificulta el conocimiento de la producción hispana de espadas, es la identificación automática de dicha fabricación con la ciudad de Toledo. La fama de esta ciudad provoca que muchas veces se identifique inmediatamente la producción peninsular con la de esta ciudad, olvidando la existencia de otros focos peninsulares. Esto se produce no sólo con las hojas de espadas, sino también con las técnicas y motivos decorativos que se identifican con una fabricación hispana ${ }^{148}$. Por ello vamos a referirnos brevemente a una serie de zonas españolas que produjeron espadas, hojas o guarniciones, al margen de la ciudad de Toledo.

\section{1) Valencia}

La producción de espadas en Valencia es quizás una de las más antiguas de la península. Ya en 1387 tenemos constancia de la presencia de este grupo de artesanos integrados en el gremio de armers cuando eligieron como divisa el color carmesí sembrado de amapolas de oro ${ }^{149}$.

Los spasers formando parte del gremio de los armers tuvieron numerosas ordenanzas gremiales que marcaban las pautas en la organización, fabricación y comercio de los espaderos valencianos hasta prácticamente el siglo XVIII (Dueñas, 1999). No podemos olvidar que el maestro elegido para retomar la fabricación de espadas en la Real Fábrica de Espadas de Toledo fue el espadero valenciano Luis Calixto (Palomares: 1772).

Hoffmeyer ya realizó un estudio tipológico para tratar de identificar las espadas catalanas bajo medievales, entre las que incluía las valencianas, basándose fundamentalmente en los pomos (Hoffmeyer, 1982: t, II 192). Aun así la identificación de la producción valenciana resulta más compleja, debido a que no fue una práctica común la colocación de inscripciones identificativas de los nombres de los espaderos, al estilo de las toledanas. Si está documentado, en cam-

\footnotetext{
148 Así Seitz (Seitz: 316) considera automáticamente como toledana una espada que presenta una decoración de atauriques dorados sobre pavonado negro existente en París (MAP J 121).

149 Cruilles: Armeros. Otros autores como Tramoyeres (1889): 110, la definen como carmesí a fajas pajizas y en el extremo del asta una figura del patrono o del murcielago valenciano (Rat Penat). Otros identifican el color de la bandera con el azul, Almela I Vives (1958).
} 
bio, el uso de marcas tanto personales como de ciudad en las hojas valencianas. Son más numerosos, en cambio, los ejemplos de piezas que poseen la firma de la ciudad en el vaceo.

Una pieza con el nombre de Valencia, la encontramos en la colección del Conde de Rochebrune. Esta posee un fuerte recazo y canal central en el que se lee IN VALLENCIA ME FECIT/ PACIENCIA VINCIT OMNIA DE UM (Charles, op. Cit.). Este texto tan largo no es muy común, ya que normalmente la única inscripción que poseen las hojas valencianas son la que hacen referencia al lugar de producción, estando normalmente escritas, al menos la preposición en latín IN VALENCIA ${ }^{150}$. A veces se completa la frase colocando en uno de los lados de la hoja la expresión ME FECIT Dicha forma aparece en varias hojas (RAM G 104; RAL IX 85; RAL: IX 79; Nápoles CA 4195, etc). Otras veces solo la palabra VALENCIA (MPP AE 660), e incluso repetida dos veces, una en cada canal (MAP J 362).

El comercio de espadas valencianas con la cercana Francia está datado en varios documentos citados por Charles (Charles: op.cit.). El primero cita una carga procedente de esa ciudad con sacos de arroz y hojas de espadas. El otro menciona un inventario de hojas de espadas de un espadero montador de guarniciones que trabajaba en la Rochelle en 1588 y que poseía 27 hojas de espadas valencianas ${ }^{151}$.

La reputación de las espadas valencianas provocaba que en los inventarios de bienes se llegaran a identificar del resto utilizando el término valencianas. Así el alguacil conquense Alfonso de Osas de entre las trece espadas que poseía a la hora de su muerte al menos dos de ellas eran valencianas ${ }^{152}$. E incluso habitantes de Toledo poseían espadas originarias de esta zona: una espada balençiana con vayna y sobre bayna ${ }^{153}$.

Por último decir que parte de la producción de hojas en Valencia durante el final de la Edad Media estuvo relacionada con la zona italiana, y más concretamente con Lombardía, de donde se importaban hojas de espadas para ser montadas por los artesanos valencianos ${ }^{154}$. Esto no quiere decir que no existiera una producción propia de hojas, sino que por la fuerte demanda o por el precio más barato de estas hojas italianas también se utilizaron este tipo piezas semifacturadas.

$\mathrm{Al}$ igual que como centro productor de hojas, Valencia fue un importante núcleo de fabricación de empuñaduras de espadas. Dentro del Gremio de Armers estaban incluidos los spasers, integrados a su vez por tres subgrupos: los forjadores, los amoladores y los fabricantes de guarniciones de espadas. E incluso dentro de este último existían artesanos especializados en la fabricación de partes concretas como el pomer o fachor de pomos Anthonio Gavaci ${ }^{155}$.

La importancia y fama de las empuñaduras valencianas llegó hasta tal punto que se llegó a conocer y fabricar en otros centros una tipología de guarniciones bajo esta denominación. Estando en uso por lo menos hasta el primer cuarto del siglo XVI. Así el espadero sevillano Francisco de Ferrera contrató en 1524 al cerrajero Francisco Sánchez para que le hiciera cien guarniciones para espadas valencianas que se entienda cruces e mançanas valencianas de fierro de la muestra que esta puesta entre nos las dichas partes... a precio d e $36 \mathrm{~m}^{156} \mathrm{r}$.

A pesar de estos datos referidos a una posible producción valenciana de espadas, la falta de documentación al respecto hace pocos fiables los datos antes aportados. Impidiéndonos por el momento afirmar la existencia de un núcleo productor importante en la capital valenciana.

150 Colección Pierre Thomsen (Bosson, et alii: 27) o la existente en Londres (WC A 546). Curiosamente Mann dice que la aparición del nombre Valencia no significa una producción en dicha ciudad española, Mann, (op. Cit): 279.

151 Algunos autores han indicado que estas referencias podrían referirse a la ciudad francesa de Valenciennes.

152 APC. Jud. 3-5.

153 Inventario de los bienes de Diego González de Cuéllar, clérigo1580. Maroto, (1998). Edición electrónica (Toledo).

154 Se tiene noticia de la existencia de una compañía de Lombardos en el Reino de Valencia compuesta por Stefano Rubia y Aluisio Monetario 1435-1445 que vendían a crédito a los artesanos «fulles de espasa a spasers». ARV P, 2433, en Furi (1985): 124.

155 Extracto de libros y papeles procedentes del gremio de Armers de Valencia existentes en el Archivo municipal de Valencia. FLG Mss 16/15.

156 APS Manuel Sigura. Lib. I 3 de febrero de 1524, en (Gestoso op. cit.: 164). 


\section{2) Vizcaya}

En primer lugar hay que matizar todo lo que se engloba bajo este término en los siglos XVI y XVII. Con él no sólo se hacía referencia a la actual provincia con capital en Bilbao, sino también a Guipúzcoa y parte de Alava. Pudiendo incluir también algunas zonas limítrofes de Navarra. Por ello cuando se hace referencia a las espadas fabricadas en aquella zona tenemos que señalar la existencia de varios focos importantes de fabricación de hojas de espadas unidos bajo esa denominación genérica.

El primero sería el que englobaría a la ciudad de Tolosa y a su entorno más cercano, como por ejemplo Alegría. Las referencias a este centro productor nos han llegado fundamentalmente a través de la creación a comienzos del siglo XVII de la Real Fábrica de Espadas en dicha capital. Pero esta creación, al igual que pasó con la toledana del XVIII, fue el resultado de un núcleo de fabricación artesanal de hojas anterior.

Así a comienzos del siglo XVI el veneciano Andrea Navagero menciona al pasar por la zona del rio Oria que en este rio existían varias ferrerías y que sus aguas eran muy buenas para templar el hierro y se templan las lanzas en Alegría y las espadas en Toloseta. Más adelante vuelve a mencionar este tema al decir que en Toloseta se hacen muy buenas espadas y se crían las hermosas astas de lanzas (García Mercadal, 1999: 46).

Su fabricación se siguió realizando durante todo el siglo XVI, dedicándose especialmente a la exportación, tanto nacional como internacional. Normalmente se trataba de hojas y espadas de carácter militar, aunque también existía una producción destinada a particulares.

y particularmente SM sea servido en muchos años para sus Reales Exercitos y armadas de la que ha mandado labrar en la dicha villa de Tolosa dandola y entregandola a esamen y prueba en manos de Geronimo Aybar Capitan y veedor de las fabricas de SM en esta probincia y en el señorio de Vizcaya

De ello se derivaron muchos problemas por las prohibiciones y dificultades que hubo entre los espaderos y las autoridades reales. Muchas de sus hojas llegaron a diversas zonas de la península como Castilla ${ }^{157}$ y Andalucía ${ }^{158}$. A esta última ciudad llegaron además de hojas y guarniciones numerosos espaderos vizcaínos y guipuzcoanos ${ }^{159}$.

Las crisis económicas y políticas que padeció la corona española supuso un fuerte revés para dichos artesanos, que no pudieron hacer frente a las importaciones masivas de hojas extranjeras mucho más baratas ${ }^{160}$, aunque de peor calidad según argumentaban los propios espaderos tolosarras:

Los maestros forjadores de espadas de la villa de Tolosa dicen que respecto de que en estos reinos se meten de otros estrangeros mucha cantidad de espadas, $y$ dagas, $y$ alfanges y montantes y cuchillos

Esta situación provocó que los forjadores de hojas de Tolosa pasaran muchas necesidades, quejándose que el dinero que se gastaban en la compra de espadas se lo llevasen forjadores extranjeros

157 Deuda de una obligacion perteneciente al tiempo que tuvieron compañia para el comercio de armas y municiones en castilla. Jacobe Martinez de Aranguren, mercader, vecino de Mondragon, contra Juan de Zaldua, mercader, vecino de la anteiglesia de San Andres de Zaldua, merindad de Durango. 1531. ARCV. Pleitos Civiles. Escribanía Moreno. Pleitos Fenecidos. C 521/3, L 96.

158 El mercader vizcaino Juan de Durango vendió 170 hojas de espadas al espadero sevillano Andrés de Rebolledo en 1510. APS Lib. II Francisco de Sigura, en GestosO: 179.

159 Pedro de Lezama espadero vizcaino estante en Sevilla. APS Of. II Lib. IV fol. 1599. 1559, en Gestoso; Domingo de Garayçabal, aprendiz de espadero con el maestro Domingo de Horozco, vecino de Elorrio, estante en Sevilla. APS Leg II fragmentos de escrituras de los siglos XVI-XVII. 1569, en Gestoso (op. Cit.):172; Juan Perez de Urrategui, espadero natural de Azcoitia vecino de Sevila. APS Lib. IV Francisco Sigura. 1507, en Gestoso, op. cit: 179.

160353 Paños de espada á trescientos tres maravedís la docena. Valuación hecha en la villa de Bilbao del precio de las mercaderías que venían de fuera del Reino. [ ... 1563, en Imprenta Real (Madrid), 1829. 
estan los maestros que labran las dichas armas parados y sin oficiales por no tener que obrar como en otros tiempos por cuya causa padecen grandes necesidades por no tener otro modo de vivir por lo que ellos habian de ganar los ganan los estrangeros demas de toda la obra que los dichos estrangeros demas de toda la obra que los dichos estrangeros traen y meten en estos reynos

A pesar de las protestas y de la creación de una Real Fábrica de Espadas en Tolosa continuó dándose esta situación y su actividad fue decreciendo poco a poco, hasta tal punto que a finales del siglo XVII las únicas espadas de Tolosa eran las procedentes de la villa francesa del mismo nombre ${ }^{161}$.

La ciudad de Mondragón ha sido siempre un referente a la hora de hablar del acero usado para la fabricación de espadas de calidad. Menos conocida resulta sin embargo, la faceta de forjadores de hojas que tuvieron muchos de los artesanos que trabajaron en dicha ciudad o en las poblaciones cercanas. Son pocos los datos que conocemos sobre el tema, aunque existe documentación que demuestra que hubo una producción organizada de hojas de armas blancas.

Finalmente el otro gran centro vasco de producción de hojas fue la propia ciudad de Bilbao. Como ciudad fuerte debido a su puerto y actividad comercial, tanto con el interior como con el exterior de la provincia, tuvo un gremio de espaderos muy activo. Siendo sobre todo un centro de atracción de otros espaderos procedentes de las numerosas poblaciones que trabajaban el hierro y el acero tanto en Vizcaya como en Guipúzcoa y Alava.

La producción de armas blancas de esta ciudad ya ha sido objeto de estudio en un número anterior de esta revista y por lo tanto no nos vamos a entretener demasiado en ella (Dueñas, 2001). Aunque, tenemos que repetir una vez más, los contactos comerciales que a través de su puerto tuvo con otras ciudades españolas como Sevilla, y extranjeras, fundamentalmente con las islas Británicas donde existen todavía espadas y empuñaduras que reciben la denominación de Bilbo.

Al igual que con las hojas bajo la denominación de Vizcaya se englobaba una zona más amplia de producción de empuñaduras. De la calidad de la producción de las segundas poseemos varios testimonios, aunque uno de los más interesantes sea el coste, el más alto de todos, de las empuñaduras vizcaínas a comienzos del XVII ${ }^{162 .}$

Es lógico esta importancia de producción de todo tipo de armas en la parte vasca ya que era el centro productor natural de los tres elementos necesarios para la fabricación de armas, hierro, carbón y madera.

En relación a la producción de empuñaduras de espadas destacaba la villa de Durango. Esas guarniciones se realizaban principalmente con destino a la exportación al resto de la península ${ }^{163}$. Siendo uno de los escasos centros que a mediados del siglo XVII podían surtir de todo tipo de armas blancas a las grandes urbes peninsulares como Madrid ${ }^{164 .}$

\footnotetext{
Cada guarnicion de espada de Vizcaya, entrefina, en blanco a seys reales

Una guarnicion de daga de guardamanos, bruñida pabonada siendo vizcayna, doze reales y sin guardamano diez
}

En Vizcaya además se realizaban gran cantidad de elementos auxiliares de la espada un adereço de espada y daga, y hierros de tiros y pretina vizcayna labrado con lima, de rayadillo menudo, que en todo son veintiseys reales

\footnotetext{
161 Tassa General de Precios 1680.

162 Tassa General de Precios. Sevilla 1627, en (Leguina, 1898: 42).

163 ARCHV. Sala de Vizcaya. Es. 47186. Pleito de Martín de Ochoetia, de Durango y Maria Pérez de Unda sobre pedir el pago de tres cargas de guarniciones.

164 Deuda de espadas, dagas, chapas, balaustres y cuchillos que el demandado debia de mandar a agustin francisco de mier, mercader de madrid. juliana de aribi, mercadera, vecina de durango francisco ugarte echabarria, mercader, vecino de Vitoria. ARCV Pleitos civiles. Escribania Masas. Pleitos fenecidos.
} 
Algunas labores reciben el término toponímico de Vizcaya, lo que nos lleva a pensar que algunos métodos y tipos de empuñaduras tendrían allí su origen.

Los adereços vizcaynos, que son las mismas veintseys pieças, quadradas de quatro esquinas, aobados, lisos de almendrilla, ochavados a la larga, seisabados a lo largo, treynta reales cada uno, pabonado o bruñido, y si fuese cincelado, y de labora que cada uno pidiese, catorze reales mas.

Incluso se releja la fabricación de empuñaduras de tipologías tan claras como la de los montantes: De pabonar una guarnición de dos manos Vizcayna que son dos pieças guarnicion y pomo lisso seys reales y si fuere bruñida en blanco, lo mismo

Otro centro productor de guarniciones de armas blancas desde el siglo XVI enclavado en la zona vasca fue la población de Vergara. Estas podían ser normales, comunes, con un coste de 306 maravedises en 1576 (Rojo, 1996: 222).

\section{3) Zaragoza}

La ciudad de Zaragoza gozó de fama por la fabricación de armas, ya desde comienzos del siglo XVI. Aun así, existieron muchas dudas en el pasado sobre si los espaderos zaragozanos forjaron hojas. Dicha cuestión aparece aclarada por la presencia en la ciudad de artesanos de primer nivel como Julián y Miguel del Rey, o Juan de Aguirre. Si bien es cierto que su importancia como centro productor de espadas fue más destacado en el siglo XVI, quedando en el siglo XVII más como un centro de montaje, fabricación y decoración de empuñaduras.

Al mismo tiempo poseyó un fuerte gremio de espaderos guarnicioneros y de doradores. Ambos tuvieron enfrentamientos por los trabajos que cada uno debían de realizar respecto de las espadas, y poseyeron ordenanzas gremiales con contenidos muy interesantes (Dueñas, 1999).

Una de las principales pistas para poder considerar a una pieza como española son las inscripciones. Estas son abundantes en las hojas pero muy escasas en las empuñaduras. Sólo en algunas cazoletas están presentes. En una de ellas encontramos la confirmación de la existencia de una producción de empuñaduras en la ciudad de Zaragoza cuando encontramos el siguiente texto:

\section{ESTA ESPADA ES DE MIGUEL ANGLADA SE HIZO EN ZARAGOZA AÑO DE $1658^{165}$.}

Algunos de estos espaderos que trabajaron en Zaragoza durante el siglo XVI procedían de la zona vasca como fue el caso de Blasco de Urresta oriundo de Tolosa y que desarrolló su trabajo como espadero en la ciudad maña ${ }^{166}$.

A pesar de todo el siglo XVII fue un momento de retroceso para la producción de espadas en general y de empuñaduras en particular, ya que como dice en la adicción a las ordenanzas de espaderos de 1602 cuando se intenta repartir el trabajo entre los oficiales espaderos por la grande necessidad que en esta ciudad hay de obra de dicho officio como son espadas y guarniciones por venir como viene todo de carreo ${ }^{167}$.

Lo que si parece que hubo fue un florecimiento en la fabricación y decoración de guarniciones de espadas, ya que se promulgaron ordenanzas de doradores y adicciones a ordenan-

165 Esta espada de taza formaba parte de la colección Paulhillac, y que actualmente forma parte del Musée de l'Armée de Paris. North (North, 1982: 62) considera que el nombre no es el del fabricante sino el del dueño, aunque nosotros creemos que se trata del espadero que realizó la empuñadura.

166 ARCV. Pleitos civiles. Escribania Zarandona y Balboa. Pleitos olvidados. C 281/5, L1.

167 AMZ. Libro de Actos Comunes año 1602 ff. 276-277 en (Redondo Veintemillas, op. Cit.: 41). 
zas de espaderos ya existentes, en las que se recogía estas prácticas, así como el auge de las mismas.

\section{4) Barcelona}

Además de una producción de espadas en general, es decir forja de hojas, su montaje y posterior venta, también existió una industria de manufactura de empuñaduras. Ya desde 1465 tuvieron ordenanzas separadas tanto los forjadores como los fabricantes de guarniciones para delimitar bien sus competencias y evitar ingerencias de un grupo en el otro. Así y aunque formaban un mismo gremio poseían una estructura independiente y la caxa común tenía dos llaves, siendo administrada alternativamente por uno y otro grupo. Además, y con el fin de que los forjadores barceloneses vendieran las hojas que produjesen a los fabricantes de guarniciones de la ciudad, se prohibió a los primeros que pudiesen tener hojas envainadas en sus tiendas. Ya que de este modo podían vender directamente a los compradores sin tener que pasar los fabricantes de empuñaduras.

Además de la práctica anteriormente citada de fabricar empuñaduras de lujo de espadas por parte de los plateros barceloneses, existió un gremio de argenters que decoraban las empuñaduras de espadas, estoques, dagas y cuchillos producidos en Barcelona168. En 1567 el concejo municipal volvió a elaborar unos estatutos que señalaban la forma y exámenes que debían de cumplir los aspirantes a espaderos en Barcelona. Entre las labores que se citan está la elaboración de guarniciones de diferentes colores, materiales, barnizes y empabonados.

Afín de evitar disputas entre los espaderos y los empabonadores sueltos que ejercían aquel arte en Barcelona, se ordenó en 1606 que éstos fuesen agregados e incorporados al oficio, gremio y cofradía de los espaderos, señalándose todas las maniobras que les correspondían en su exercicio, a las que se debían limitar exclusivamente.

\section{5) Sevilla}

Son muchos los artesanos que aparecen en la capital hispalense bajo la denominación de espaderos, muchos de ellos recogidos en el magnífico trabajo de Gestoso (Gestoso, 18991908).

El grado de especialización de los espaderos sevillanos llegó a tal extremo que existían espaderos dedicados a la realización de los puños de las espadas. Como oficial de hacer puños de espadas se denomina en agosto de 1621 a Juan Suárez quien vivía en la calle de la Mar (Gestoso, op. Cit.: 33). Esta era la principal calle de concentración de espaderos en la ciudad tal y como lo indica el propio gremio cuando se reúnen en 1717 con ocasión del declive del dicho gremio, al señalar que hasta el año de 1702 estuvo este gremio en toda su opulencia, tanto que casi todas las casas de la calle de la Mar, estaban ocupadas por ellos, y con el tiempo se habían extendido al sitio de las gradas y otras muchas partes de la ciudad (Leguina, 1898:33)

También recibían empuñaduras importadas de otras zonas de la península ibérica, destacando una vez las que procedían de la zona vasca. Así el espadero sevillano Juan de Pedraza pagó $6^{169} .120$ mrs por trece docenas de guarniciones de espadas en junio de 1529.

\footnotetext{
168 AHCB Gremios reg. 1132 año 1449.

169 APS. Manuel de Sigura Lib. I fol 526, en Gestoso,op. Cit.: 178.
} 


\section{CONCLUSIÓN}

Uno de los objetivos de este artículo como dijimos en la introducción, es el de ampliar el concepto que de una espada española se tiene. Así ante la falta de estudios específicos la producción hispana ha quedado encasillada dentro de una tipología de espadas muy concreta. En el mismo sentido se ha generado una focalización excesiva de la fabricación de hojas españolas en el centro toledano. Olvidando la existencia de otros núcleos de producción de gran importancia y de cuyo estudio podríamos obtener gran cantidad de datos sobre la manufactura hispana de espadas. Otro límite se establece al dar por buena la creencia generalizada de que la producción de guarniciones en la península ibérica era escasa, e incapaz de realizar piezas de una calidad media y alta. Todo ello impide conocer la riqueza de piezas que eran capaces de realizar los artesanos hispanos tanto en variedad tipológica, como en labores tales como la decoración y conocimiento de técnicas de realización de empuñaduras de más o menos lujo.

Sistemáticamente se repiten una serie de estereotipos sobre la producción española de espadas tanto a nivel nacional como internacional. Y lo que es peor, esto tiene un reflejo en la catalogación de piezas de posible origen español existentes en diversas colecciones a lo largo del mundo, por no encajar dentro de estas características comúnmente aceptadas.

Está claro que la producción de espadas en la corona española, especialmente de hojas, se vió reducida en cantidad y calidad a lo largo del siglo XVII. Los motivos para este retroceso en la producción de armas blancas fueron varios. En primer lugar los propios al periodo de crisis y recensión que sufrió el imperio español en ese momento. Inflacción, carestía, guerras, epidemias y hambrunas no fueron el mejor caldo de cultivo para la fabricación de espadas, a pesar de que en la sociedad española seguían estando muy presentes en todos los órdenes sociales. En una población estabilizada cuantitativamente, más que fabricar nuevas piezas, se reutilizaban las ya existentes limpiándolas y cambiándoles, si acaso, las empuñaduras a la moda del momento, conchas y tazas. Por ello los espaderos hispanos del siglo XVII se dedicaron especialmente a esas labores, mientras los míticos forjadores desaparecían poco a poco.

Además la legislación real y municipal era más restrictiva respecto al portar y uso de espadas. Se vigilaban sus formas y utilización, perdiendo poco a poco presencia en la sociedad española.

Finalmente uno de los grandes males que afectó a la espadería española, derivado de las condiciones políticas y económicas del momento, fueron la falta de competitividad ante las importaciones extranjeras. Resulta paradigmáticas las quejas que los espaderos tolosarras esgrimieron ante el rey por la entrada masiva de hojas y armas blancas de fuera del reino, conscientes de las diferencias de precios de estas últimas atacan a la calidad de las mismas respecto a las fabricadas en la capital guipuzcoana.

la obra que los dichos estrangeros traen y meten en estos reynos es en mucho de servicio de SM ansi por lo dicho coo por que no es de la bondad de que se lo hace en estos reynos porque la que viene de Genoba e Italia es toda de fierro como se echa de ver por la obra y que viene de Francia y Alemania aunque tengan apariencia de buena tampoco lo es porque toda ella es tambien de hierro y la templan con yerbas y drogas de forma que en forjandose, tostandose si la toman a amolar se le quita toda la fuerza primera y descubre la malicia que tiene porque tentandola queda como cosa echa solo de hierro para como remedio

Así mismo se manifiesta una preocupación por la continuación de oficios en los cuales la práctica y los conocimientos de los mayores resultaban tan importantes:

y que los dichos maestros forjadores se conserben en sus oficios y tengan oficiales para adelante se enseñen y se valgan del dinero que los dichos estrangeros toman en estos reynos y quiza lo pasan a los suyos VS debe ser servido de suplicar a SM provea de remedio en lo susodicho mandado y vedado en es- 
tos reynos no entren de reynos estrangeros ningunas de las dichas armas pues en estos reynos se labran quantas sean necesarias para ellos

También los extranjeros que visitan la Península Ibérica a mediados del siglo XVII dejan constancia de esta realidad de falta de producción de hojas y el recurso a la importación de las mismas, al igual que sucedía con gran cantidad de productos manufacturados. Antonio de Brunel (García Mercadal: t, III, 294) ${ }^{170}$ menciona el hecho de que desde diferentes puertos de la costa atlántica francesa, especialmente desde Bretaña y Normandía, se enviaban a los puertos de Bilbao y Cádiz muchos productos entre los que incluye hasta quincallería y hojas de espada; por donde he sabido que era un abuso el creer que hoy las buenas hojas de espada vengan de España. Es cierto que este autor menciona que se sigue fabricando hojas en Toledo y en zonas de Vizcaya, que son más caras que las extranjeras, pero en el primer caso es más la fama que perdura que una realidad, mientras que en el norte ya hemos visto los problemas que también existían.

La historiografía clásica sigue estando en uso, y por tanto se siguen aplicando una serie de convencionalismos tipológicos que llevan a identificar a muchas espadas hispanas como extranjeras, confundiéndose especialmente con la producción italiana.

\section{AGRADECIMIENTOS}

Nos gustaría agradecer a doña Maria Isabel Martínez Zamora su valiosa colaboración elaborando los dibujos que ilustran este trabajo.

GERMÁn DUEÑAs BERAIZ

Museo del Ejército de Madrid - german_duenas@yahoo.es

\section{ABREVIATURAS}

APD: Armería del Palazzo Ducale. Venecia

ART: Armeria Reale. Turín

CE: Colección Estruch

CO: Collezione Oldescachi. Roma

DGM: Deutsche Gesichte Museum. Berlín

FLG: Fundación Lázaro Galdiano. Madrid

HMD: Historiches Museum. Dresde

HRKM: Hofjad und Rustkammer des Kunsthistorichen Museum. Viena

IVDJ: Instituto Valencia de Don Juan. Madrid

LSH: Livrustkamaren. Estocolmo

MAP: Musée de l'Armée. Paris

MEM: Museo del Ejército de Madrid

MMA: Metropolitan Museum of Art. Nueva York

MNM: Museo Naval de Madrid

MPP: Museo Poldi Pezzoli. Milán

MSF: Museo Stibbert. Florencia

RA: Royal Armouries. Leeds

VAM: Victoria and Albert Museum. Londres

WC: Wallace Collection. Londres

WC: Windsor Castle

170 El francés Antonio de Brunel cruzó parte de la Península Ibérica en 1665. 


\section{BIBLIOGRAFÍA}

Beaumont, E. (1885 ): La fleur de belles epées. París, Boussod, Valadon et Cie.

BlAIR, C. (1970): «A royal swordsmith and damascener Diego de Çajas» Metropolitan Museum Journal, v.3.

BLAIR, C. (1972): European Armour circa 1066 to circa 1700. London.

Boccia, L.G.; Godoy, J.M. (1986): Musei e gallerie di Milano. Museo Poldi-Pezzoli. Armeria. Electa edizioni. Milano.

Bofarull y Sans, F: (1910): Colección de documentos inéditos del Archivo de la Corona de Aragón. Gremios y cofradías del Archivo de la Corona de Aragón. Barcelona.

BonASSIE, P. (1975): La organización del trabajo en Barcelona a fines del siglo XV. Barcelona.

Bosson, C.; Geroudet, R.; HeERE, E. (1972): Armes Anciennes des Collections Suisses. Musée Rath Geneve. Ginebra, Laussanme. CSIC.

Bruhn De Hoffmeyer, A. (1963): «From Mediaeval Sword to Renaissance Rapier», Gladius II.

BRUHN DE HOFFMEYER, A. (1972): «Arms and armour in Spain». Gladius.

CABRERA DE CoRdobA, L. (1998 reedic.): Historia de Felipe II, Rey de España. Valladolid.

CAPMANY y MONTPAlau, A. (1779): Memorias históricas sobre la marina, comercio y artes de la antigua ciudad de Barcelona. Madrid.

CHARLEs, R. (1993): Études sur les épées. Paris.

CirLOT, M.V. (1980): Un modelo de clasificación de la espada. A propósito de «The rapier and small-sword, 1460-1820, de AV.B. Norman» en Gladius.

CORREAS, G. (1627): Vocabulario de refranes y frases proverbiales Barcelona, Ed. Louis Lombet. 2000.

COVARRUBias (1611): Tesoro de la lengua castellana. Toledo.

CRUILLES, MARQuÉs De, (1883): Los gremios de Valencia. Valencia.

DAVILLIER, CH. (1879): Recherches sur l'orfevrerie en Espagne au moyen àge et à la renaissance: Documents inédits tirés des archives Espagnoles. Paris.

DueÑAs Beraiz, G. (2001): «La producción de armas blancas en Bilbao durante el siglo XVI». Gladius, XXI: 269-290.

DueÑAs Beraiz, G. (1999): Los gremios de espaderos españoles en la Península Ibérica (S. XVIXVII). Aproximación a su estudio (Grado de Salamanca inédito). Departamento de Historia Moderna, Medieval y Contemporánea. Universidad de Salamanca.

Garcia MerCadal, J. (1999): Viajes de extranjeros por España y Portugal (VI vols.). Valladolid.

GeStOSO y PÉREZ, J. (1899-1908): Ensayo de un diccionario de los artífices que florecieron en Sevilla desde el S. 13 al 18 inclusive, 2 vols. Seville.

LAKING,G.F. (1920-1922): A record of european armour and arms through seven centuries, (V vols.). Londres.

LEGUiNA, E. (1897): Los maestros espaderos. Sevilla.

LEGUINA, E. (1912): Glosario de voces de armería. Madrid. 
Mann, J. (1962): Wallace Collection Catalogue. European Arms and Armour. (II vol.). London. The trustees of the Wallace Collection.

MARTinez del Peral, R. (1992): Armas Blancas en España e Indias. Madrid.

MoreLl, B. (1986): Mercaderes y artesanos en la Sevilla del descubrimiento. Sevilla.

NoRman, A.V. (1980): The rapier and small sword 1460-1820. Londres, Arms and Armour Press.

NoRTH, A.(1982): An Introduction to European Sword. Londres, Victoria and Albert Museum: HMSO.

NuÑez De CEPEDA, M. (1948): Los antiguos gremios y cofradías del viejo Pamplona, Pamplona.

OAKESHOTT, R. E. (1980): European weapons and armour. Suffolk.

PelaeZ DEL VALLE, J.M. (1983): «La espada ropera española en los siglos XVI y XVII», Gladius, XVI: 147-199.

PesCAdOR Del Hoyo (1989): «La espada de Felipe IV en la Armería Real de Madrid», Reales Sitios. 3er trimestre.

Quevedo y Villegas, Francisco de (1619-1626): Premática que se ha de guardar para las dádivas a las mujeres de cualquier estado o tamaño que sean.

REDONDO VeINTEMILlAs, Guillermo: (1982): Las corporaciones de artesanos de Zaragoza en el siglo XVII. Zaragoza.

REVERSAU, J.P. (1993): Armes et armures de Montmorency. Paris.

RoBert, L. (1891): Catalogue des collections composant Le Musée de Artillerie en 1889. Tomo III. Paris.

RodRíGuez VILLA (1883): Inventario de Don Beltrán de la Cueva. Tercer duque de Alburquerque 1560. Madrid.

Rojo, A. (1996): El siglo de oro. inventario de una epoca. Salamanca; Junta de Castilla y León. Consejería de Educación y Cultura.

SANTOS, F. (1663): Día y noche de Madrid.

SEITZ, H.: (1981): Blankwaffen. Geschichte und Typenentwiklung im Europaïchen Kulturbereich von der prähistorischen Zeit bis zum Ende des 16 Jahrhunderst (2 vol.). Klinkhart \& Biermann, Munich.

SEMPERE Y GUARINOS, J, (1788): Historia del lujo y de las leyes suntuarias de España. Imprenta Real.

SuÁREZ DE FigueroA, C. (1617): El pasajero. Madrid.

VAlencia De Don Juan, Conde Viudo de [Juan Bautista Crooke y Navarrot] (1898): Catálogo Histórico-Descriptivo de la Real Armería de Madrid. Real Casa. Madrid.

VARGAS MACHUCA, B. (1600): Libro de exercicios de la gineta. Madrid

Velez De Guevara, (1641): El diablo cojuelo.Ximenez DE EMBun, T. (1993): Descripción histórica de la antigua Zaragoza y de sus términos municipales. Valencia. 